U.S. Department

of Transportation

National Highway

Traffic Safety

Administration

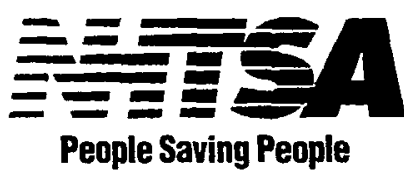

DOT HS 808346

November 1995

Final Report

\title{
Understanding Youthful Risk Taking and Driving: Database Report
}


This publication is distributed by the U.S. Department of Transportation, National Highway Traffic Safety Administration, in the interest of information exchange. The opinions, findings and conclusions expressed in this publication are those of the author(s) and not necessarily those of the Department of Transportation or the National Highway Traffic Safety Administration. The United States Government assumes no liability for its contents or use thereof. If trade or manufacturers' name or products are mentioned, it is because they are considered essential to the object of the publication and should not be construed as an endorsement. The United States Government does not endorse products or manufacturers. 
Technical Report Documentation Page

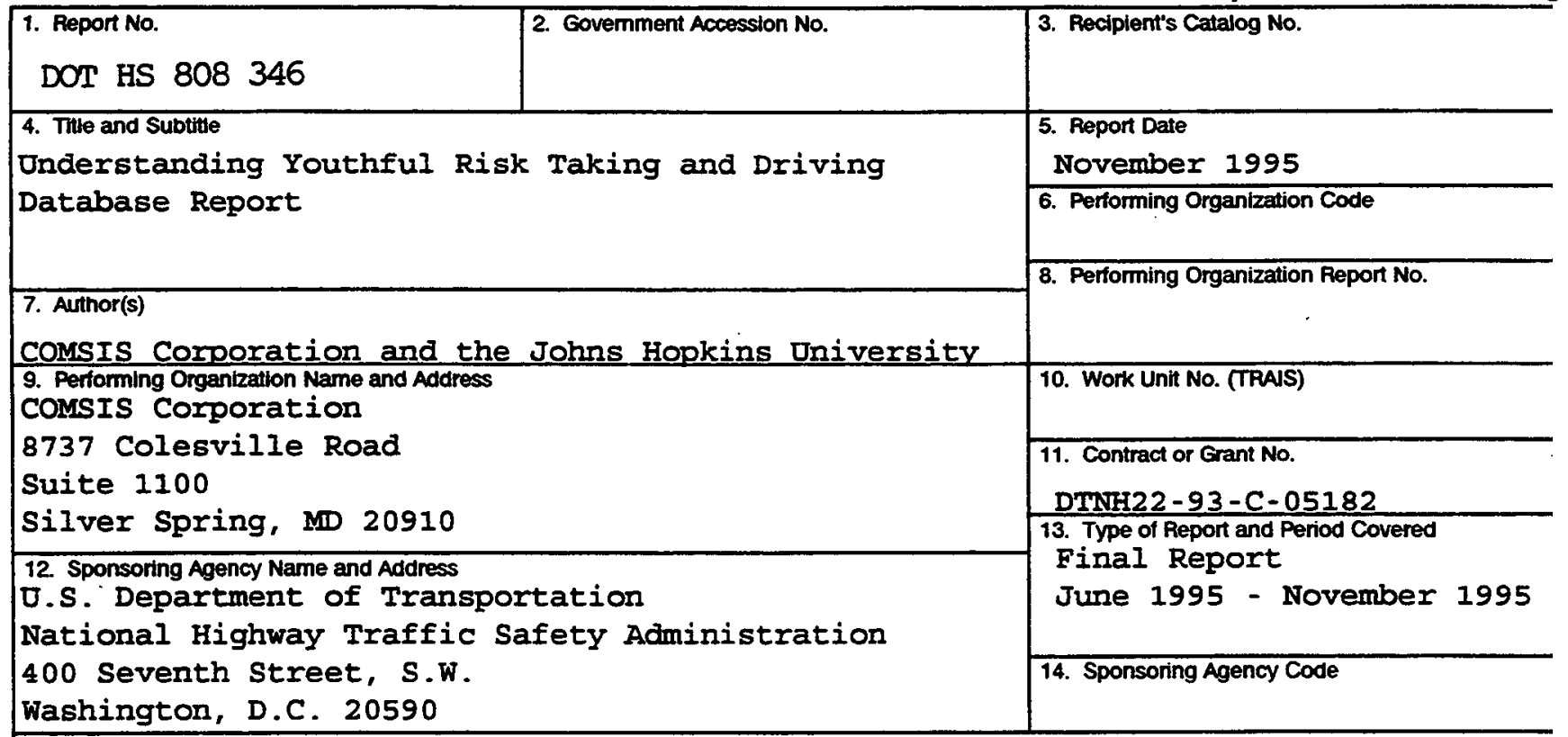

15. Supplementary Notes

16. Abstract

This report catalogs national databases that contain information about adolescents and risk taking behaviors. It contains descriptions of the major areas, unique characteristics, and risk-related aspects of each database. Detailed information is provided concerning data collection procedures, including survey questions, variables, and sampling and data collection methods. Information is also provided as to where to request each database, the accessibility of the data, and the kinds of elecronic media available.

This report also contains information on databases that states collected on various domains of risk taking behaviors, and, in some cases, protective factors. The state databases were included in this report because a number of the surveys conducted by particular states include a more fine-grained examination of risk taking behaviors than national databases.

\begin{tabular}{|c|c|c|c|}
\hline $\begin{array}{l}\text { 17. Koy Words } \\
\text { Risk Taking } \\
\text { Youth } \\
\text { Driving } \\
\text { Alcohol }\end{array}$ & $\begin{array}{l}\text { Violence } \\
\text { Sexual Activity }\end{array}$ & $\begin{array}{l}\text { 18. Distribution statement } \\
\text { This document is availabl } \\
\text { from the National Technic } \\
\text { Service, Springfield, Vir }\end{array}$ & $\begin{array}{l}\text { to the public } \\
\text { Information } \\
\text { inia } 22161\end{array}$ \\
\hline $\begin{array}{l}\text { 19. Securtty Classtf. (of this report) } \\
\text { Onclassified }\end{array}$ & \multicolumn{2}{|c|}{$\begin{array}{l}\text { 20. Securtly Classif. (of this page) } \\
\text { Unclassified }\end{array}$} & 22. Price \\
\hline
\end{tabular}

Form DOT F 1700.7 (8-72) Reproduction of completed page authorized




\section{CONTENTS}

I. NATIONAL DATABASES $\ldots \ldots \ldots \ldots \ldots \ldots \ldots \ldots \ldots$

INTRODUCTION TO NATIONAL DATABASES $\ldots \ldots \ldots \ldots \ldots \ldots \ldots$

Table 1, National Databases by Topic Area . . . . . . . . . . . . 5

Fatal Accident Reporting System (FARS) $\ldots \ldots \ldots \ldots \ldots \ldots \ldots \ldots$

General Estimates System (GES) $\ldots \ldots \ldots \ldots \ldots \ldots \ldots \ldots$

High School and Beyond (HS\&B), $1980 \ldots \ldots \ldots \ldots \ldots \ldots$

Monitoring the Future: A Continuing Study of the Lifestyles and Values of

Youth ....................... 14

National and State Data Files on Adolescent Fertility, 1960-1988 . . . . . . . 20

National Archive on Sexuality, Health, and Adolescence (NATASHA) . . . . 22

National Education Longitudinal Study, 1988: Follow-Ups 1990, 1992, 1994 . . . 24

1992 National Health and Social Life Survey . . . . . . . . . . . . . . . . 27

National Health Interview Survey: AIDS Knowledge and Attitudes Supplement

(1992) . . . . . . . . . . . . . . . . . . . . . . . 30

National Health Interview Survey: Child Health Supplement (1988) . . . . . . 32

National Health Interview Survey: Drug and Alcohol Use Supplement (1991) . . 36

National Health Interview Survey: Injury Control and Child Safety and Health

(1990) . . . . . . . . . . . . . . . . . . . . . . . 38

National Health Interview Survey: Pregnancy and Smoking Supplement (1990,

1991) . . . . . . . . . . . . . . . . . . . . . . . . 41

National Household Survey on Drug Abuse . . . . . . . . . . . 43

National Longitudinal Study of Adolescent Health (Add HEALTH) . . . . . . 45

National Longitudinal Survey of Youth . . . . . . . . . . . . . . 48

National Survey of Adolescent Males, 1988 and $1990-91 \ldots \ldots \ldots \ldots$. . . . 51

National Survey of Children: Waves 1 (1976), 2 (1981), and 3 (1987) . . . . . 54

National Survey of Families and Households, $1988 \ldots \ldots \ldots \ldots \ldots$

National Survey of Family Growth, Cycle IV, 1988; and Telephone Reinterview,

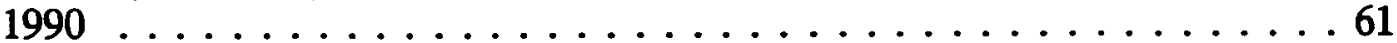

National Youth Survey [United States]: Wave VI, $1983 \ldots \ldots \ldots \ldots \ldots 6$

Teenage Attitudes and Practices Survey II (TAPS II), $1993 \ldots \ldots \ldots \ldots 6$

Uniform Crime Reporting (UCR) Program . . . . . . . . . . . . . . . . . . . 69

The Woodlawn Mental Health Longitudinal Community Epidemiological

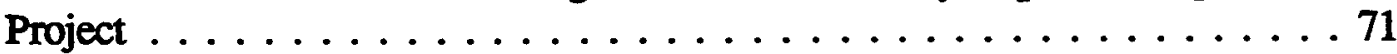

Youth Risk Behavior Survey (YRBS) $\ldots \ldots \ldots \ldots \ldots \ldots \ldots \ldots$

II. STATE DATABASES $\ldots \ldots \ldots \ldots \ldots \ldots \ldots \ldots$

INTRODUCTION TO STATE DATABASES $\ldots \ldots \ldots \ldots \ldots \ldots \ldots$

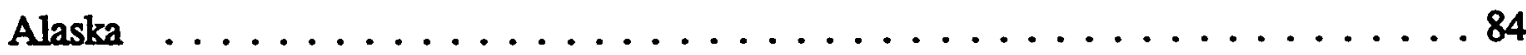

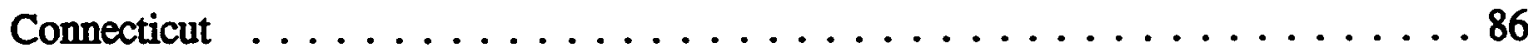

Hawaii . . . . . . . . . . . . . . . . . . . 89 


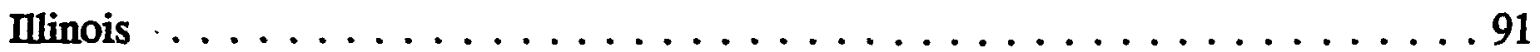

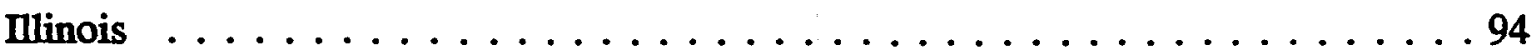

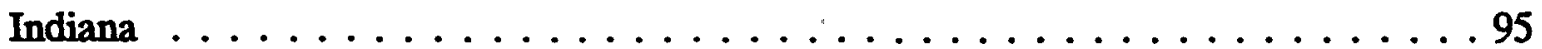

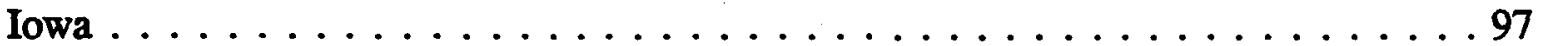

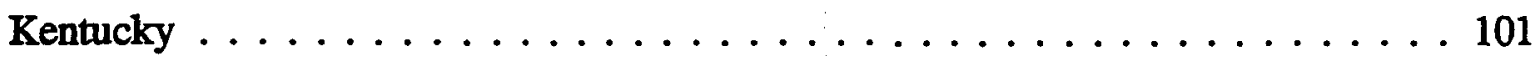

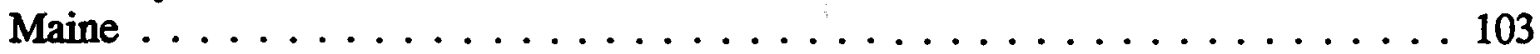

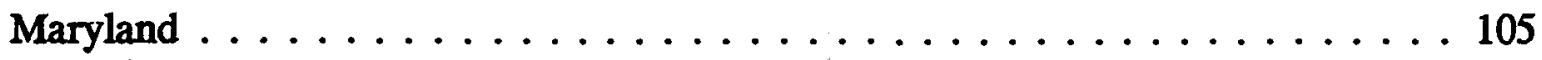

Massachusetts ........................... 107

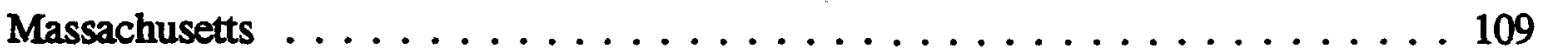

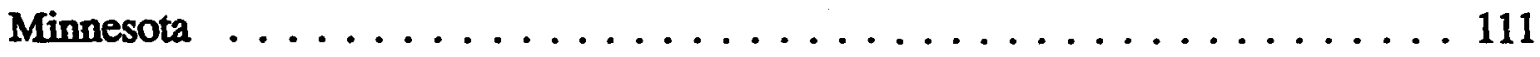

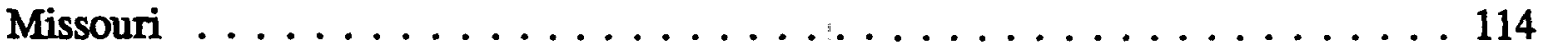

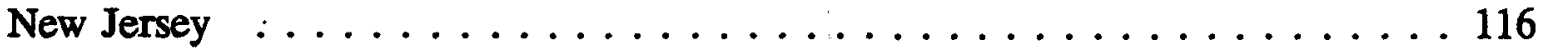

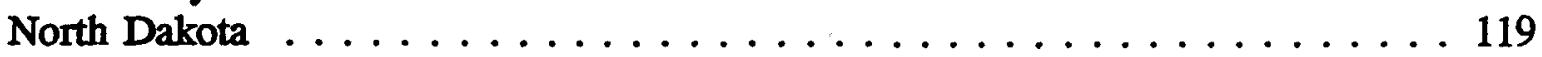

North Dakota . . . . . . . . . . . . . . . . . . . . 120

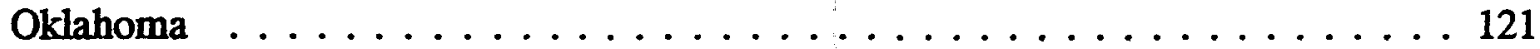

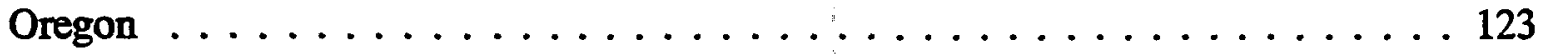

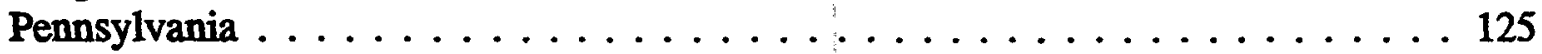

Rhode Island . . . . . . . . . . . . . . . . . . . . . . 128

South Carolina . . . . . . . . . . . . . . . . . . . 130

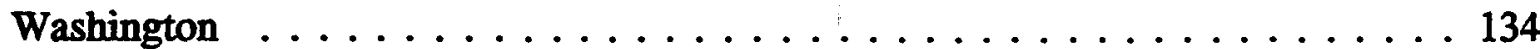

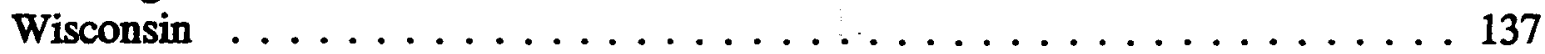

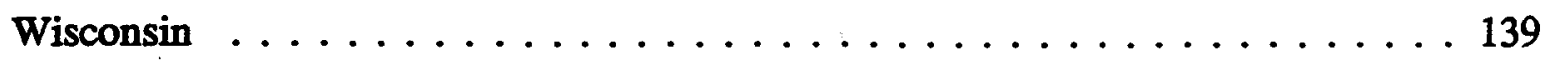

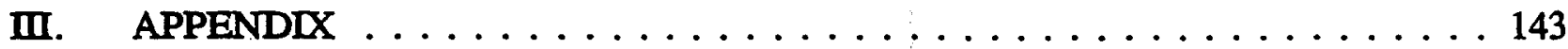

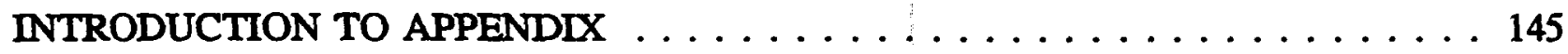


I. NATIONAL DATABASES 


\section{INTRODUCTION TO NATIONAL DATABASES}

This report catalogues national databases that contain information about adolescents and risk taking behaviors. It contains descriptions of the major research areas, unique characteristics, and risk-related aspects of each database. Detailed information is provided concerning data collection procedures, including survey questions, variables, and sampling and data collection methods. Information is also provided as to where to request each database, the accessibility of the data, and the kinds of electronic media available. This report may be used to select the database or combination of databases that best address individual research needs concerning the lives of young people in the United States.

Individually, each database selected for inclusion in this report provides a piece of the youthful risk taking puzzle. The databases provide information on a wide range of risk taking and protective behaviors that together build a biopsychosocial profile of youthful risk taking behavior and the context in which it operates. Each database has a national representative sample, risk taking or protective variables, and may have some of the of the following features:

- Multiple risk-related aspects

- Convergent sources of data within a database. For example, information about the same youth might have been collected from the youth him/herself, his/her parents, peers, or even independent sources.

- Community factors, such as school variables and community economic conditions.

The databases that met these criteria most frequently were longitudinal, population-based studies sponsored by government agencies. The most prominent of these agencies are the National Center for Health Statistics (NCHS), within the Centers for Disease Control and Prevention of the U. S. Department of Health and Human Services, and the National Center for Education Statistics (NCES), within the U. S. Department of Education. Also included are population-based surveys with sponsorship from the Bureau of Labor Statistics of the U. S. Department of Labor and from the Substance Abuse and Mental Health Services Administration of the U. S. Department of Health and Human Services.

In addition to population-based surveys, record-based surveys were selected to provide access to publicly recorded consequences of adolescent risk taking. Within this category, crash statistics may be accessed through NHTSA's Fatal Accident Reporting System and General Estimates System. Crime and delinquency data may be accessed via the FBI's Uniform Crime Reporting (UCR) Program. And births to teenagers are recorded in the Child Trends-sponsored National and State Data Files on Adolescent Fertility.

Another variety of database product is the coordinated collection of databases brought together from various sources. These collections aid the researcher in analysis by allowing common variables to be linked across studies. Collections of this kind include the National Archive on Sexuality, Health, and Adolescence (NATASHA), and the American Family Data Library, which is featured in the appendix.

Finally, to round out the picture of adolescent risk taking, items were chosen that reflect the physical well being of young people. Supplements to the National Health Interview Survey 
were chosen for this purpose, including the Injury Control and Child Safety and Health File and the Child Health Supplement.

Many of the databases in this report can be ordered directly from the sponsor. Others are available through data archiving services, such as the Inter-university Consortium for Political and Social Research (ICPSR) and Sociometrics Corporation. ICPSR's archive of data mainly serves its member (educational) institutions. Non-members may also order data for a price. While ICPSR and Sociometrics offer many of the same databases, Sociometrics' wide variety of data formats and topical collections of data seem more geared towards independent researchers.

Information in this report is organized in a format that should allow easy access to and cross-referencing of information. Depending on availability of documentation and survey instruments, the contents of the databases are represented through sample questions, variables, or both. The risk-related aspects can be easily referenced across databases using Table 1 .

The appendix to this report lists databases that may include one or more of the riskrelated aspects of interest, but were not included in the collection of National Databases. Reasons for exclusion are noted. Among the appendixed databases, surveys frequently lacked national representation, sample populations were slightly older than the years of adolescence, or data did not contain risk-taking elements. In a few cases, more recent data of the same kind is available from the same research sponsor, and that data was included in the national collection. Despite these drawbacks, the databases in the appendix can be used to focus on specific issues or populations of interest. 
Iable 1. National Databases by Topic

\begin{tabular}{|c|c|c|c|c|c|c|c|c|c|c|c|c|c|c|c|c|c|}
\hline & \multicolumn{17}{|c|}{ Risk-rolated aspects } \\
\hline Database & 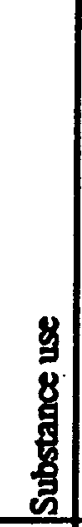 & $\begin{array}{r}8 \\
8 \\
8 \\
\\
\end{array}$ & . & 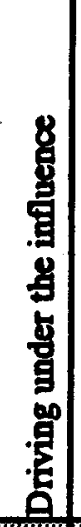 & $\begin{array}{l}\frac{y}{8} \\
8 \\
\text { 莺 }\end{array}$ & $\begin{array}{l}8 \\
\frac{8}{8} \\
\frac{7}{8} \\
8\end{array}$ & 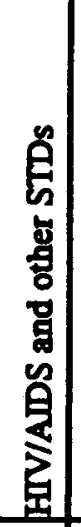 & 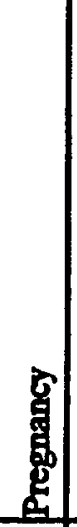 & 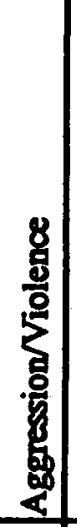 & 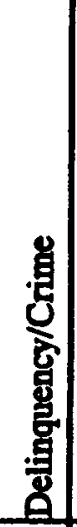 & 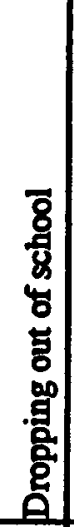 & 昜 & 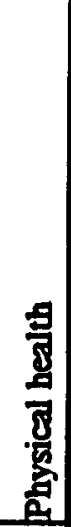 & 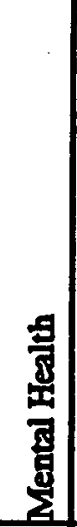 & 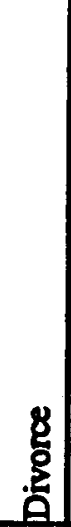 & 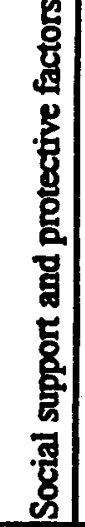 & 弯 \\
\hline Fatal Aocident Reporting System (FARS) & & & & & & & & & & & & & & & & & crash statistics \\
\hline General Estimates System (GES) & & & & & & & & & & & & & & & & & crash statistics \\
\hline $\begin{array}{l}\text { High School and Beyond (HS\&B), } \\
\text { Fourth Follow Up, } 1992 .\end{array}$ & & & & & & & & & & & & & & & & & under achievement \\
\hline Monitoring the Future & & & & & & & & & & & & & & & & & \\
\hline $\begin{array}{l}\text { National and State Data Files } \\
\text { on Adolescent Fertility, 1960-1988 }\end{array}$ & & & & & & & & & & & & & & & & & lack of prenatal care \\
\hline $\begin{array}{l}\text { National Archive on Sexuality, Health, } \\
\text { and Adolescence (NATASHA) }\end{array}$ & & & & & & & & & & & & & & & & & \\
\hline Nationai Education Longitudinal Stuờy & & & & & & & & & & & & & & & & & school environment \\
\hline $\begin{array}{l}\text { National Health and Social Life Survey, } \\
1992\end{array}$ & & & & & & & & & & & & & & & & & prostitution \\
\hline $\begin{array}{l}\text { National Health Interview Survey: AIDS } \\
\text { Knowledge and Attitudes Supplement }\end{array}$ & & & & & & & & & & & & & & & & & \\
\hline $\begin{array}{l}\text { National Health Interview Survey: Child Health } \\
\text { Supplement }\end{array}$ & & & & & & & & & & & & & & & & & $\begin{array}{l}\text { developmental } \\
\text { disorders, } \\
\text { passive smoking }\end{array}$ \\
\hline $\begin{array}{l}\text { National Health Interview Survey: Drug and } \\
\text { Alcohol Use Supplement }\end{array}$ & & & & & & & & & & & & & & & & & \\
\hline $\begin{array}{l}\text { National Health Interview Survey: Injury Control } \\
\text { and Child Safety and Health File }\end{array}$ & & & & & & & & & & & & & & & & & \\
\hline $\begin{array}{l}\text { National Health Interview Survey: Pregnancy } \\
\text { and Smoking Supplement }\end{array}$ & & & & & & & & (6, & & & & & & & & & $\begin{array}{l}\text { passive smoking, } \\
\text { fetal \& newborn }\end{array}$ \\
\hline
\end{tabular}




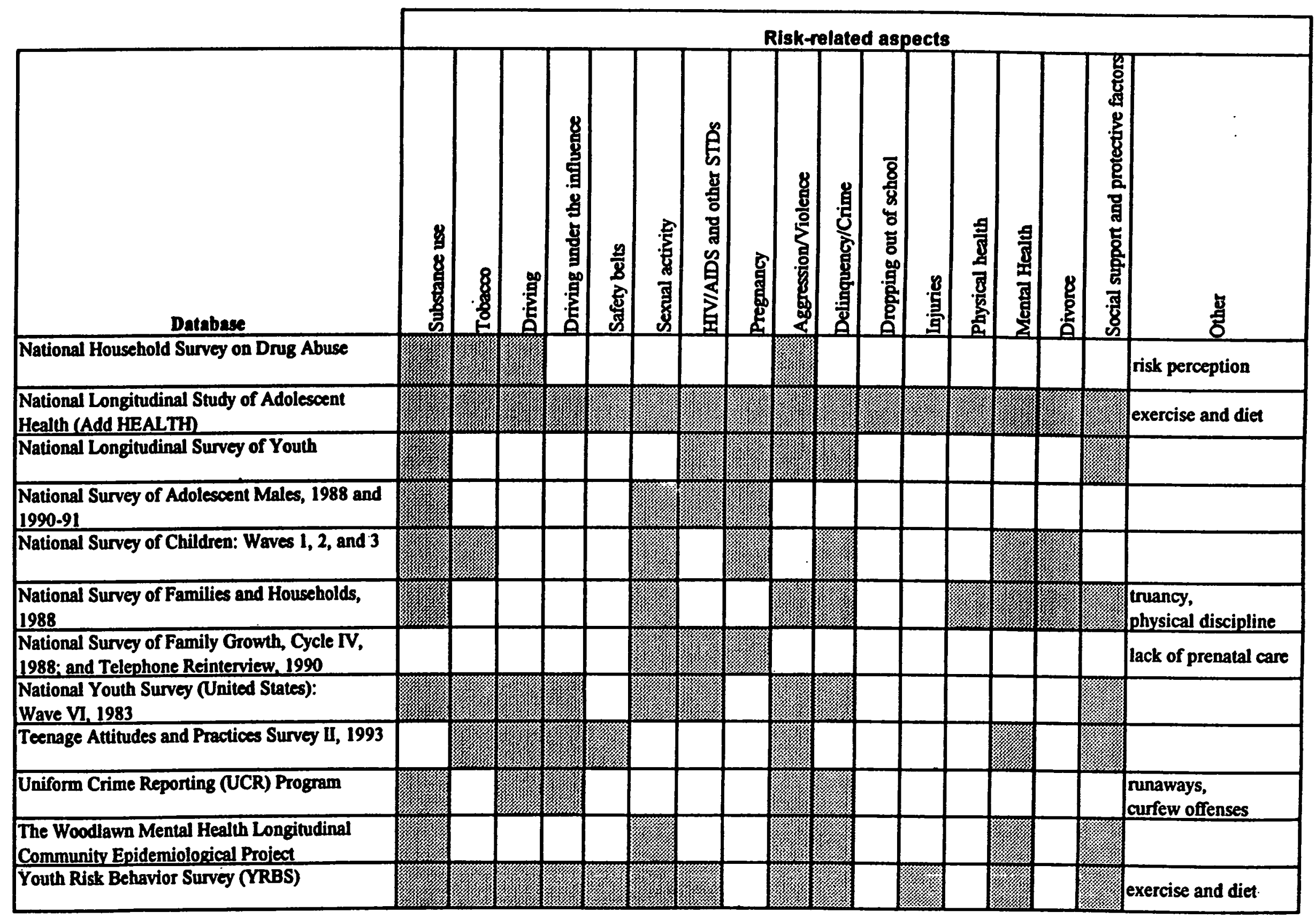

\section{0-91}

National Survey of Children: Waves 1, 2, and 3

National Survey of Families and Households,

Wave VI. 1983

Uniform Crime Reporting (UCR) Program

The Woodlawn Mental Health Longitudingl

Community Epidemiological Project

Youth Risk Behavior Survey (YRBS)

exercise and diet 
Fatal Accident Reporting System (FARS)

AVAILABILITY:

Sponsoring Agency: National Highway Traffic Safety Administration (NHTSA), U. S. Department of Transportation

Where to request database: DOT/ Volpe National Transportation Systems Center Kendall Square

Cambridge, MA 02142

Telephone: (617) 494-2640

Contact Person: $\quad$ Marjorie Saccoccio, DTS-44

DOT/ Volpe

Tonja Lindsey

National Highway Traffic Safety Administration

U.S. Department of Transportation

Telephone: (202) 366-0854

\section{ACCESSIBIITY:}

- $\quad$ Computer tapes, $1 / 4$ " cartridges, $\$ 170$ per year of data

- CD-ROM, $\$ 170.00$ for 1988-1994 data

- $\quad 3.5^{\prime \prime}$ diskettes, $\$ 100$ per year of data

DATA FORMAT:

- PC-SAS or ASCII file

YEAR(S) OF DATA COLLECTION:

- In progress since 1975. Data currently available through 1994.

- Ongoing data collection. Daily updates are sent to NHTSA's central computer database.

\section{MAJOR AREAS:}

- Crash level describes time of incident, environmental conditions, the count of fatalities and the use of emergency medical services.

- Vehicle level describes the vehicle, its specific role in the incident, and the incident's impact upon the vehicle.

- Driver level contains license-related information

- Person level contains victim information

MAJOR OR SAMPLE QUESTIONS:

- No questionnaire element. See "Method of Data Collection" and "Variables" sections. 


\section{SAMPLE CHARACTERISTICS:}

- Occupants of vehicles or nonmotorists whose death results from a crash involving a motor vehicle traveling on a trafficway customarily open to the public. The death must occur within thirty days from the time of the crash.

\section{METHOD OF DATA COLLECTION:}

- Police crash reports

- State vehicle registration files

- State driver licensing files

- State highway department data

- Vital statistics

- Death certificates

- Coroner/medical examiner reports

- Hospital medical reports

- Emergency medial service reports

\section{VARIABLES:}

- More than 100 data elements

- Crash level variables include accident date, atmospheric condition, first harmful event, hit and run, light condition, number of drinking drivers in crash, number of fatalities in crash, speed limit, time

- Vehicle level variables include crash avoidance maneuver, impact point--initial, manner of leaving the scene, number of deaths in vehicle, number of occupants in vehicle, rollover

- Driver level variables include compliance with license restrictions, driver drinking, violations charged

- Person level variables include age, air bag availability/function, alcohol test results, death certificate number, death date, death time, drug test results, ejection, ejection path, extrication, injury severity, method of alcohol determination, method of other drug determination by police, gender, time of crash to time of death

\section{UNIQUE CHARACTERISTICS:}

- Contains data on all reported fatal traffic crashes within the 50 states, the District of Columbia, and Puerto Rico

RISK-RELATED ASPECTS:

- Driving under the influence

- Safety belts

- Driving

- Crash statistics 


\section{General Estimates System (GES)}

\section{AVAIIABIIITY:}

Sponsoring Agency:

Where to request database:

Contact Person:
National Highway Traffic Safety Administration (NHTSA), U. S. Department of Transportation

DOT/ Volpe National Transportation Systems Center Kendall Square

Cambridge, MA 02142

Telephone: (617) 494-2640

Marjorie Saccoccio, DTS-44

DOT/ Volpe

Tonja Lindsey

National Highway Traffic Safety Administration

U.S. Department of Transportation

Telephone: 202/366-0854

\section{ACCESSIBIIITY:}

- Computer tapes, $1 / 4^{\prime \prime}$ cartridges, $\$ 150$ per year of data

- CD-ROM, $\$ 150.00$ for 1988-1994 data

- $\quad 3.5^{\mathrm{n}}$ diskettes, $\$ 100$ per year of data

\section{DATA FORMAT:}

\section{- PC-SAS or ASCII file}

YEAR(S) OF DATA COLLECTION:

- In progress since 1988. Data currently available through 1994.

- Ongoing data collection. GES data collectors make weekly visits to approximately 400 police jurisdictions in 60 sites across the United States, where they sample about 48,000 police crash reports (PARs) per year.

\section{MAJOR AREAS:}

- Crash level includes time of incident, environmental conditions, the count of injured people.

- Vehicle/driver level includes the vehicle's description, its specific role in the incident, most harmful event, critical event, driver actions.

- Person level contains victim information, including injury severity, restraint type, age, gender, and police-reported alcohol or drug involvement. 
General Estimates System

\section{MAJOR OR SAMPLE QUESTIONS:}

- No questionnaire element. See "Method of Data Collection" and "Variables" sections.

\section{SAMPLE CHARACTERISTICS:}

- Occupants of vehicles or nonmotorists whose death results from a crash involving a motor vehicle traveling on a trafficway customarily open to the public. The death must occur within thirty days from the time of the crash.

\section{METHOD OF DATA COLLECTION:}

- $\quad$ Police crash reports

\section{VARIABLES:}

- Approximately 90 data elements.

- Crash level variables include alcohol involved in crash, atmospheric condition, first harmful event, light condition, manner of collision, maximum injury severity, time of crash, month of crash, number injured in crash, number of nonmotorists, number of vehicles, pedestrian/pedalcyclist accident type, speed limit,

- Vehicle/driver level variables include accident type, critical event, corrective action attempted, damage areas, damage severity, driver distracted by, driver drinking in vehicle, driver maneuvered to avoid, driver presence, driver's vision obscured by, driver's zip code, hit and run, jackknife, travel speed

- Person level variables include age, air bag availability/function, ejection, injury severity, person's physical impairment, police-reported alcohol involvement, police-reported drug involvement, seating position, gender, taken to hospital or treatment facility

\section{UNIQUE CHARACTERISTICS:}

- GES numbers are estimates of counts of crashes and injuries and are subject to sampling and nonsampling errors.

\section{RISK-RELATED ASPECTS:}

- Driving

- Driving under the influence

- Safety belts

- Injuries sustained in crashes 
High School and Beyond (HS\&B), 1980

Sophomore and Senior Cohort Third Follow Up (1986);

Sophomore Cohort Fourth Follow Up (1992)

AVAILABILITY:

Sponsoring Agency: $\quad$ U.S. Department of Education

Office of Educational Research and Improvement

Where to request database: NCES Longitudinal Studies Branch

555 New Jersey Ave., N.W.

Washington, D.C. 20208-5652

Telephone: (202) 219-1365

Internet address: ADAMICO@INET.ED.GOV

Contact Person: $\quad$ Aurora D'Amico

\section{ACCESSIBIITY:}

- Cartridge tape

DATA FORMAT:

- Logical record length with SPSS and SAS data definition statements

YEAR(S) OF DATA COLLECTION:

- Both cohorts (1980 senior class and 1980 sophomore class) were surveyed in 1980, 1982, 1984, and 1986; and the 1980 sophomore class was surveyed again in 1992.

\section{MAJOR AREAS:}

- Educational aspirations

- Educational outcomes

- Labor outcomes

MAJOR OR SAMPLE QUESTIONS:

\section{- See variables below}

\section{SAMPLE CHARACTERISTICS:}

- Two cohorts: 1980 senior class, and 1980 sophomore class.

- Two-stage stratified probability sample design with schools as the first-stage units and students within schools as the second-stage units.

- 1,122 schools were selected from a frame of 24,725 schools with grades 10 or 12 or both. Within each school, 36 seniors and 36 sophomores were randomly selected. 
- Subsampling plans for follow-ups emphasized retention of racial and ethnic minorities, especially those students with above average High School and Beyond achievement test scores, students who attended private high schools, school dropouts, transfers and early graduates, and students whose parents participated in the base year Parent's Survey on financing postsecondary education.

\section{METHOD OF DATA COLLECTION:}

- School-based student questionnaire

- Information about school

- Teacher comment checklist

- Parent questionnaire

- Follow-ups of 1980 sophomore class: student questionnaire, school information in first follow-up, high school and postsecondary transcripts, drop-out data

- Follow-ups of 1980 senior class: individual questionnaire, postsecondary transcripts

\section{VARIABLES:}

- Age, gender, high school diploma status, socioeconomic status, test score composite, race/ethnicity, parents' educational attainment, religious background

- Teacher observations about the student

- School-reported enrollment, staff characteristics, educational programs, facilities, services, dropout rates, special programs for handicapped and disadvantaged students

- Parents' reported family attitudes, family income, employment, occupation, salary, financial planning

- College expectations in sixth grade, postsecondary expectations, first institution start date, number of applications to college, accepted at first-choice college, undergraduate major, undergraduate degree status, graduate school application status.

- Locus of control, community orientation, work status, unpaid activities, marital status, number of marriages, unemployment benefits, occupational characteristics, salary, education-related debt

- Transcripts and credits earned

\section{UNIQUE CHARACTERISTICS:}

- Student drop-outs' employment and earning outcomes.

- Test score composites and subsequent educational attainments, i.e., whether the test scores predicted what they were supposed to predict.

- Despite the college-preparation emphasis during the teenage years, only one fourth of the 1980 high school sophomores attained a bachelor's degree in the 10 years following high school.

- Ability to identify students who did not finish school or otherwise fulfill their potential. When these students' early test scores predicted academic achievement, some risk factors appear to have influenced the negative outcome. 
RISK-REILATED ASPECTS:

- Dropping out of school

- Mental health

- Social support and protective factors

- Under achievement 
Monitoring the Future: A Continuing Study of the Lifestyles and Values of Youth

AVALABIITTY:

Sponsoring Agencies:

National Institute on Drug Abuse

U.S. Department of Health and Human Services

Institute for Social Research

The University of Michigan

Ann Arbor, MI 48206-1248

Telephone: (313) 763-5043

attn: Joyce Buchanan or Ginger Maggio

Where to request database: Inter-University Consortium for Political and Social Research (ICPSR)

P.O. Box 1248

Ann Arbor, MI 48106

Telephone: (313) 763-5010

Contact Person:

Pat Maurer

\section{ACCESSIBILITY:}

- ICPSR 6367, $\$ 550$

- File transfer protocol (ftp), 2400 foot magnetic tape, or IBM 3480 data cartridge

- Annual codebook entitled Questionnaire responses from the nation's high school seniors contains analysis and all variables. Available for $\$ 60$ per year.

DATA FORMAT:

- Logical record length with SAS and SPSS data definition statements

YEAR(S) OF DATA COLLECTION:

- In progress since 1975. Data is available from ICPSR for the years 1976-1993.

- New data continues to be collected annually.

- Nationally representative groups of high school seniors have been surveyed annually since 1975.

- Nationally representative groups of eighth- and tenth-graders have been surveyed annually since 1991 .

- Representative subsamples of the seniors in the survey were followed up annually since 1976.

- Representative subsamples of the eighth- and tenth-graders in the survey were followed up since 1993. 


\section{MAJOR AREAS:}

- Drug use prevalence among eighth, tenth, and twelfth graders, young adults, and college students

- Trends in drug use, including use at earlier grade levels

- Attitudes and beliefs about drugs and the social milieu

- Educational, occupational, social, and material aspirations

- Opinions concerning political and social issues, e.g. disarmament, race relations

\section{MAJOR OR SAMPLE QUESTIONS:}

- Have you ever smoked cigarettes?

- How frequently have you smoked cigarettes during the past 30 days?

- During the last twelve months, how often have you been around people who were taking each of the following to get high or for "kicks"?

- How do you think your close friends feel (or would feel) about you... Taking cocaine once or twice? ... Taking four or five drinks nearly every day? ...Smoking one or more packs of cigarettes per day?

- During an average week, how much do you usually drive a car, truck, or motorcycle? Not at all/ 1 to 10 miles/ 11 to 50 miles/ 51 to 100 miles/ 100 to 200 miles/ More than 200 miles

- Within the LAST 12 MONTHS how many times, if any, have you received a ticket (OR been stopped and warned) for moving violations, such as speeding, running a stoplight, or improper passing? None/ Once/ Twice/ Three times/ Four or more times

- How many of these tickets or warnings occurred after you were...

- Drinking alcoholic beverages?

- Smoking marijuana or hashish?

- Using other illegal drugs?

- We are interested in any accidents which occurred while you were driving a car, truck, or motorcycle. ("Accidents" means a collision involving property" damage or personal injury--not bumps or scratches in parking lots.) During the LAST 12 MONTHS, how many accidents have you had while you were driving (whether or not you were responsible)? None/ One/ Two/ Three/ Four or more

- How many of these accidents occurred after you were...

- Drinking alcoholic beverages?

- Smoking marijuana or hashish?

- Using other illegal drugs?

- Has your use of alcohol, marijuana, or other illegal drugs ever caused any of the following problems for you? (For each problem, mark all drugs that have caused you this problem).

Has your use of these drugs...

- Caused you to behave in ways that you later regretted

- $\quad$ Hurt your relationship with your parents 
- Hurt your relationship with your spouse, fiancee, or girlfriend/boyfriend

- $\quad$ Hurt your relationships with your friends

- Hurt your relationships with teachers or supervisors

- $\quad$ Involved you with people you think are a bad influence on you

- Hurt your performance in school and/or on the job

- Caused you to be less interested in other activities than you were before

- Caused you to be less stable emotionally

- $\quad$ Caused you to have less energy

- Interfered with your ability to think clearly

- Had other bad psychological effects

- Caused your physical health to be bad

- Caused you to drive unsafely

- $\quad$ Gotten you into trouble with the police

- Caused you none of the above problems

- Never used [alcohol, marijuana, or other illegal] drugs

What have been the most important reasons for your using narcotics other than heroin without a doctor's orders? (Mark all that apply)

- To experiment--to see what it's like

- $\quad$ To relax or relieve tension

- $\quad$ To feel good or get high

- $\quad$ To seek deeper insights and understanding

- $\quad$ To have a good time with my friends

- $\quad$ to fit in with a group I like

- $\quad$ To get away from my problems or troubles

- $\quad$ Because of boredom, nothing else to do

- Because of anger or frustration

- To get through the day

- $\quad$ To increase the effects of some other drug(s)

- $\quad$ To decrease (offset) the effects of some other drug

- $\quad$ To get sleep

- As a substitute for heroin

- $\quad$ To relieve physical pain

- $\quad$ To control coughing

- $\quad$ Because I am "booked"-I have to have it

How much do you agree or disagree with each of the following statements?

- $\quad$ The nation needs much more long-range planning and coordination to be prepared for the future.

- $\quad$ I enjoy the fast pace and changes of today's world.

- Things change too quickly in today's world

- I think the times ahead for me will be tougher and less fun than things are now. 
- Of all the time you spend with other people, about how much is spent with people over 30 ?

Would you like to spend more time, or less time, with people over 30 if you could?

- Would you like to spend more time, or less time, working with or helping younger children?

- How satisfied are you with...

- $\quad$ Your job? (If you have no job, leave blank)

- $\quad$ The neighborhood where you live?

- Your personal safety in your neighborhood, on your job, and in your school-safety from being attacked and injured in some way?

- The safety of things you own from being stolen or destroyed in your neighborhood, on your job, and in your school?

- Your educational experiences?

- Your friends and other people you spend time with?

- $\quad$ The way you get along with your parents?

- Yourself?

- Your standard of living--the things you have like housing, car, furniture, recreation, and the like?

- The amount of time you have for doing things you want to do?

- The way you spend your leisure time-recreation, relaxation, and so on?

- Your life as a whole these days?

- The way our national government is operating?

- The amount of fun you are having?

- Which of the following people live in the same household with you? (Mark all that apply.)

- I live alone

- $\quad$ Father (or male guardian)

- Mother (or female guardian)

- $\quad$ Brother(s) and/or sister(s)

- Grandparent(s)

- $\quad$ My husband/wife

- My children

- Other relative(s)

- Non-relative(s)

These next questions concern your health. During the LAST 30 DAYS, on how many days (if any) did you have the following problems or symptoms?

- Headache

- Sore throat or hoarse voice

- Trouble with sinus congestion, runny nose, or sneezing

- Coughing spells

- Chest colds

- $\quad$ Coughing up phlegm or blood 
- $\quad$ Shortness of breath when you were not exercising

- Wheezing or gasping

- $\quad$ Trouble remembering things

- Difficulty thinking or concentrating

- $\quad$ Trouble learning new things

- Trouble sleeping

- Trouble getting started in the morning

- $\quad$ Stayed home most or all of a day because you were not feeling well

\section{SAMPLE CHARACTERISTICS:}

- Data is available for five groups:

- $\quad$ Eighth grade students

- Tenth grade students

- Twelfth grade students

- College students

- $\quad$ Young adults through age 32 who are high school graduates.

- For eighth and tenth graders, random selection of geographic areas and schools parallels that of the seniors. At the student level:

- $\quad$ For eighth graders, approximately 160 schools are sampled, and approximately 18,000 to 19,000 students are surveyed.

- $\quad$ For tenth graders, approximately 125 schools are sampled, and approximately 15,000 students are sampled.

- Each year, approximately 16,800 seniors participate in the survey.

- Multi-stage random sampling of high school seniors nationwide.

- $\quad$ Stage 1: selection of particular geographic areas;

- $\quad$ Stage 2: selection of one or more high schools in each area (with probability proportionate to size);

- $\quad$ Stage 3: selection of seniors within each high school.

\section{METHOD OF DATA COLLECTION:}

- Participants complete surveys in their classrooms.

- Seniors are administered one of six different forms of the questionnaire. Each form shares a set of core questions but includes different subsections.

Eighth and tenth graders are administered one of two different forms.

All future eighth grade follow-ups will be done by mail.

The senior follow-up (2,400 of the original 15,000-17,000 seniors) includes an oversample of drug users. This group was divided into two matched groups. One group is surveyed in odd-calendar years, and the other group is surveyed in evencalendar years, until participants reach the age of 35 . After age 35, participants are surveyed every five years thereafter. 
Monitoring the Future

\section{VARIABLES:}

Region, grade, age, gender, year of graduation, GPA, college plans.

- More than 1,300 variables each year, including frequency and lifetime, annual, thirtyday and daily prevalence of tobacco, alcohol, and various drugs, e.g., marijuana, cocaine, LSD, other psychedelics, amphetamines, tranquilizers, barbiturates, methaqualone, quaaludes, heroin, other opiates, steroids, inhalants, MDMA.

- Perceived availability of each type of drug, peer approval of substance use

- Traffic crashes, tickets, driving under the influence of alcohol or other substances, being a passenger of a driver under the influence of alcohol or other substances

- Attitudes toward government, social institutions, race relations, changing roles for women, educational aspirations, occupational aims, and marital and family plans.

\section{UNIQUE CHARACTERISTICS:}

- Differentiation of the effects of historical time period, age of respondent, and cohort of respondent, in substance use of various types.

- Comparison between college students and non-college students one to four years after completing high school.

- Surveys from 1991 and later that include eighth- and tenth-grade students allow comparison between junior high school students, high school seniors, and high school graduates. Analysis of drug prevalence rates can be adjusted for high school dropouts using the dropout data contained in the National Household Survey on Drug Abuse.

- Relationships between hundreds of potential "risk factors" and drug use can be examined through bivariate tables that show responses to each question distributed against an index of lifetime illicit drug involvement. Trend data may also be examined through this volume's across-time references. While these tables express relationships between all variables and drug use, secondary analyses could show distributions of all responses against other variables of interest, such as the driving questions.

\section{RISK-RELATED ASPECTS:}

$\begin{array}{ll}\text { - } & \text { Substance use } \\ \text { - } & \text { Driving } \\ \text { - } & \text { Driving under the influence } \\ \text { - } & \text { Menysical health } \\ \text { - Social support and protective factors }\end{array}$


National and State Data Files on Adolescent Fertility, 1960-1988

AVAILABIIITY:

Sponsoring Agency:

Where to request database:

Contact Person:
Child Trends

Sociometrics Corporation

170 State Street, Suite 260

Los Altos, California 94022

Telephone: (415) 949-3282

Fax: (415) 949-3299

Email: eric@socio.com

Eric Lang

Sociometrics Corporation

\section{ACCESSIBIIITY:}

- $\quad$ Sociometrics reference: DAAPPP E8-E9

- Mainframe computer tape, $\$ 100$

- 1 IBM hi-density disk (5.25" or 3.5"), $\$ 100.00$

- CD-ROM, $\$ 225.00$

DATA FORMAT:

- Raw data, SPSS program statements

YEAR(S) OF DATA COLLECTION:

- $\quad$ Each year 1960-1988

MAJOR AREAS:

- Pregnancy

- Marriage status

- Health of mother and child

SAMPLE CHARACTERISTICS:

- Since this data set is a compilation of secondary, aggregate-level data, no new sampling was involved.

- Sources include data files from the Vital Registration System; the National Center for Health Statistics, U.S. Department of Health and Human Services; the Alan Guttmacher Institute; the Bureau of the Census, U. S. Department of Commerce; and the Office of Family Assistance, Family Support Administration, U.S. Department of Health and Human Services.

- Data may be grouped by age for women less than 15 years old, 15-17, 18-19, and 2024. 


\section{METHOD OF DATA COLLECTION:}

- Compilation and analysis of secondary data

\section{VARIABLES:}

- Age, race, year

- Number of births, out-of-wedlock births, abortions

- Birth rates, pregnancies, and abortions per 1,000 women

- Low birth weight incidence

- Percent of women unmarried

- Total number of first births

- Infant mortality rates

- Late or lack of prenatal care

- Number and percent of teen mothers on AFDC

UNIQUE CHARACTERISTICS:

- Provides statistics for the entire nation over the years 1960 to 1988.

RISK-REILATED ASPECTS:

- Pregnancy

- Lack of prenatal care 
National Archive on Sexuality, Health, and Adolescence (NATASHA)

AVAILABILITY:

Sponsoring Agency:

Sociometrics Corporation

Where to request database:

Sociometrics Corporation

170 State Street, Suite 260

Los Altos, California 94022

Telephone: (415) 949-3282

Fax: (415) 949-3299

Email: eric@socio.com

Contact Person:

Eric Lang

ACCESSIBIITT:

- Sociometrics reference: NATASHA

- $\quad$ PC CD-ROM or Mac CD-ROM, $\$ 950$

DATA FORMAT:

- Microcomputer and mainframe formats

- Graphic interfaces and pull-down menus

- Raw data files and separate SPSS program statement files

YEAR(S) OF DATA COLLECTION:

- 125 major U.S. studies (185 Data Sets) conducted over a 45-year time period.

MAJOR AREAS:

- Adolescent bealth, sexuality, and fertility behavior

MAJOR OR SAMPLE QUESTIONS:

- Varies with each data set

SAMPLE CHARACTERISTICS:

- Varies with each data set

METHOD OF DATA COLLECTION:

- Varies with each data set

- A nationally appointed panel of experts selected studies to include in NATASHA using the following criteria: technical quality, substantive utility, policy relevance, and potential for secondary analysis. 
VARIABLES:

- More than 70,000 variables; over 795,000 cases

- Specific variables vary with each data set

UNIQUE CHARACTERISTICS:

- Crosstabulated data allows user to examine virtually any pair of variables from over 125 major U.S. studies

- National and local data is presented together.

RISK-RELATED ASPECTS:

- Sexual activity

- Pregnancy

- HIV/AIDS and other STDs 
National Education Longitudinal Study, 1988: Follow-Ups 1990, 1992, 1994

AVAILABILITY:

Sponsoring Agency:

U.S. Department of Education

Where to request database:

Longitudinal and Household Studies Branch

National Center for Education Statistics

U. S. Department of Education

555 New Jersey Ave., NW, Room 417b

Washington, DC. 20208-5651

Telephone: (202) 219-1743

Fax: (202) 219-1728

Internet: Peggy_Quinn@ed.gov

Contact Person:

Peggy Quinn

\section{ACCESSIBIITY:}

- NCES, CD-ROM (free), Data cartridge

- ICPSR 9859 (also available through ICPSR), $\$ 300$

- File transfer protocol (ftp), 2400 foot magnetic tape, or IBM 3480 data cartridge

DATA FORMAT:

- Logical record length with SAS and SPSS data definition statements

YEAR(S) OF DATA COLLECTION:

- Base year, 1988, and follow-ups in 1990, 1992, and 1994

MAJOR AREAS:

- Student data

- School data

- Dropout data

- Teacher data

MAJOR OR SAMPLE QUESTIONS:

- Here are some reasons other people have given for leaving school. Which of these would you say applied to you?

- On the whole, do you feel that leaving school was a good decision for you? Please explain why you feel that way.

- Have you ever participated in an alternative program?

- Whether or not you already have a job, were you looking for a job last week?

- On how many occasions (if any) have you taken cocaine in any form (including crack)? 
- Think about how you see your future. What are the chances that...you will graduate from high school? ...you will stay in good health most of the time? ...life will turn out better for you than it has for your parents?

- Do you belong to a gang?

\section{SAMPLE CHARACTERISTICS:}

- NELS:88 followed a two-stage sampling procedure, by school and student. Between 24 and 26 students in the 8th grade were selected within each school.

- $\quad$ NELS:90 used a two-stage sampling of core group of students who were in the 1988 eighth grade sample, distributed across 1,500 schools.

- To be a valid probability sample of all students currently enrolled in the tenth grade in the 1989-90 school year regardless of the 1988 survey, students were included who were tenth-graders in 1990 but not in the eighth grade during the 1987-1988 school year.

- Base-year students who had dropped out of school between 1988 and 1990 were subsampled.

\section{METHOD OF DATA COLLECTION:}

- School-based questionnaire

\section{VARIABLES:}

- Dropout component provides data on the process of dropping out of school as it occurs from eighth grade on:

- School attendance, including absences and tardiness

- Determinants of leaving school

- $\quad$ Self-perceptions and attitudes

- Work history

- Relationships with school personnel, peers, and family

- Student component collected background information:

- $\quad$ Students' home and school environments, including home language

- Participation in classes and extracurricular activities

- $\quad$ Current jobs

- $\quad$ Students' goals, aspirations, and opinions about themselves

- Tenth grade achievement and scholastic growth between 1988 and 1990 in the subject areas of mathematics, science, reading, and social studies.

- Students' educational setting

- Substance abuse, importance of wedlock for sexual relationships, student/friends belong to a gang, importance of several life goals/ideals

- Teacher component elicited evaluations of:

- Student characteristics and performance in the classroom

- Curriculum information

- Teacher demographic and professional characteristics 
- $\quad$ Parent-teacher interactions

- $\quad$ Time spent on various tasks

- Perceptions of school climate and culture

- School component was completed by administrators:

- Educational setting and environment

- $\quad$ Grading and testing structure

- Program and facilities

- Parental interactions and involvement

- $\quad$ Teaching staff characteristics

\section{UNIQUE CHARACTERISTICS:}

- The data concerning specific students was compiled from multiple points of view: students, teachers, and administrators. Baseline 1988 data also contains parents' survey responses.

- Extensive sections on school effectiveness and climate should allow for analysis of environmental factors that contribute to dropping out of school.

- Captures the population of early dropouts (those who leave school prior to the end of the tenth grade), while monitoring the transition of the student population into high school.

\section{RISK-RELATED ASPECTS:}

\section{- Substance use}

- Dropping out of school

- Social support and protective factors

- School environment 
AVAILABILTT:

Sponsoring Agencies:

Robert Wood Johnson Foundation

Henry J. Kaiser Family Foundation

Rockefeller Foundation

Andrew Mellon Foundation

John D. and Catherine T. MacArthur Foundation

New York Community Trust

American Foundation for AIDS Research

The Ford Foundation

(Project directors: Edward O. Laumann, Robert

T. Michael, Stuart Michaels, University of

Chicago, and John H. Gagnon, State University of New York at Stony Brook)

Where to request database:

Sociometrics Corporation

170 State Street, Suite 260

Los Altos, California 94022

Telephone: (415) 949-3282

Fax. (415) 949-3299

Email: eric@socio.com

Contact Person:

Eric Lang

Sociometrics Corporation

\section{ACCESSIBUITY:}

- Sociometrics reference: AIDS 12-13

- Tape in either microcomputer or mainframe formats, $\$ 150$

- CD-ROM, $\$ 225.00$

\section{DATA FORMAT:}

- Raw data file

- SPSS program file

- SAS program file

- Dictionary file, i.e., list of variable and:value labels

- Descriptive statistics file for variables with more than 50 value categories.

YEAR(S) OF DATA COLLECTION:

- Single point in time: Data were collected between February and September, 1992. 


\title{
MAJOR AREAS:
}

\author{
- Sexual behavior \\ - Number of partners, frequency of particular practices, timing of sexual events \\ - Attitudes toward sex outside of marriage \\ - Appeal of particular sexual techniques \\ - Satisfaction levels with particular sexual relationships
}

\section{MAJOR OR SAMPLE QUESTIONS:}

- see Laumann, E.O., Gagnon, J.H., Michael, R.T., \& Michaels, S. (1994). The Social Organization of Sexuality: Sexual Practices in the United States. Chicago: University of Chicago Press.

\section{SAMPLE CHARACTERISTICS:}

- $\quad 18-59$ year olds with adequate English proficiency to participate in the interview, and who lived in households in the 50 states and the District of Columbia between February and September, 1992.

- Multistage area probability sampling design, by geographic and by household, based on 1980 SRC/NORC sample frame.

- Blacks and Hispanics were oversampled.

- 3,432 interviews were completed.

\section{METHOD OF DATA COLLECTION:}

- Face-to face interviews

- Interviewers were recruited from local areas where the interviews would take place.

\section{VARIABLES:}

- 1,604 variables

- Age, gender, gender role, race, ethnicity, region/state, religion, political identification

- Demographics of each of respondent's sexual partners

- Physical health, death of children, blood transfusions, painful urination, painful intercourse, genital sores/itching, vaginal discharge, health interference with sex last 12 months, stress/emotional problems interference with sex

- Resources utilized for sex problems (e.g., psychiatrist, clergy, marriage counselor),

- Education level of each sexual partner

- Source of sex education that taught respondent most (e.g., peers, TV, school, magazines)

- Occupation, wealth and finances

- Childbearing and pregnancy, abortion

- STDs, HIV/AIDS, HIV prevention knowledge, number of person with AIDS respondent has known, relationship to them, their race, whether they are still alive.

- Contraception

- Anal intercourse, non-penetrative sex, oral-genital/oral-anal, vaginal intercourse 
- Attitudes towards multiple partners, forced sex, voyeurism, sex with stranger, watching partner undress

- Think homosexuality/ premarital sex / teen sex/ extramarital sex/ is wrong.

- Substance use

- alcohol consumption past year

- $\quad$ number of drinks consumed on typical day

- whether before or during sex, respondent or each of respondent's partners drank/took drugs/was affected by alcohol or drugs

- $\quad$ ever inject drugs with needle/with used needle

- number of sexual partners who have injected drugs

Crime, delinquency, and behavior problems

- $\quad$ age first in jail

- $\quad$ ever spent night in jail/prison/detention center

- $\quad$ number of days spent in jail

- Rape, threats used, weapons used, respondent's age at time, relationship to person who forced unwanted sex (e.g., friend, acquaintance, stranger, just met, spouse)

- Prostitution

- $\quad$ ever paid/ever been paid for sex

- number of partners you have paid or who have paid you

- $\quad$ gender of those partners

- $\quad$ respondent's age at time (before or after 18)

- Dating/courtship, cohabitation, marriage, divorce

- Knowing and liking sexual partner's friends, know/enjoy partner's family; partner enjoys respondent's family

- Sexually explicit recreation activities

- Residential mobility, neighborhood/community

\section{UNIQUE CHARACTERISTICS:}

- Historically significant and controversial study

- Specificity: who does what with whom for how long and how happy they are with it.

\section{RISK-RELATED ASPECTS:}

$\begin{array}{ll}- & \text { Substance use } \\ \text { - } & \text { HIVIJalAdivity } \\ \text { - } & \text { Pregnancy } \\ \text { - } & \text { Delinquency/crime } \\ \text { - } & \text { Physical health } \\ \text { - } & \text { Pocial support and protective factors } \\ & \text { Prostion }\end{array}$


National Health Interview Survey: ADS Knowledge and Attitudes Supplement (1992)

AVAILABIITY:

Sponsoring Agency:

National Center for Health Statistics

Centers for Disease Control and Prevention

U. S. Department of Health and Human Services

Where to request database:

Presidential Building, Room 850

6525 Belcrest Road

Hyattsville, Maryland 20782

Telephone: (301) 436-7087, ext. 151

Fax: (301) 436-3484

Contact Person:

Charlotte Schoenborn

\section{ACCESSIBILITY:}

- $\quad$ Cartridge tape, $\$ 200$ (NCHS)

- ICPSR 6050 (also available through ICPSR)

- File transfer protocol (ftp), 2400 foot magnetic tape, or IBM 3480 data cartridge

DATA FORMAT:

- $\quad$ Fixed-block format

- All files for a given year have the same record length and block size

YEAR(S) OF DATA COLLECTION:

- The NHIS has been in progress since 1957. Data is currently available through 1992.

- The AIDS Knowledge and Attitudes Supplement was introduced in 1987 and repeated each year thereafter.

- Ongoing, with a probability sample of households interviewed each week

MAJOR AREAS:

- AIDS knowledge and awareness

- Amount and distribution of illness

- Effects of illness in terms of disability and chronic impairments

- Kinds of health services people receive

- Core variables are contained in Person files . 
NHIS: AIDS Knowledge and Attitudes

\section{SAMPLE CHARACTERISTICS:}

- Multistage probability sampling design, with black persons oversampled.

- Universe is the civilian, noninstitutionalized population of the 50 United States, plus the District of Columbia.

- In each household in the National Health Interview Survey Sample, one person 18 years or older was randomly sampled.

\section{METHOD OF DATA COLLECTION:}

- Personal interviews

- Telephone interviews in follow-up years for participants who are hard to reach in person.

\section{VARIABLES:}

- Approximately 220

- Demographics include gender, age, race, marital status, veteran status, education, income, industry and occupation codes, limits on activity

- Attitudes toward and knowledge of Acquired Immune Deficiency Syndrome (AIDS), the effects of the disease, how it is spread, where to obtain information on AIDS, blood tests, how to avoid getting the disease, and personal knowledge of anyone who had tested positively for the virus, or had the disease.

- Awareness of the drug AZT, perceptions of the effectiveness of condoms, knowledge of condom use

\section{UNIQUE CHARACTERISTICS:}

- Ability to link AIDS knowledge and awareness variables to any of the other NHIS supplements and variables.

\section{RISK-RELATED ASPECTS:}

- Sexual activity

- HIV/AIDS and other STDs

- Physical health 
National Health Interview Survey: Child Health Supplement (1988)

\section{AVAILABILITY:}

Sponsoring Agencies: National Center for Health Statistics

National Institute for Child Health and Human

Development

Health Resources and Services Administration

U. S. Department of Health and Human Services

Where to request database: Sociometrics Corporation

170 State Street, Suite 260

Los Altos, California 94022

Telephone: (415) 949-3282

Fax: (415) 949-3299

Internet: eric@socio.com

National Center for Health Statistics

Presidential Building, Room 850

6525 Belcrest Road

Hyattsville, Maryland 20782

Telephone: (301) 436-7087, ext. 151

Fax: (301) 436-3484

Contact Person: $\quad$ Eric Lang, Sociometrics

Charlotte Schoenborn, NCHS

Mary Morris, ICPSR

\section{ACCESSIBIITY:}

- ICPSR 9375, file transfer protocol (ftp), 2400 foot magnetic tape, or IBM 3480 data cartridge

- $\quad$ Cartridge tape, $\$ 200$, (NCHS)

- Sociometrics reference: AFDA Data Set Nos. 33-34

- $\quad$ Mainframe computer tape, $\$ 150.00$

- CD-ROM, $\$ 225.00$

\section{DATA FORMAT:}

- Raw data

- $\quad$ SPSS program statements

- SAS program statements

- Mainframe orders include SPSS Dictionary and Statistics files. 
YEAR(S) OF DATA COLLECTION:

- NHIS data has been collected continuously since 1957.

- The Child Health Supplement was given in 1988.

\author{
MAJOR AREAS: \\ - Child care \\ - Child's parents' marital history \\ - Geographic mobility \\ - Pregnancy and birth circumstances \\ - Injuries, impairments \\ - Acute conditions, chronic conditions \\ - Passive smoking \\ - $\quad$ Sleep habits \\ - School problems, developmental problems \\ - Use of health care services
}

\title{
SAMPLE CHARACTERISTICS:
}

- NHIS universe is the resident, civilian, noninstitutionalized population of the United States.

- NHIS-CH sample of 17,110 participants represents the national population of $0-17$ year olds.

- Age distributions were as follows: under 6 years old, $\mathrm{N}=6,193 ; 6-16, \mathrm{~N}=9,733 ; 17$ $24, \mathrm{~N}=1,184$.

- There were 13,642 white respondents, 2,929 black respondents, and 539 respondents of other races.

- $\quad$ Multistage sampling by 198 primary sampling units (PSU's), by area segments (8 households) and permit area segments (4 households living in dwellings built after the 1980 census). The current sample design was implemented in 1985 and will continue through 1995.

- All households within area and permit area segments were selected for inclusion.

- Blacks were oversampled.

\section{METHOD OF DATA COLLECTION:}

- Face-to-face interviews in the respondent's home.

- All household members age 19 and over are present during the interview.

- 17- and 18-year-olds may answer for themselves; proxy respondents are used for younger participants. 
NHIS: Child Health Supplement

\section{VARIABLES:}

- 1,347 variables

- Relationship of respondent to sample child, number of persons in child's household, marital status between child's biological parents

- Child's gender, age, reported main racial background, marital status of child, completed grade level, school enrollment status.

- Annual family income, household members' occupations, geographic region

- Height and weight of all household members

- Child's birthweight, prenatal care, mother's smoking status while pregnant

- Age and settings of childcare

- Doctor visits, hospital visits, treatments for delays in development, treatment for learning disability, repeated attendance at same place for routine health care

- $\quad$ Accident, injury, and poisoning (AIP) incidents, treatments

- Description of child's dwelling

- Child's expulsions/suspensions from school, repeated grades, parent-faculty conferences, household members' educational levels

- Amount of time child wears safety belt while in car

- Smoking status of household members

- Activity limitation of child, at all ages; health status; health conditions; days of restricted activity in past two weeks; interviewer's assessment of child's health and physical coordination

- Missing extremities, impairment of specific extremities, incidence of repeated tonsillitis, ear infections, food/digestive allergy, frequent diarrhea, other bowel trouble, sickle cell anemia, anemia, asthma, mononucleosis, hepatitis, meningitis, bladder or UT infection, rheumatic fever, pneumonia, hay fever, respiratory allergy, deafness, blindness, crossed-eyes, trouble seeing, eczema/skin allergy, epilepsy, seizures with fever, frequent/severe headaches, stammering/stuttering, other speech defect, enuresis or bedwetting, arthritis/joint disease, disease affecting bone, cerebral palsy, congenital heart disease, other heart disease

- Conditions requiring surgery in last 12 months, any conditions that lasted 3 months or more, days of school missed

- Results of each AIP condition that occurred: broken/dislocated bones, cuts/scrapes/puncture wounds, head injury/concussion, bruise/contusion/internal bleeding, burn/scald, poisoning from chemicals, sprain/strain/pulled muscles, respiratory problem, other conditions; where AIP occurred

- Child has a regular sleeping room, shares room or sleeps alone, shares with whom, relationship of each household member to child

- Number, age, and gender of siblings and other children in household

- Marital status of biological parents, date marriage ended, date of parent's death, year current marriage began, intervening time

- Child has sudden changes in mood or feeling, feels or complains that receives no love, is rather high strung/tense/nervous, cheats or tells lies, is too fearful or anxious, 


\section{NHIS: Child Health Supplement}

argues too much, has difficulty concentrating, is easily confused, bullies/is cruel or mean to others, is disobedient at home/school, does not seem to feel sorry after misbehaves, has trouble getting along with other kids/teachers, is impulsive/acts without thinking, feels worthless or inferior, is not liked by other children, has a one track mind and has obsessions, is overly active and cannot sit still, is stubborn/sullen/irritable, has very strong temper and loses it easily, is unhappy/sad/depressed, is withdrawn and does not get involved; breaks and destroys things on purpose, clings to adults, cries too much, demands a lot of attention, is too dependent on others, feels others are out to get him/her, hangs around with troublemaking kids, is secretive and keeps things to him/herself, worries too much.

- Number of above mental health problems endorsed often-true/sometimes-true/do not know, age respondent first noticed child's emotional/behavioral problem, child has ever had emotional/behavioral problems, ever received treatment, number of times saw doctor in past year, school time missed, child went to special class, taken medicine for emotional/behavioral problem, seen psychiatrist/counselor

- Times child has moved, distance traveled in last move

- How often child sees mother/father, ever lived/last lived with biological mother/father

- $\quad$ Age first noticed childhood development delays/learning disability, school missed/attended special classes as a result of developmental delays/learning disabilities.

- $\quad$ Receipt of Medicaid, AFDC assistance, Head Start enrollment

UNIQUE CHARACTERISTICS:

- $\quad 95 \%$ to $98 \%$ response rate

- Separate sections of the questionnaire refer to conditions that affect the child's health and the health of others who reside in the child's household.

\section{RISK-RELATED ASPECTS:}

- Tobacco (parents)

- Passive smoking, child

- Safety belts

- Delinquency

- Dropping out of school

- Accidents, injuries, and poisonings

- Physical health (chronic and acute illnesses)

- Mental health (behavioral and emotional maladjustment)

- Social support and protective factors

- Developmental disorders 
National Health Interview Survey: Drug and Alcohol Use Supplement (1991)

AVAILABILITY:

Sponsoring Agency:

National Center for Health Statistics

Centers for Disease Control and Prevention

U. S. Department of Health and Human Services

Where to request database:

Presidential Building, Room 850

6525 Belcrest Road

Hyattsville, Maryland 20782

Telephone: (301) 436-7087, ext. 151

Fax: (301) 436-3484

Contact Person:

Charlotte Schoenborn

\section{ACCESSIBILTTY:}

- $\quad$ Cartridge tape, $\$ 200$ (NCHS)

- ICPSR 6132 (also available through ICPSR), $\$ 250$

- File transfer protocol (ftp), 2400 foot magnetic tape, or IBM 3480 data cartridge

DATA FORMAT:

- Fixed-block format

- All files for a given year have the same record length and block size

YEAR(S) OF DATA COLLECTION:

- The NHIS has been in progress since 1957. Data is currently available through 1992.

- Ongoing, with a probability sample of households interviewed each week

- The Drug and Alcohol Use Supplement was given in 1991. Previously, alcohol supplements were given in 1988 and 1983.

\section{MAJOR AREAS:}

- Amount and distribution of illness

- Effects of illness in terms of disability and chronic impairments

- Kinds of health services people receive

- Core variables are contained in files for Household, Person, Condition, Doctor Visit, and Hospital data.

\section{SAMPLE CHARACTERISTICS:}

- Multistage probability sampling design, with black persons oversampled.

- Universe is the civilian, noninstitutionalized population of the 50 United States, plus the District of Columbia. 
- In 1991, the Drug and Alcohol Use Supplement was administered to all participants 18-44 years of age.

\section{METHOD OF DATA COLLECTION:}

- Personal interviews

- Telephone interviews for participants who are hard to reach in person.

\section{VARIABLES:}

- Demographics include age, gender, race, national origin, education level, marital status, family income, family size, occupation, region, usual activity, veteran status.

- Health utilization variables include number of restricted-activity, bed, school- or work-loss days; dental and doctor visits, hospital days, height and weight, selfassessed health status.

- Use of alcohol, sedatives, tranquilizers, painkillers, inhalants, stimulants, heroin, hallucinogens, marijuana, and cocaine

- Substance abuse: ever, how often, when last used, at what age first used

- Activities performed while under the influence of drugs and/or alcohol

- Attempts to cut down on the use of these substances

UNIQUE CHARACTERISTICS:

- All conditions are coded according to Health Interview. Survey Medical Coding Manual and Short Index, a modification of the International Classification of Diseases (ICD), using the limited diagnostic detail that respondents are able to provide.

\section{RISK-RELATED ASPECTS:}

$\begin{array}{ll}- & \text { Substance use } \\ \text { - Driving } \\ \text { - Priving under the influence } \\ \text { Physical health }\end{array}$


National Health Interview Survey: Injury Control and Child Safety and Health (1990)

AVAILABIIITY:

Sponsoring Agency:

National Center for Health Statistics

Centers for Disease Control and Prevention

U. S. Department of Health and Human Services

Where to request database:

Presidential Building, Room 850

6525 Belcrest Road

Hyattsville, Maryland 20782

Fax: (301) 436-3484

Contact Person:

Sherry L. Montag

Telephone: (301) 436-3496, ext 128

\section{ACCESSIBIITY}

- Cartridge tape

DATA FORMAT

- $\quad$ Fixed-block format

- All files for a given year have the same record length and block size

YEAR(S) OF DATA COLLECTION

- The NHIS has been in progress since 1957. Data is currently available through 1992.

- Ongoing, with a probability sample of households interviewed each week

- The Injury Control and Child Safety and Health file was included in 1990 as part of the Health Promotion and Disease Prevention (HPDP) Supplement. A previous HPDP supplement was included with the NHIS in 1985.

\section{MAJOR AREAS:}

- Prevention of common household injuries

- Parent's safety preparedness

- Poisoning, automobile crashes, smoke inhalation, and scalding

\section{MAJOR OR SAMPLE QUESTIONS:}

- Do you have the telephone number for a Poison Control Center in your area?

- When riding in a car, does [child] wear a seat belt all or most of the time, some of the time, once in a while, or never?

- How many smoke detectors are installed in this home?

- Do you know about what the hot water temperature is in this home? 


\section{NHIS: Injury Control and Child Safety and Health}

\section{SAMPLE CHARACTERISTICS}

- Multistage probability sampling design, with black persons oversampled.

- Universe is the civilian, noninstitutionalized population of the 50 United States, plus the District of Columbia.

- There is a record for every HIS sample child 0-17 years old.

- A responsible adult responded on behalf of children under the age of 17. 17-year old children had the option to respond for themselves. The responsible adult was usually the Health Promotion and Disease Prevention sample person, and was usually the child's parent or guardian.

- $\quad 82.7 \%$ response rate

\section{METHOD OF DATA COLLECTION}

- Personal interviews

\section{VARIABLES:}

- Type of living quarters, has telephone, gender, age, month and year of birth, main racial background, Hispanic origin (e.g., Multiple Hispanic, Puerto Rican, Cuban, Mexican-American, etc.), marital status, veteran status, active guard/reserve status for persons on active duty in armed forces, education of individual (completed years), highest education of responsible adult family member, family income, HIS poverty index, type of family, [respondent's] relationship to reference person, size of family, parent/other adult relative (never married)

- Health status, activity limitation status, limitation of school activities, needs help with personal care, respondent status (under 17, self-entirely, self-partly, proxy, unknown), condition list assigned and asked (skin and musculoskeletal, impairments, digestive, miscellaneous, circulatory, respiratory), total restricted activity days in past two weeks, bed days in past two weeks/ 12 months, work/school-loss days in past two weeks, other days of restricted activity in past two weeks, doctor visits in past 12 months, interval since last doctor visit, number of conditions (total acute and chronic), number of acute incidence conditions, number of two-week doctor visits, number of short-stay hospital episodes in past 12 months, number of short-stay hospital episodes in past 12 months excluding delivery, short-stay hospital days in past 12 months excluding delivery, number of short-stay hospital discharges in past 6 months, number of days in short-stay hospital in past 12 months for discharges in past 6 months, number of short-stay hospital discharges in past 6 months excluding delivery

- Type of substratum, region, geographic distribution, type of PSU, central city, not central city, nonfarm, farm, interim basic weight before age-sex-race adjustment,

- Have heard of poison control centers, know the poison control center telephone number in your area, have ipecac syrup in household, buckled in car safety seat when brought from hospital at birth, child now bas a car safety seat, amount of time child 
is buckled in child safety seat when riding in car, amount of time child wears safety belt when riding in car, sample person's use of safety belt in car

- Child ever breast-fed, age child stopped breast-feeding, when child completely stopped breast-feeding, time units child stopped breast-feeding

- Number of smoke detectors in home, number of smoke detectors that work, smoke detector works now, how you know smoke detector is working, smoke detector next to sleeping area

- Know hot water temperature in this home, hot water temperature (degrees F), hot water temperature approximate, how hot water temperature estimated, used a thermometer to test hot water in past 12 months, above what temperature will hot water cause scald injuries, respondent identity (e.g. parent, guardian)

\section{UNIQUE CHARACTERISTICS:}

- The breadth and scope of the National Health Interview Surveys allow researchers to pose questions such as, what is the association between simple parental preventive measures and adolescents' substance use behaviors? (See HIS, 1991: Drug and Alcohol Supplement; Pregnancy and Smoking Supplement).

\section{RISK-RELATED ASPECTS:}

- Safety belts

- Injuries (household and traffic)

- Physical health

- Social support and protective factors 
National Health Interview Survey: Pregnancy and Smoking Supplement (1990, 1991)

AVAILABIIITY:

Sponsoring Agency:

Where to request database:

Contact Person:
National Center for Health Statistics

Centers for Disease Control and Prevention

U. S. Department of Health and Human Services

Presidential Building, Room 850

6525 Belcrest Road

Hyattsville, Maryland 20782

Telephone: (301) 436-7087, ext. 151

Fax: (301) 436-3484

Charlotte Schoenborn

\section{ACCESSIBIITY:}

- $\quad$ NCHS, cartridge tape, $\$ 200$

- ICPSR 6132 (also available through ICPSR), $\$ 250$

- File transfer protocol (ftp), 2400 foot magnetic tape, or IBM 3480 data cartridge

\section{DATA FORMAT:}

- $\quad$ Fixed-block format

- All files for a given year have the same record length and block size

\section{YEAR(S) OF DATA COLLECTION:}

- The NHIS has been in progress since 1957. Data is currently available through 1992.

- Ongoing, with a probability sample of households interviewed each week

- The Pregnancy and Smoking Supplement was given in 1990 and 1991. 1985 data is also available under the supplement title "Smoking History During Pregnancy."

\section{MAJOR AREAS:}

- Amount and distribution of illness

- Effects of illness in terms of disability and chronic impairments

- Kinds of health services people receive

- Core variables are contained in files for Household, Person, Condition, Doctor Visit; and Hospital data.

\section{SAMPLE CHARACTERISTICS:}

- Multistage probability sampling design, with black persons oversampled.

- Universe is the civilian, noninstitutionalized population of the 50 United States, plus the District of Columbia.

- In 1991, the Pregnancy and Smoking Supplement was presented to all female participants 18-49 years of age. 


\section{NHIS: Pregnancy and Smoking Supplement}

\section{METHOD OF DATA COLLECTION:}

- Personal interviews

- Telephone interviews for participants who were hard to reach in person.

\section{VARIABLES:}

- Demographics include age, gender, race, national origin, education level, marital status, family income, family size, occupation, region, usual activity, veteran status.

- Health utilization variables include number of restricted-activity, bed, school- or work-loss days

- Dental and doctor visits

- Hospital days

- Height and weight

- $\quad$ Self-assessed health status

- Live birth status in the last five years, breast-feeding, period when breast milk was child's only food, age of child when breast-feeding stopped

- Number of cigarettes smoked during lifetime and in last year, current smoking, and whether smoking was daily

- Quitting attempts for one day or more, within last twelve months, number of times quitting, and why they had stopped smoking

\section{UNIQUE CHARACTERISTICS:}

- All conditions are coded according to Health Interview Survey Medical Coding Manual and Short Index, a modification of the International Classification of Diseases (ICD), using the limited diagnostic detail that participants are able to provide.

RISK-RELATED ASPECTS:

$\begin{array}{ll}- & \text { Tobacco } \\ - & \text { Pregnancy } \\ \text { - } & \text { Physical health } \\ \text { - } & \text { Passive smoking, fetal and newborn }\end{array}$




\section{National Household Survey on Drug Abuse}

AVAIIABIIITY:

Sponsoring Agency: Substance Abuse and Mental Health Services Administration

Office of Applied Studies

(SAMHSA/OAS)

U. S. Department of Health and Human Services

Where to request database: SAMHSA, Office of Applied Studies

5600 Fishers Lane, Room 16C-06

Rockville, MD 20857

Telephone: (301) 443-7980

Contact Person: Janet Greenblatt

\section{ACCESSIBILITY:}

- Tape

DATA FORMAT:

- Logical record length, rectangular file structure.

- $\quad$ 1990: 9,259 cases, 1,006 variables, record length: 1,953

- 1991: 32,594 cases, 1,283 variables, record length, 2,615

- SAS public use tape available for 1985, 1988, 1990, 1991, and 1992

- ASCII files available for 1990 and 1991

YEAR(S) OF DATA COLLECTION:

- Ongoing data collection. In progress since 1971. Data available through 1993.

\section{MAJOR AREAS:}

- Any illicit drug use

- Marijuana and hashish use

- Cocaine use

- Other illicit drug use

- Alcohol use

- Tobacco use

\section{MAJOR OR SAMPLE QUESTIONS:}

- How much do people risk harming themselves physically and in other ways when they... Try PCP once or twice? (No Risk/Slight Risk/Moderate Risk/Great Risk)

- In the past 12 months, did you drive unsafely?

- During the past 12 months, have you hurt someone badly enough to need bandages or a doctor? 


\section{SAMPLE CHARACTERISTICS:}

- Representative sample of civilian, noninstitutionalized population of the United States, 12 years old or older.

- In 1993, 26,489 people were contacted, with a response rate of $79.2 \%$

- Varying selection probabilities resulted in oversampling of blacks, Hispanics, young people (age 12-34), and six large metropolitan areas. Persons age 18-34 identified as current cigarette smokers were also oversampled.

\section{METHOD OF DATA COLLECTION:}

- In-home interviews with option to have interviewer read questions aloud or to use paper and pencil method

- Self-administered tests and answer sheets mailed to participants' homes

\section{VARIABLES:}

- Age, gender, race/ethnicity, population density, region, metropolitan area, education, employment.

- Recency of use, frequency of use, opinions about drugs, demographic characteristics, problems associated with drug use, drug abuse treatment experience

\section{UNIQUE CHARACTERISTICS:}

- Large sample size; continuous data collection effort for more than 20 years

- Estimates of number of users are analyzed to describe changes in prevalence over time and rates to describe differences in use between population subgroups.

- Analysis focuses primarily on past month use.

\section{RISK-REIATED ASPECTS:}

\section{- Substance use \\ - Driving \\ - Aggression/violence}

- Risk perception. (See Advance Report Number 5 (SAMHSA 1994) for percentages of respondents who report that participants perceive "great risk of harm" in using each drug at specified levels of frequency). 
National Longitudinal Study of Adolescent Health (Add HEALTH)

\section{AVAILABIITY:}

Sponsoring Agencies:

U. S. Department of Health and Human Services

National Institute of Child Health and Human Development (NICHD)

The National Cancer Institute

The National Institute of Alcohol Abuse and Alcoholism

The National Institute on Deafness and Other Communication Disorders

The National Institute on Drug Abuse

The National Institute of General Medical Sciences

The National Institute of Mental Health

The National Institute of Nursing Research

The Office of AIDS Research, NIH

The Office of the Director, NIH

The Office of Research on Women's Health, NIH

The Office of Population Affairs, HHS

The National Center for Health Statistics, CDC, HHS

Office of Minority Health, CDC, HHS

Office of Minority Health, Office of the Assistant Secretary for Health, HHS

Office of the Assistant Secretary for Planning and Evaluation, HHS

The National Science Foundation

36 additional professional and scientific organizations

Where to request further information:

Address:

Contact Person(s):

Christine Bachrach, Ph.D., Chief

Demographic and Behavioral Sciences Branch

NICHD

Telephone: (301) 496-1174

Fax: (301) 496-0962

Richard Udry

Principal Investigator

University of North Carolina at Chapel Hill

Telephone: (919) 966-2829

\section{ACCESSIBILITY}

Data will be available in late 1996 from the Carolina Population Center, University of North Carolina at Chapel Hill 


\section{DATA FORMAT}

- To be announced

\section{YEAR(S) OF DATA COLLECTION}

- Prospective longitudinal study

- School interviews (1995) have been collected and will be available for public use in the summer of 1996

- Neighborhood and community data is currently being collected

- At-home interviews with a subsample of 20,000 adolescents who participated in the school interviews will be conducted in the summer of 1996

\section{MAJOR AREAS:}

- Family relationships

- Family income

- Health insurance

- Parents' health behavior

- Peer group

- School

- Neighborhood and community

- $\quad$ Adolescent health status and health behaviors.

- Positive influences and behaviors that promote good health

- Religious involvement

- Work and community activity

- Educational goals

- Parenting

- Risk-taking behaviors

- Poverty

- Housing quality

- Religious attendance

- Unemployment rates

- Access to health services

- Public policies and expenditures

\section{SAMPLE CHARACTERISTICS}

- $\quad$ Students in grades 7-12

- Oversamples of high status black youth

- Oversamples of Cuban, Puerto Rican, and Chinese youth

- Oversamples of physically disabled youth

- Over 90,000 students participated in the school phase of data collection

- School administrators

- Parents 


\section{METHOD OF DATA COLLECTION}

- In-school computer-based questionnaires

- Personal in-home interviews with adolescents and their families

- Independent measures of local and neighborhood characteristics

\section{UNIQUE CHARACTERISTICS:}

- Contains and surpasses the descriptive and risk-taking information of the YRBSS.

- Environmental influences on adolescent health are measured through both the research participants' reports and independent community data sources.

\section{RISK-RELATED ASPECTS:}

- Substance use

- Tobacco

- Driving

- Driving under the influence

- Safety belts

- Sexual activity

- HIV/AIDS/STDs

- Pregnancy

- Aggression/violence

- Delinquency

- Dropping out of school

- Injuries

- Physical health

- Divorce

- Mental health

- Social support and protective factors

- Exercise and diet 


\section{National Longitudinal Survey of Youth}

\section{AVAILABILITY:}

Sponsoring Agency:

Where to request database:

Contact Person:
U.S. Department of Labor, Bureau of Labor Statistics

NLS Public User's Office, Center for Human Resource Research

The Ohio State University

921 Chatham Lane

Suite 200

Columbus, Ohio 43221-2418

Telephone: (614) 442-7300

Rita Jain

U.S. Department of Labor

Bureau of Labor Statistics

Telephone: (202) 606-7405

Email: JainRita@PSB.BLS.GOV

\section{ACCESSIBIITY:}

- CD-ROM and magnetic tape

- $\$ 20$ for CD-ROM

DATA FORMAT:

- DOS, with its own software, in $1 / 2$ byte integers

- Produces an ASCII dataset.

- SAS or SPSS cards are available to read ASCII dataset.

YEAR(S) OF DATA COLLECTION:

- Each interview for a given cohort was administered within a specific three month span.

- Ongoing data collection except for Older Men and Young Men groups:

- Older Men: 13 interviews between 1966 and 1990

- $\quad$ Mature Women: 17 interviews between 1967 and 1995

- $\quad$ Young Men: 12 interviews between 1966 and 1981

- Young Women: 18 interviews between 1968 and 1991

- Youth: annually, 1979 through 1994

MAJOR AREAS:

- The Youth survey instruments contain core sets of questions on the following topics:

- Marital history

- Schooling 


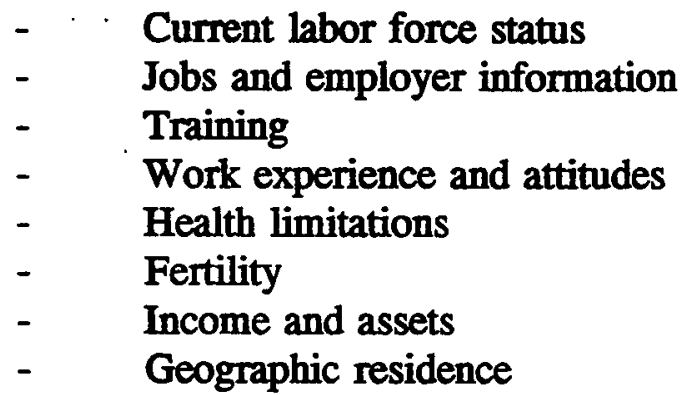

\section{SAMPLE CHARACTERISTICS:}

- Representative sample of civilian noninstitutionalized population of the United States at time of the initial survey.

- Five groups: older men (ages 45-59 in 1966), mature women (ages 30-44 in 1967), young men (ages 14-24 in 1966) and young women (ages 14-24 in 1968), and youth (ages 14-21 as of January 1, 1979).

- The "Young Men" group was discontinued after the 1981 survey.

- The "Older Men" group was not surveyed between 1984 and 1989. It was surveyed for the last time in 1990, and then discontinued.

- Blacks were oversampled.

- Oversamples of blacks, Hispanics, economically disadvantaged nonblacks/nonHispanics, and youth in the military were included in the new, 1979 cohort. The military oversample and the economically disadvantaged nonblack/non-Hispanic oversample were discontinued in 1984 and 1990, respectively.

\section{METHOD OF DATA COLLECTION:}

- Interviews in person, by mail, or over the telephone

- Both paper/pencil and computer-assisted interviewing techniques were employed.

\section{VARIABLES:}

- More than 2,000 variables each year.

- Cohort, age, gender, race/ethnicity, civilian/military, state or country of birth, number of siblings, religious affiliation, childhood residences

- Household composition

- Educational status and attainment, high school courses, final grades, respondent- and school-specific information

- Aptitude and intelligence scores

- Occupation, types of training certificates received, government training and jobs, military experience, labor market activity and transitions, detailed work histories, income and assets

- Marital history, fertility, child care

- Health variables, e.g., weight, height, ICD-9 codes for conditions limiting labor market activity, AIDS knowledge, occupational injuries/illnesses

- Alcohol and substance use 
- Ilegal activities (1980 survey), e.g., self-reported participation in activities such as skipping school, alcohol/marijuana use, vandalism, shoplifting, drug dealing, robbery, reported arrest records, contacts with criminal justice system

- $\quad$ Attitudes and aspirations

- Geographic information

UNIQUE CHARACTERISTICS:

- Extensive research applications--more than 1,500 studies have been performed using NLS data

- The NLS of Youth uses an event history format, i.e., notation of the dates of events in worklife

- The NLS of Youth has a retention rate of over $91 \%$ after 11 years.

- Special sections of the youth survey have included questions on job search methods, migration, attitudes towards work, educational and occupational aspirations and expectations, school discipline, self-esteem, time use, and childhood residences.

\section{RISK-REILATED ASPECTS:}

- Substance use

- HIV/AIDS and other STDs (including respondent's AIDS knowledge)

- Pregnancy

- Aggression/violence

- Delinquency/crime

- Social support and protective factors 


\author{
AVAILABILITY: \\ Sponsoring Agency: Urban Institute \\ 2100 M Street, NW \\ Washington, D.C. 20037 \\ (202) 833-7200 \\ (Investigators: Freya Sonenstein, Joseph Pleck, \\ Leighton $\mathrm{Ku}$, and Charles Calhoun) \\ Where to request database: Sociometrics Corporation \\ 170 State Street, Suite 260 \\ Los Altos, California 94022 \\ Telephone: (415) 949-3282 \\ Email: eric@socio.com \\ Contact Person: \\ Eric Lang, Sociometrics Corp. \\ Jeannette Burrell, Urban Institute Press
}

ACCESSIBILITY:

- Sociometrics reference: DAAPPP Data Set No. G6

- Mainframe computer tape, $\$ 100$

- 3 IBM hi-density disks (5.25" or $\left.3.5^{\prime \prime}\right), \$ 100.00$

- CD-ROM, $\$ 225.00$

DATA FORMAT:

- Raw data

- $\quad$ SPSS program statements

- SAS program statements

YEAR(S) OF DATA COLLECTION:

- 1988 (Wave 1)

- $1990-91$ (Wave 2)

MAJOR AREAS:

- Adolescent males' behaviors, education and knowledge concerning:

- human sexuality

- contraception

- $\quad$ sexually transmitted diseases

- Participants' history of sexual activity and contraception use 
MAJOR OR SAMPLE QUESTIONS:

- Now think about what might happen when you meet a new person with whom you have intercourse for the first time. What are the chances that if the girl knew you had a condom ready the first time you had sex with her, she would be upset?

- The last time you had intercourse, did you and (INITIALS) discuss using contraception, that is, something to prevent pregnancy or sexually transmitted disease?

- Which method did you use most often? Condom, rubber/ Diaphragm/ Douching (washing out) after intercourse/ Foam, jelly, cream, or a suppository/ IUD, coil, loop/ Pill/ Rhythm, or safe period (by calendar or by temperature/cervical mucus)/ Today sponge/ Withdrawal, pulling out/ Combination of methods (SPECIFY)/ Other (SPECIFY)

- If a young man makes a woman pregnant, a judge can make him pay for raising the child (True/False)

- To avoid catching AIDS, doctors have suggested several changes people can make in their sexual behavior. In which of the ways shown on this card, if any, have you changed your sexual behavior since you first heard about AIDS? Just tell me the numbers for any changes you have made. 01. Decided to wait to have sexual intercourse/ 02. Stopped having sexual intercourse/ 03. Stopped having other types of sexual relations/ 04. Don't have sex as often/05. Stopped having sex with more than one woman/ 06. Stopped having sex with women I don't know well/ 07. Stopped having sex with women who used needles to take drugs/ 08. Started using condoms/ 09. No changes/10. Other changes (SPECIFY)

\section{SAMPLE CHARACTERISTICS:}

- Nationally representative sample of never-married, non-institutionalized males ages 15 to 19 living in the contiguous United States. The sample size was 1,880 in 1988. In $1990,1,676$ of the original sample participated in the second wave.

- Hispanics and blacks were oversampled

- $\quad 74 \%$ response rate for original sample. $89 \%$ response rate for the second wave.

\section{METHOD OF DATA COLLECTION:}

- In-home face-to-face interviews

- Self-administered questionnaires for sensitive questions

\section{VARIABLES:}

- 1,816 variables across Waves 1 and 2

- Age, place of birth, number of siblings, birth order position, education level, highest grade/year respondent thinks he/she will ever complete, school's religious affiliation, employment, residence type

- Ethnicity, language, religion

- Personal disposition, e.g., self-satisfaction, peer pressure, parent's influence

- Sexuality communication with parents, from schools 
- Contraceptive knowledge

- Expected utility of condoms

- Attitudes towards fathering children

- Sexual experience, e.g., age of first intercourse, number of partners, number of partners in last 12 months/in last 4 weeks, likelihood of contraception use in future

- One-time sexual experiences, reason for not having sexual intercourse again, contraceptive use

- Satisfaction with condom use

- Contraceptive experience, e.g., breakage instances, partner approval

- Last partner/next to last partner, e.g., age at time, partner's age, length of relationship, discussion of contraception, type of contraception, reasons for not using contraception, consistency of contraception use.

- Partners in past 12 months

- First intercourse, e.g., age, partner's age, contraception use, reasons for not using contraception

- Knowledge, e.g., pregnancy, contraception, HIV transmission

- AIDS worry, personally know someone with AIDS

- Premarital intercourse and pregnancy attitudes

- Instances of impregnating partner, outcome

- Relationship attitudes

- Interviewer's evaluation

UNIQUE CHARACTERISTICS:

- Extensive personal histories of sexual activity and contraception use were gathered, as well as respondents' perceptions of the various costs and benefits of contraceptive use and fathering children

RISK-RELATED ASPECTS:

$\begin{array}{ll}- & \text { Substance use } \\ \text { - } & \text { Sexual activity } \\ \text { - } & \text { PrVIAIDS and other STDS } \\ \text { Pregnancy }\end{array}$


National Survey of Children: Waves 1 (1976), 2 (1981), and 3 (1987)

AVAILABIITT:

Sponsoring Agency:

Where to request database:

Contact Person:
Child Trends, Inc.

Sociometrics Corporation

170 State Street, Suite 260

Los Altos, California 94022

Telephone: (415) 949-3282

Fax: (415) 949-3299

Eric Lang

Sociometrics Corporation

\section{ACCESSIBILITY:}

- Sociometrics reference: DAAPPP Data Set F5-G2

- Mainframe computer tape, $\$ 150,11 \mathrm{IBM}$ hi-density disks $\left(5.25^{\prime \prime}\right.$ or $\left.3.5^{\prime \prime}\right)$, $\$ 150$, or CD-ROM, $\$ 225.00$

- $\quad$ Also available through ICPSR (ICPSR 8670)

- $\quad$ File transfer protocol (ftp), 2400 foot magnetic tape, or IBM 3480 data cartridge

DATA FORMAT:

- Raw data

- SPSS program statements (used to create SPSS files with the raw data)

YEAR(S) OF DATA COLLECTION:

- 1976 (Wave 1), 1981 (Wave 2), and 1987 (Wave 3)

\section{MAJOR AREAS:}

Wave 1: children's home care and relationships

- $\quad$ Measures of child development and well-being

- Replication of items from previous national studies of children and parents

- Wave 2: effect of marital conflict and disruption on children

- Behavioral and mental health measures were taken of children who were experiencing various stages of the marital disnuption process at the time of the survey.

- Influence of child, parent, and family factors that were thought to influence the risk of childhood problems associated with marital disruption were also examined.

Wave 3: social, psychological, and economic well-being of sample members as they became young adults.

- Sexual and fertility behavior was a particular emphasis 


\title{
SAMPLE CHARACTERISTICS:
}

- Universe: children between the ages of seven and eleven, or born between September 1,1964 and December 31, 1969, living in households in the 48 contiguous states.

- Multi-stage stratified probability sample by household and child. In families with two eligible children, both were interviewed; if there were three or more, two were selected at random.

- Black households were over-sampled to produce interviews with approximately 500 black children.

- Only a randomly selected sub-sample of those children living in low-conflict families at Wave 1 was followed up. Therefore, Waves 2 and 3 consisted predominantly of children in high-conflict, high-disruption families.

\section{METHOD OF DATA COLLECTION:}

- Personal interviews in children's homes.

- In Wave 1, information was gathered through interviews with the child's parent prior to interviewing the child, and a year later, information about the interviewed child's school was collected.

\section{VARIABLES:}

- Relationship between child and the parent living outside home.

- Drinking, smoking, drug use, delinquency

- Dating, sexual activity, contraception, pregnancy, childrearing, receipt of child

- Physical, social, and psychological well-being

- Education, work, marital, and child-bearing patterns

\section{UNIQUE CHARACTERISTICS:}

- Additional responses from teachers and parents

\author{
RISK-RELATED ASPECTS: \\ - Substance use \\ - Tobacco \\ - Sexual activity \\ - Pregnancy \\ - Delinquency/crime \\ - Divorce \\ - Mental health
}


National Survey of Families and Households, 1988

\section{AVAILABIITY:}

Sponsoring Agency: Center for Population Research

National Institute of Child Health and Human

Development

U. S. Department of Health and Human Services

(Investigators: James Sweet, Larry Bumpass, Vaughn

Call)

Where to request database: Sociometrics Corporation

170 State Street, Suite 260

Los Altos, California 94022

Telephone: (415) 949-3282

Fax: (415) 949-3299

Email: eric@socio.com

Contact Person:

Eric Lang

\section{ACCESSIBIITTY:}

- Sociometrics reference: AFDA Data Set Nos. 01-05

- Mainframe computer tape, $\$ 150.00$

- CD-ROM, $\$ 225.00$

DATA FORMAT:

- Raw data

- $\quad$ SPSS program statements

- SAS program statements

YEAR(S) OF DATA COLLECTION:

- 1988 data collection was the first wave of a prospective study. Data was collected again in 1992, but is not yet publicly available.

\section{MAJOR AREAS:}

- Life history

- Family process

- $\quad$ Stepparenting

- Attitudes towards cohabitation without marriage

- $\quad$ Sibling relationships

- Effects of divorce

- Child custody and child support arrangements following divorce 


\section{National Survey of Families and Households}

\section{MAJOR OR SAMPLE QUESTIONS:}

- How [do you] discipline [your] children?

- [Have any of your children] ever run away? [Did it happen] more than once? How long [was he/she] gone?

- Does [your] child have [his/her] own car, motorcycle, or moped? How much of total cost did child pay/ How much of maintenance and insurance does child pay?

- How much conflict do you have with child's father/mother over issues? Is there a legal agreement regarding child support?

\section{SAMPLE CHARACTERISTICS:}

- National probability sample of 9,643 U.S. households that included oversampling of the following groups:

- African-Americans

- Hispanics

- Households with children where one parent was absent

- Households with children who have a step parent

- $\quad$ Households with children where both parents were absent

- Households with couples who had been married since January 1, 1982

- One adult household member was randomly selected to be targeted as the respondent.

\section{METHOD OF DATA COLLECTION:}

- In-home interviews.

- A random sample of the remaining adults in the household completed selfadministered questionnaires.

- Spouse or cohabitating partner of the respondent completed self-administered questionnaires.

- A tertiary respondent questionnaire was administered to the head of the household when neither the selected primary respondent nor the primary respondent's spouse/cohabitating partner was related to the head of the household.

\section{VARIABLES:}

- Race, ethnicity, religion, region/state, income, satisfaction with income, child support payments, changes in standard of living with divorce, specific items and amounts that child support covers

- Adoptions dates, relationships with adopted children, number of adopted children.

- Birthrates of each child, birthrates of each member of the household

- Childcare arrangements, where, with whom, hours last week

- Child suspended/expelled more than once, age of child last time suspended/expelled

- Any of children run away from home, age child ran away last time, length of time child gone last time

- Any children been in trouble with police, child in trouble with police more than once, age child in trouble with police last time 
National Survey of Families and Households

- Respondent's contraception practices, cohabitation reasons, anticipation of marriage, dates began living together, dates ended living with last partner, will respondent and current boy/girlfriend cohabit, chances that respondent and partner will eventually separate

- How often respondent participates in service clubs, veterans groups, political groups, labor unions, youth groups, school groups, nationality groups, farm organizations, professional groups, church groups

- Respondent's number of dates with opposite sex last month, number of persons dated last year, number days together past week, how soon respondent dated after separation, does respondent have steady boy/girlfriend

- Number of times (12-18 year old) child dated last month, does child have steady boy/girlfriend

- Housing now compared to when married, describe mother's/father's living accommodations, stepparent's living accommodations, structure type, number of stories

- Respondent's education, child's education, dates of enrollment, dates stopped attending, enrollment status (full/part time), school type, whether enrolled in particular years, year degrees conferred, amount of education child will get, whether (12-18 year old) child had regular homework last year/must child do homework before pleasure, why child is not attending school

- Respondent's social life, comparison between now and when married

- Gender of respondent and each child

- Each household member's time spent performing each household chore (e.g., shopping, cleaning, car maintenance, driving other household members)

- Hours/week each child under/over 19 years old drives

- Date of death of each person's death, disability/functional impairment of each household member, kind of illness/disability of each household member, average hours per week respondent helped person with disability

- Household structure and composition, relationships with other kin, respondent's satisfaction with marriage/relationship, chances respondent and current partner will separate

- Respondent's overall happiness/emotional security compared to when married, whether/age each child saw doctor for emotional problems, number of days last week respondent felt bothered/had poor appetite/felt blue/trouble concentrating/felt depressed/everything was an effort/felt fearful/slept restlessly/talk less than usual/felt lonely/felt sad/couldn't get along

- Community rural/urban, percent individuals below poverty line/percent change county population

- Important for child to get along w/other kids less than 5 years old/5 -18 years old/318 years old/relied on clergyman/rabbi for support during separation

- Respondent's occupation, start and stop dates for each job

- Out of wedlock pregnancies and parenthood 
- How would separation change being parent, difficulty raising each child, importance of child to follow family rules, be kind and considerate, always do what respondent asks, carry out own responsibilities, keep busy by him/herself, try new things

- Harder to love step-children than own children, stepparent more friend than parent to stepkids, as easy to discipline step-kids as own kids, having stepkids as satisfying as own kids, hard raising stepkids because used to different rules, parents should help kids with college expenses/financially if needed/encourage independence for daughters/sons, kids should help aging parents financially if needed

- Respondent wishes could be free of responsibility of being parent, last 30 days any good time with child, argue or difficulty with child last month, spouse had good time with child last month, has respondent spanked child in past week, how often child up later than bedtime, how often respondent read to child/reminds child of chores/disagrees about dress/boy/girlfriend, disagrees about child's sexual behavior/friends/drinking/smoking/drugs/money/school/getting along with family

- Respondent helps child with transportation/car repairs/housework/advice or moral support

- How often does respondent spank or slap child, hug child, yell at child

- Frequency of child's contact with parent outside household, type of contact, date allocation

- Parent spends time with child in outings away from home/reading to child/work on .project or play at home/have private talks/helping with reading or homework/PTA or other social activities/religious youth group/community youth group/sports group

- Child fussy or irritable, keeps self busy, loses temper easily, cheerful and happy, fearful and anxious, bullies/cruel/mean to others, does what respondent asks, gets along with other kids, can be left alone for short time, unhappy/sad/depressed

- How is life for this child, paid job interesting/boring, respondent's parenting interesting/boring, things to do as husband/wife interesting/boring, housework/paid job overwhelming/manageable

- Respondent/spouse/partner/child drinks too much alcohol/has problem with drug use

- Get along with siblings, child receives/gives help to siblings

- Age of respondent's first sexual intercourse, ok for unwed 18 year olds to have sex if love each other, sex life if married, how would separation change sex life, sex life now compared to when married, frequency of sex with someone of opposite sex last month

\section{UNIQUE CHARACTERISTICS:}

- Convergent validity of multiple respondents in the same household describing child's behavior, their relationship with the child, and their relationship with other respondents

- Possibility of child modeling adult's risk-taking behaviors 
RISK-RELATED ASPECTS:

- Substance use

- Sexual activity

- Aggression/Violence

- Delinquency/crime

- Physical health

- Mental health

- Divorce

- Social support and protective factors

- Physical discipline

- Truancy 
National Survey of Family Growth, Cycle IV, 1988; and Telephone Reinterview, 1990 AVAILABIIITY:

Sponsoring Agency:

Where to request database:

Contact Person:
National Center for Health Statistics Centers for Disease Control and Prevention U. S. Department of Health and Human Services

National Technical Information Service 5285 Port Royal Road Springfield, Virginia 22161

(703) $487-4650$

Joyce Abma

Family Growth Survey Branch

Division of Vital Statistics

National Center for Health Statistics

6525 Belcrest Road, Room 840

Hyattsville, Maryland 20782

(301) 436-8731

\section{ACCESSIBIIITY:}

- $\quad$ NCHS Accession no. PB90-501248, $\$ 240$

- GPO order number 017-022-01306-1 for 1990 Telephone Reinterview CD-ROM , $\$ 16.00$

- ICPSR (ICPSR 9473), $\$ 250$, file transfer protocol (ftp), 2400 foot magnetic tape, or IBM 3480 data cartridge

DATA FORMAT:

- 9-track code, either extended binary coded decimal interchange code (EBCDIC) alone or in combination with binary code.

YEAR(S) OF DATA COLLECTION:

- $\quad$ Cycles I-IV are multiple random samples: 1973, 1976, 1982, 1988

- In addition, a telephone follow-up was administered in 1990 to earlier cohorts.

- The latest random sample, Cycle V, is currently being administered, and should be completed in September, 1995. Data tapes for cycle V should be available in early 1996.

MAJOR AREAS:

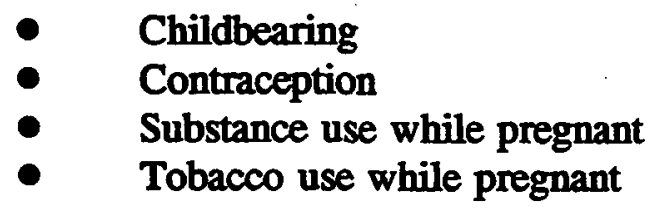




\section{National Survey of Family Growth}

- Knowledge, attitudes, and behavior related to Human Immunodeficiency Virus (HIV)

- Related aspects of maternal and child health

\section{MAJOR OR SAMPLE QUESTIONS:}

- Are you pregnant now? How many pregnancies have you had that ended in ...miscarriage? ...stillbirth? ...abortion? ...live birth?

- Thinking back, after your first menstrual period, when did you have sexual intercourse for the first time--what month and year was that?

- The last time you had intercourse, did you or your partner use any method of birth control or family planning? What method [from the following list] was that?

- Looking to the future, do you (and your husband/partner) intend to have a(nother) baby at some time?

\section{SAMPLE CHARACTERISTICS:}

- Women 15-44 years of age. In Cycles I and II (1973 and 1976), the survey was limited to women who had ever been married or had their own children living with them. In Cycles III and IV (1982 and 1988), all women 15-44 years of age were included.

- The 8,450 women interviewed for Cycle IV were drawn from households in which someone had been interviewed for the National Health Interview Survey (NHIS), between October 1985 and March 1987. Black women were oversampled.

\section{METHOD OF DATA COLLECTION:}

- Questionnaire mailed to married or unmarried women

- Telephone interviews

- Personal interviews

\section{VARIABLES:}

- Ethnic and racial background, education, religious service attendance, income

- Social and economic characteristics

- Month and year of first intercourse (1982 and 1988 only)

- Pregnancy, contraception, cohabitation, marriage, and divorce

- Employment, occupation, child care

- Fecundity, infertility, and sterility

- Prenatal medical care, use of family planning services

- Birth expectations

- Contraception use for each pregnancy interval

- Whether each pregnancy was planned by the woman and her partner

- Occurrence of sexually transmitted diseases, including AIDS

- Adoption 
UNIQUE CHARACTERISTICS:

- National Survey of Family Growth project seeks to understand the relationships between family planning and pregnancy practices and population growth.

- Interval data allows for analysis of differences in behavior during and between each pregnancy. For example, time without intercourse may be examined. This variable is expressed as the dates at the beginning and end of this period. Other examples of interval data include the date that the respondent began using contraception and the date she stopped using contraception or the date she became pregnant.

RISK-RELATED ASPECTS:

- Tobacco

- Substance use

- Sexual activity

- HIV/AIDS and other STDs

- Pregnancy

- Physical health (under-utilization of prenatal medical care) 


\section{AVAILABIITTY:}

Sponsoring Agencies:

Center for Studies of Crime and Delinquency

National Institute for Mental Health

U. S. Department of Health and Human Services

National Institute for Juvenile Justice and Delinquency Prevention

U. S. Department of Justice

Where to request database: ICPSR 426 Thompson St.

Ann Arbor, MI 48109-1248

Telephone: (313) 764-2570

Contact Person: Piper Simmons

Telephone: (313) 763-5010

\section{ACCESSIBILITY:}

- ICPSR 9948, $\$ 350$

- File transfer protocol (ftp), 2400 foot magnetic tape, or IBM 3480 data cartridge

DATA FORMAT:

- Card Image, rectangular file structure

YEAR(S) OF DATA COLLECTION:

- $1976,1977,1978,1979,1980,1983$.

- Multiple random samples.

- 1987 data is currently being processed. The dataset should be available through ICPSR around November, 1995.

\section{MAJOR AREAS:}

- Emphasis on adolescent lifestyles, conceptualized as groups of both healthcompromising and health-enhancing behaviors

- Environmental mediators of adolescent lifestyles, with emphasis on neighborhood problems, community involvement, and home life

\section{SAMPLE CHARACTERISTICS:}

- Representative sample by area probability sampling of young people and their parents in the United States

- $\quad$ Adolescents aged 11-17 in 1976 


\section{METHOD OF DATA COLLECTION:}

- Telephone interviews

\section{VARIABLES:}

- Gender, ethnicity, birth date, age, marital status, employment, information on the marital status and employment of the parents

- Causal attributions and consequences of various types of behavior

- Presence of neighborhood problems such as unemployment, racial conflict, traffic, prostitution, and various crimes

- Disruptive events in the home, parental aspirations for youth, labeling, integration of family and peer contexts, attitudes towards deviance in adults and juveniles, parental discipline, community involvement

- Status offenses (runaway, truancy), public disorder, property damage, minor theft, minor violence

- Drug sales, serious theft, serious violence

- Tobacco, alcohol, marijuana, hard drugs, problem use of alcohol, problem use of drugs, drunkenness, DUI, sexual intercourse, sexual deviance (defined in the survey as any of the following: voyeurism, pedophilia, exhibitionism, use of pornographic materials, sadism, masochism), STDs

\section{UNIQUE CHARACTERISTICS:}

- Data may be analyzed to examine developmental progressions of risk-taking behavior and clusters of behavior.

- Consideration given to both health-promoting and health-compromising behavior and community influences

\section{RISK-RELATED ASPECTS:}

$\begin{array}{ll}\text { - } & \text { Substance abuse } \\ \text { - } & \text { Dobacco } \\ \text { - } & \text { Driving } \\ \text { - } & \text { Sexual activity } \\ \text { - HIV/AIDS and other STDs } \\ \text { - } \\ \text { - Delinquency } \\ \text { Social support and protective factors }\end{array}$




\section{AVAILABILITY:}

Sponsoring Agency:

Where to request database:

Centers for Disease Control and Prevention

U. S. Department of Health and Human Services

Presidential Building, Room 850

6525 Belcrest Road

Hyattsville, Maryland 20782

Telephone: (301) 436-7087

Fax: (301) 436-3484

Contact Person:
Robert K. Merritt, M.A.

Behavioral Scientist

Office on Smoking and Health

National Center for Chronic Disease Prevention and Health Promotion

Telephone: (404) 499-5703

\section{ACCESSIBILITY:}

- $\quad$ NCHS cartridge tape, $\$ 200$

- Also available through ICPSR (ICPSR 6375)

- File transfer protocol (ftp), 2400 foot magnetic tape, or IBM 3480 data cartridge

DATA FORMAT:

- Logical record length with SAS and SPSS program statements

\section{YEAR(S) OF DATA COLLECTION:}

- Initial cohort in 1989 and 1992; new 1992 cohort

\section{MAJOR AREAS:}

- Cigarette use

- Chewing tobacco, snuff, or smokeless tobacco use

- Influence of psychopharmacologic properties of nicotine 
- Other risk-taking behaviors and family patterns

\section{SAMPLE QUESTIONS:}

- How old were you when you smoked your first WHOLE cigarette?

- Think about the last 30 days. On how many of these days did you use chewing tobacco or snuff?

- During the LAST FOUR WEEKS, have you ridden in a vehicle driven by someone who had been drinking or using drugs?

- Participants who had used tobacco were asked if they used tobacco because "it relaxes or calms me" and if they used it because "it's really hard to quit."

\section{SAMPLE CHARACTERISTICS:}

- For TAPS (1989), 12,097 teenagers were sampled from the last two quarters of the 1988 NHIS and the first two quarters of the 1989 NHIS. 9,135 of these respondents were interviewed using computer-assisted telephone interviewing. The remainder responded to questionnaires through the mail. National representation was achieved through adjustments to the data.

- Of the 9,135 respondents (aged 12-18 years) to the 1989 TAPS telephone interview, 7,960 participated in TAPS-II (these respondents were aged 15-22 years).

- An additional 4,992 persons from a new probability sample of 5,590 persons aged 1015 years participated in TAPS-II.

- In each TAPS II sample component, all persons eligible in a household were selected.

- Black persons were oversampled.

\section{METHOD OF DATA COLLECTION:}

- Telephone interviews.

- Self-administered tests and answer sheets mailed to participants' homes

\section{VARIABLES:}

- Respondents' race, education, geographic region; reference persons' race, education, occupation, and marital status; presence of parent(s) or other adult relative in household, family income, education of the adult.

- Approximately 230 variables, relating mostly to tobacco use and attitudes about tobacco, but also including safety belts, fitness, alcohol, marijuana, drugs in general, school, diet, accidents, physical fights, riding with a drunk driver, riding a motorcycle, sleep disturbances, anxiety and depression

- Lifetime use (number of cigarettes), frequency of use (days), intensity of use (number of cigarettes)

\section{UNIQUE CHARACTERISTICS:}

- Level of detail in capturing respondents' thoughts about tobacco use.

- Items capture relation between use of tobacco and reasons for using tobacco. 


\title{
RISK-RELATED ASPECTS:
}

\author{
- Tobacco \\ - Driving \\ - Driving under the influence \\ - Safety belts \\ - Aggression/violence \\ - Mental health (depression, anxiety, body image) \\ - Social support and protective factors
}




\section{Uniform Crime Reporting (UCR) Program}

AVAILABILTY:

Sponsoring Agency:

Federal Bureau of Investigation

Where to request database:

Uniform Crime Reports

Federal Bureau of Investigation

Washington, D.C. 20535

Telephone: (202) 324-5015

\section{ACCESSIBILITY:}

- Magnetic tape and cartridge, $\$ 140$ per tape

- Availability depends on specific combinations of data requested

\section{DATA FORMAT:}

- Variable-length, packed-decimal formatted records

- Conversion is necessary for SAS and SPSS processing

- The following combinations of data may be requested from the FBI:

- $\quad$ All states or up to 10 states

- All population groups or up to 10 groups within the states selected

- One to ten years

YEAR(S) OF DATA COLLECTION:

- Ongoing, 1930 to present

\section{MAJOR AREAS:}

\section{- Arrests \\ - Crimes \\ - Crime trends}

\section{SAMPLE CHARACTERISTICS:}

- Persons arrested in the United States.

\section{METHOD OF DATA COLLECTION:}

- Local agencies complete FBI-provided forms, tally sheets, and self-addressed envelopes.

- Some states collect local crime data and compile it on a state-wide level before submitting it to the FBI. These state programs must conform to FBI standards for data collection, recording, processing, and timeliness.

\section{VARIABLES:}

- Case number, date, name and alias, address, gender, race, age, date and place of birth, occupation, number of previous arrests, identifying features (marks, scars, 


\section{Uniform Crime Reporting Program}

etc.), arrest/summons or notice, offense charged, facts of arrest (time, place, and other details), drinking/drunk/or narcotic, final disposition and date (if found guilty, for what offense).

- State, originating agency, group (distributed by population size of city or county), division (U.S. possessions, e.g., Puerto Rico, Canal Zone), region within U.S., year, Metropolitan Statistical Area (MSA) number in which city is located, suburban agency

- Report indication (juvenile and adult, juvenile only, adult only, not reported), reported age, reported race, reported ethnic origin

- Offense: murder and non-negligent manslaughter, manslaughter by negligence, forcible rape, robbery, aggravated assault, burglary-breaking or entering, larceny-theft (except motor vehicle), other assaults, arson, forgery and counterfeiting, fraud, embezzlement, stolen property-buying/receiving/possessing, vandalism, weaponscarrying/possessing/etc., prostitution and commercialized vice, sex offenses (except forcible rape and prostitution), drug abuse violations, sale/manufacturing, opium and cocaine and their derivatives (morphine, heroin), marijuana, synthetic narcoticsmanufactured narcotics which can cause true drug addiction (demerol, methadone), other dangerous non-narcotic drugs (barbiturates, benzedrine), possession (subtotal), gambling, bookmaking (horse and sport book), number and lottery, all other gambling, offenses against family and children, driving under the influence, liquor laws, drunkenness, disorderly conduct, vagrancy, all other offenses (except traffic), suspicion, curfew and loitering law violations, runaways

- Male totals by age, female totals by age, juvenile totals by race and ethnic origin, adult totals by race and ethnic origin

UNIQUE CHARACTERISTICS:

- Continuous data collection for sixty-five years

- Establishes nationwide prototypical classification system for all types of criminal offenses

- Ability to analyze incidence and prevalence of each type of offense by age, region, and race/ethnicity.

RISK-REILATED ASPECTS:

- Substance use

- Driving under the influence

- Driving

- Aggression/violence

- Delinquency/crime

- Curfew offenses

- Runaways 
The Woodlawn Mental Health Longitudinal Community Epidemiological Project

AVAILABILITY:

Sponsoring Agency:

Johns Hopkins University

School of Hygiene and Public Health

Health Policy and Management

(Author: Margaret Ensminger)

Where to request database:

The Henry A. Murray Research Center

A Center for the Study of Lives

Radcliffe College

Ten Garden Street

Cambridge, Massachusetts 02138

Contact Person:

Copeland H. Young

Senior Research Assistant

The Henry A. Murray Research Center

Telephone: (617) 495-8140

Fax: (617) 496-3993

\section{ACCESSIBILITY:}

- Machine-readable data files will be available from the Murray Center. As of September, 1995, only one of the four cohorts has been formatted into datasets that will be available to the public. Documentation is in the final stages of being written, and the rest of the cohorts remain to be processed.

YEAR(S) OF DATA COLLECTION:

- Cohort 1 consists of children $(\mathrm{N}=1,700)$ who were first graders in the 1964-65 school year.

- Cohort 2 members $(\mathrm{N}=1,600)$ were in first grade during the 1965-66 school year.

- Cohort 3a members $(\mathrm{N}=1,242)$ were first graders in the 1967-68 school year. A follow-up with a sample of this group $(\mathrm{N}=705)$ was conducted in 1975 .

- Cohort $3 b(N=1,242)$ are the mothers of participants in Cohort 3a and were interviewed in 1967. A sample $(\mathrm{N}=939)$ of these mothers were re-interviewed in 1975.

- All child cohorts were interviewed three times in the first grade, once in the third 'grade, and again at a ten-year follow up at which point the children had reached adolescence' (ages 16-17). 
MAJOR AREAS:

- Environmental supports, interventions, and stressors, and their role in children's mental health, scholastic achievement, and risk-taking behaviors.

\section{MAJOR OR SAMPLE QUESTIONS:}

Highlights from "What's Happening" a social adaptation questionnaire administered to adolescents in the ten-year follow up.

How often have you engaged in sexual intercourse? Never, once or twice, or more often[?]

- How do you feel about someone your age using birth control? Mark how you feel somewhere between strongly approve to strongly disapprove.

- For the most part, how much do you and your parents agree on these sexual matters? Mark how much you agree from very, very much to not at all.

- What kinds of rules do your parents have about your use of the following: [Do they absolutely forbid it, leave it all up to you, or something in between?] Beer and wine/ Drugs/ Cigarettes

- About how many classes do you skip in an average week? These are classes that you just cut out on. None, one, two to three, four to five, six or more.

- Have you ever been stopped, taken to the police station or appeared in court for any of the following things:
A. Disorderly conduct
B. Run away
C. Truancy
D. Curfew violation
E. Larceny or theft
F. Burglary or breaking and entering
G. Assault
H Vandalism, or
I Narcotics drug laws

- Now I'm going to go through the same list of drugs and I would like to know how often you have ever used each of the following drugs.

A. Marijuana or hashish-have you used it 40 times or more ever, 20 to 39 times ever, 10 to 19 times ever, three to nine times ever, one to two times ever, or have you never used it.

B. LSD or other psychedelics

C. Uppers, methedrine, or amphetamines

D. Downers or barbiturates without a doctor's prescription

E. Tranquilizers without a doctor's prescription

F. Cocaine

G. Heroin, methadone, opium or morphine

H. Glue, gas or other inhalants

I. Cough syrup or codeine taken without a doctor's prescription 
J. Hard liquor or whiskey

K. Beer or wine

Highlights from "Mother's Ouestionnaire"

- How true is this of your child? not at all, just a little, pretty much, very much:

Picky and finicky about food, underweight, overweight, restless or awakens at night, has nightmares, afraid of new situations, afraid of people, afraid of

being alone, afraid to go to school, body shakes, stutters, doesn't speak clearly other than stuttering, lets himself get pushed around by other children, sucks thumb, bites or picks nails, plays with own sex organs, involved in sex play with other children, looks stony-faced, has weird, odd, strange movements or looks, says weird, odd, or strange things, runs to bathroom constantly, wets bed, wets self during day, has had accidents with bowel movements in the last year, complains of the following even when doctor finds nothing wrong: headaches, stomachaches, vomiting, aches and pains, loose bowels

"How I Feel" Written Ouestionnaire

- Respondent marks box next to the responses "almost not at all," "a little," "pretty much," or "a lot" for the following items: I feel sad, I feel nervous, I feel shy and lonely, I break rules in the school classroom, I act too young for my age, I could do my work better in school, I get restless in school and don't pay attention

- All in all how do I feel I am doing in school? (I feel I'm doing pretty well/ I feel I'm having a little trouble, I feel I'm having pretty much trouble, I feel I'm having a lot of trouble)

"How I Feel" Tapescript Questionnaire

Six point scale for responses, ranging from "Very, very much" to "Not at all":

I feel strong and healthy; I feel nervolis; I feel sad; I can change my plans or my mind if I get new information; I feel empty inside; People hide from me what they really feel; I have a tough time making up my mind; Doing well in school is important to me; I have serious personal problems; I enjoy myself much of the time; I feel under pressure; I cry and don't know why; I enjoy solving difficult problems; There are times when I really feel bad inside; I enjoy being with members of my family; When I get angry, I stay angry; I have faith in myself and other people; I feel like I'm in another world; People have turned against me; I have many hobbies; I live by strict rules and habits; I like being the way I am; I believe that things usually turn out for the best; I need outside help with my problems; I am a warm and friendly person; I feel tense; I feel hopeless; If someone insults me, I am likely to hit them; When I have questions in school, I know how to get the answers; I sometimes hear strange things when I am alone; I don't often trust people; When things are not neat and orderly, I feel upset; I have a sense of humor; I believe people will generally do the right thing; My hands sometimes shake; I yell at people; I'm good at what I do; I feel like I am boiling inside; When faced with a problem I can work it out; I sometimes think the world is ending; I like to do new things I haven't done before; I worry about what others will do with what they know about me; I enjoy being with 
kids my age; If things are not just a certain way, I feel upset; I work well under pressure; I expect to be successful in life; New situations make me tense; I sometimes think people are following me; I enjoy parties I go to; I lose my temper

- Satisfaction with: height, weight, overall facial looks, complexion, chest, stomach, hips, seat, sex organs, overall body appearance

- Six point scale for responses, ranging from "Very, very much" to "Not at all": It is important to me to have a close friend to confide in; Something is wrong with my mind; I am a talented person; I feel ashamed of myself; Having fun is important to me; Weird, odd and strange things happen to me; I find myself double-checking things; I expect to have good jobs later on; I feel upset; I can always be counted on to do a good job; I feel tight inside; I feel angry; People think of me as understanding and sympathetic; I sometimes hear voices or sounds other don't; Someday I hope to teach, help or care for youngsters; People talk behind my back; When I fail at something, I try again; I have upsetting thoughts that won't go away

- How do your teachers thing you're doing in school? Respond between "very, very well" to "not well at all."; How satisfied are you with your teacher's opinion of how you're doing? Respond between "very, very much" to "not at all."; How do your parents think you're doing at home? Respond between "very, very well" to "not well at all. "; How satisfied are you with your parents' opinion of how you're doing? Respond between "very, very much" to "not at all."; How well-liked are you by your friends? Respond between "very, very much" to "not at all."; How satisfied are you with how well they like you?; How well-liked are you by friends of the opposite sex? Respond between "very, very much" to "not at all."; How satisfied are you with how well they like you?

- Six point scale for responses, ranging from "Very, very much" to "Not at all": I like to do the best work that I can; I feel like a stranger much of the time; I startle easily; It's easy for me to relax and enjoy myself; I feel guilty; I like to share my feelings with others; I get into fights; I keep myself cleaner than I really need to ; I am a worthwhile person; I have many personal troubles; I don't feel worth much; I make friends easily; I should talk to a doctor about my problems; People would be better off without me

Teacher Observation of Classroom Adaptation

4 point scale $(0=$ within minimal limits of acceptable behavior; $1=$ mildly excessive; 2 =moderately excessive; 3 =severely excessive) ratings for the following:

Excessively lacking in involvement with classmates; excessively aggressive behavior; excessively immature behavior; excessively not working up to his ability; excessively restless

- Global rating of classroom adaptation

Interviewer's observations

6 point bipolar adjective scales to rate respondent: friendly/hostile; didn't understand questions/understood questions; relaxed/tense; interested/uninterested; evasive/frank and candid; cooperative/uncooperative 
- 6 point bipolar adjective scales to rate respondent's home: comfortable/uncomfortable; neat/disorderly; dirty/clean; peaceful/hectic; (leaving out individual preferences and not counting the cost or condition of the furniture, please indicate the description of the part of the household that you saw): thoughtfully arranged and decorated/there seemed no attempt to arrange or decorate

- Did you see mother and a child interact? (yes/no); If Yes: Respondent's probable behavior toward child: capable/not capable; warm/cold; in control/not in control; strict/permissive; interested/uninterested

- Type of structure?, public housing?, Condition of structure? Condition of living quarters inside (including walls, windows, floors, doors and ceilings)? Location of structure? Estimated racial make-up of the block?

\section{SAMPLE CHARACTERISTICS:}

- $\quad$ All students ( $N=1,700$; initial ages: 6-7 years) in the 1964-65 through 1967-68 firstgrade classes from nine public and three parochial schools in an African-American community on the South Side of Chicago.

- $100 \%$ of participants were African-American. $53 \%$ were members of the poverty class, $40 \%$ were working class, and $7 \%$ were upper middle/middle class.

\section{METHOD OF DATA COLLECTION:}

- Prospective data collection efforts have included the following:

- Interviews with participant

- Interviews with mother

- Direct clinical observation of mother and child

- $\quad$ Administration of standardized tests and inventories, e.g. Metropolitan

Readiness Test, Mother Symptom Inventory, children's "How I Feel," Teacher's Observation of Classroom Adaptation (TOCA), grades, intelligence tests, readiness for school and achievement tests, adolescent's "How I Feel", adolescent's "What's Happening," criminal justice (police arrest) records.

- Recent retrospective data collection efforts have focused on substance abuse and criminality indicators for the 1966-67 cohort of first graders, e.g., motor vehicle records, criminal justice records, drug- and alcohol-treatment records.

\section{VARIABLES:}

Prospective home environment and social functioning variables: adults present in the household, child-rearing role specification, affection and rule setting and enforcing, value orientations around purposes of education, sense of potency, internality/externality, formal and informal social integration of family, involvement with school

- Prospective school environment and social functioning variables: adequacy of the child's performance on each of the social task demands set by teacher in first and third grades: Teacher's Observation of Classroom Adaptation (TOCA) 
- Prospective psychiatric variables (mother and child):

- Direct clinical observation using Psychopathology Rating Scales and Social Contact Measurements (flatness [of affect and behavior], depression, anxiety, hyperkinesis, bizarre behavior, global assessment of sickness.

- Mother Symptom Inventory (when child is in first grade), tension, nervousness, sadness, child's self-perception of competency in performing third grade tasks.

- Follow-up (age 16 or 17) scholastic aptitude: Grades, intelligence tests, readiness for school and achievement tests.

- Follow-up (age 16 or 17) psychological well-being variables: psychiatric symptoms, self-esteem, self-perception of social adaptational status in important social fields, and satisfaction with social adaptational status--at age 16 or 17.

- Follow-up (age 16 or 17) social adaptation variables: Criminality, frequency of drug use, reports of family practices and values around affection and rules, self reports of delinquency, sexual behavior and attitudes, teenage motherhood, welfare recipiency.

\section{UNIQUE CHARACTERISTICS:}

- Life-span developmental approach

- Epidemiological data

- Ecological validity through construction of social adaptation measures using criteria of raters occurring naturally in the participant's environment.

- Distinction between social role performance and psychological status outcomes.

- By marking the last item on the "What's Happening" questionnaire, respondents had the opportunity to be contacted by a counselor from a local youth program if the respondent wished to discuss any of the issues further.

\section{RISK-RELATED ASPECTS:}

$\begin{array}{ll}- & \text { Substance use } \\ \text { - } & \text { Sexual activity } \\ \text { - } & \text { Aggression/violence } \\ \text { - } & \text { Melinquency/crime } \\ \text { - Social support and protective factors }\end{array}$




\section{Youth Risk Behavior Survey (YRBS)}

\section{AVAILABILTTY:}

Sponsoring Agencies: National Center for Health Statistics Centers for Disease Control and Prevention National Center for Chronic Disease Prevention and Health Promotion Division of Adolescent and School Health U. S. Department of Health and Human Services

Where to request database: National Center for Health Statistics Presidential Building, Room 850 6525 Belcrest Road Hyattsville, Maryland 20782 Telephone: (301) 436-7087

Fax: (301) 436-3484

Government Printing Office Superintendent of Documents Sales Desk (202) $512-1800$

National Technical Information Service 5285 Port Royal Road Springfield, Virginia 22161 (703) $487-4650$

Contact Person:

Laura Kann (404) 488-5330

Center for Disease Control and Prevention 4770 Buford Hwy., N.E., MS-K33 Atlanta, Georgia 30341-3724

Charlotte Schoenborn, Statistician National Center for Health Statistics Telephone: (301) 436-3484, ext. 151

\section{ACCESSIBIITT:}

- Cartridge tape is available from the Division of Health Interview Statistics, $\$ 200$

- CD-ROM is available from the Government Printing Office and from the National Technical Information Service, $\$ 15.00$

- YRBS data is available through 1992. 
Youth Risk Behavior Survey

DATA FORMAT:

- Fixed-block format

YEAR(S) OF DATA COLLECTION:

- The school based survey was used in 1990, 1991, and biennially thereafter. Schoolbased surveys were conducted in 1993 and 1995, but data for these survey administrations is not yet available.

- The household-based survey was added in 1992.

MAJOR AREAS:

- Behaviors that contribute to unintentional and intentional injuries

- Tobacco use

- Alcohol and other drug use

- Sexual behaviors

- Dietary behaviors

- Physical activity

MAJOR OR SAMPLE QUESTIONS:

- How often do you wear a safety belt when riding in a car driven by someone else?

- During the past $\mathbf{3 0}$ days, on how many days did you carry a weapon such as a gun, knife, or club?

- How old were you when you smoked a whole cigarette for the first time?

- During your life, how many times have you sniffed glue, or breathed the contents of aerosol spray cans, or inhaled any paints or sprays to get high?

- The last time you had sexual intercourse, did you or your partner use a condom?

- During the past 30 days, did you exercise to lose weight or to keep from gaining weight?

- Yesterday, how many times did you eat cookies, doughnuts, pie, or cake?

- In an average week when you are in school, on how many days do you go to physical education (PE) classes?

\section{SAMPLE CHARACTERISTICS:}

- National data are representative of students in grades 9-12 in public and private schools in the 50 states and the District of Columbia.

- Schools with substantial numbers of black and Hispanic students were sampled at relatively higher rates than were all other schools.

- The 1992 household-based survey was completed by a nationally representative sample of 12-21 year olds. This group included young people who did and did not attend school or college. In 1992, 10,645 youths participated, with a response rate of $77.2 \%$. 
- In the 1993 school-based survey, 16,296 surveys were completed in 155 schools. The 1993 school response rate was $78 \%$ and student response rate was $90 \%$, for an overall response rate of $70 \%$.

\section{METHOD OF DATA COLLECTION:}

- For the national school-based surveys, participants completed questionnaires in their classrooms.

- For the national household-based surveys, participants listened to questions through audio headphones and responded using paper and pencil answer sheets.

\section{VARIABLES:}

- Age, race/ethnicity, grade in school

- Safety belt use, motorcycle helmet use, bicycle helmet use, rode with driver who had been drinking alcohol

- Weapon-carrying, gun-carrying, 30-day incidence of weapon-carrying, fighting, injured in fight, 12-month incidence of physical fighting, felt unsafe to go to school, weapon-carrying on school property, threatened or injured with weapon on school property, in physical fight on school property, property stolen or deliberately damaged on school property

- Suicide ideation, suicide plan, suicide attempt, suicide attempt required medical attention

- Lifetime cigarette use, current cigarette use, frequent cigarette use, regular cigarette use, smokeless tobacco use, lifetime alcohol use, current alcohol use, episodic heavy drinking, lifetime marijuana use, current marijuana use, lifetime cocaine use, current cocaine use, lifetime crack or freebase use, lifetime illegal steroid use, lifetime injected-drug use, cigarette use on school property, smokeless tobacco use on school property, alcohol use on school property, marijuana use on school property, offered/sold/given illegal drug on school property

- Ever had sexual intercourse, four or more sex partners during lifetime, currently sexually active, condom use during last sexual intercourse, birth control pill use during last sexual intercourse

- Thought they were overweight, were attempting weight loss, ate fruits and vegetables, ate no more than two servings of food typically high in fat content, participated in vigorous physical activity, participated in stretching exercises, participated in strengthening exercises, enrolled in PE, attended PE daily

\section{UNIQUE CHARACTERISTICS:}

The Youth Risk Behavior Survey (YRBS) is the data collection instrument of the Youth Risk Surveillance System (YRBSS), which collects data at the national, state, and local levels. See the state section of this report for more information pertaining to state YRBSS participation. 
- Large number of variables within six broad risk areas revealed associations among various risk behaviors.

- Self-report of risk behaviors may be more candid in the school-based YRBS than in the household-based NHIS Youth Risk Behavior Supplement.

- Significant differences by region, race/ethnicity, and gender

- Detailed questions related to both behaviors that contribute to unintentional injuries and behaviors that contribute to intentional injuries

\section{RISK-RELATED ASPECTS:}

- Substance use

- Tobacco

- Driving

- Driving under the influence

- Safety belts

- Sexual activity

- HIV/AIDS, and other STDs

- Aggression/violence

- Delinquency/crime

- Injuries

- Physical health (exercise and diet)

- Mental health

- Protective factors 
II. STATE DATABASES 


\section{INTRODUCTION TO STATE DATABASES}

This section contains information on databases that states collected on various domains of risk taking behaviors, and, in some cases, protective factors. There is wide variation in the amount of resources states provide for collecting information on youthful risk taking. Some states put no resources into data collection, while others participate in the Youth Risk Behavior Surveillance System (YRBSS) and/or conduct their own surveys, some of which are quite extensive. In addition to conducting surveys, several states compile databases on youthful risk taking behaviors from multiple sources, such as state accident data. It must be noted that the databases reported in this section do not include YRBSS data, unless otherwise noted.

The state databases were included in this report because a number of the surveys conducted by particular states include a more fine-grained examination of risk taking behaviors than national databases. For instance, Hawaii has done much work in collecting information on youth gang participation, and has published several reports on the subject. South Carolina, for example, has conducted a survey of risk and protective factors among high school students, as well as participants in a program for dropouts and individuals working on earning a GED. A review of these databases facilitates preliminary explanations or insights into these areas, and also facilitates formulating questions for future qualitative and quantitative research. It must be noted, however, that the strategies for sample selection vary widely from randomized designs to convenience samples.

Several states have implemented novel uses for survey findings. For instance, some procedures involved student participants scanning their own response forms and receiving immediate feedback, comparing the respondent to state norms. Others provided referral information on their feedback forms for students determined high risk for mental health problems. Some states used survey questions from national surveys, such as Monitoring the Future, so that data from the state could be compared to a national sample. In some states, the data were collected over multiple years to examine trends in risk taking behavior. Finally, a number of states used survey results to target interventions to a specific risk taking behavior or to a specific school or community.

The format for reporting information on the databases is identical to the one used in the national section. Unlike the databases reported in the national section, state databases are usually not available for public use. This is often to ensure the confidentiality of school and individual participants, or because the resources to administer dissemination of the databases are nonexistent. However, many states publish reports of survey findings that are available to the public. This is noted on the database fact sheets. 


\begin{abstract}
Alaska
AVAILABILITY:

Sponsoring Agency: Community Health Services

Division of Public Health

Alaska Department of Health and Social Services

P.O. Box 110614

Juneau, AK 99811-0614

Telephone: (907) 465-3140

Contact Person: Michele Hansen

Telephone: (907) 561-4406
\end{abstract}

DATABASE/REPORT: The State of Adolescent Health in Alaska, May 1990

ACCESSIBILITY:

- Report

YEAR(S) OF DATA COLLECTION:

- 1988-89

MAJOR AREAS:

- $\quad$ Risky driving

- Impaired driving

- Violence

- Substance use

- Adolescent sexuality

- Physical health

- Emotional health/suicide

SAMPLE CHARACTERISTICS:

- $\quad 5,458$ students, grades 7 through 12

METHOD OF DATA COLIECTION:

- Self-report

UNIQUE CHARACTERISTICS:

- The results are included in a report, Alaska's Adolescents: A Plan for the Future. 
RISK-RELATED ASPECTS:

- Substance use

- Sexual activity

- Aggression/violence

- Driving

- Driving under the influence 


\section{Connecticut}

AVAILABIITY:

Sponsoring Agency:

Connecticut Department of Public Health and Addiction Services

150 Washington Street

Hartford, Connecticut 06106

Telephone: (203) 566-7867

Contact Person:

Mary Adams

DATABASE/REPORT: Connecticut Health Check

\section{ACCESSIBILTTY:}

- Report

YEAR(S) OF DATA COLLECTION:

- Started 1985; revised in 1987

- Yearly questionnaire

- Data is summarized on a school-year basis.

MAJOR AREAS:

- Impaired driving

- Violence

- Substance use

- Smoking

- Adolescent sexuality

- Exercise

- Diet

- Mental Health

- AIDS (whether talked to girl friend or boy friend about AIDS)

\section{MAJOR OR SAMPLE QUESTIONS:}

- Where do you get MOST of your information about health (parents, friends, readi: $\mathrm{g}$, school, TV)?

- Mark the GRADE you are in on the card.

- How often do you play or exercise hard enough to sweat and breathe heavily for :: least $\mathbf{3 0}$ minutes at a time?

- How often do you eat breakfast?

- How often do you eat fruits and vegetables?

' How often do you brush your teeth?

- How often do you snack on food such as chips, candy, cookies, etc.?

- Do you think you are: too thin, too fat, about right? 
- Do you get enough sleep and feel rested?

- Do you like yourself?

- Do you get along well with your parents?

- Do you talk with your parents about problems?

- Do you ever worry that a parent will hit you or hurt you?

- Do you always protect your skin with a sun screen or covering so you won't get a sunburn?

- Do you wear a safety belt when riding a car?

- Do you wear a helmet when you ride your bicycle?

- How important is it for you to be like your friends and not feel different or left out?

- How many cigarettes have you smoked in your life?

- Do you smoke cigarettes now?

- Do you think you will smoke when you are older?

- Have you ever used smokeless tobacco (chewing tobacco or snuff)?

- Do you drink beer, wine, wine coolers, or other alcoholic drinks (other than for religious reasons)?

- What is the MOST alcoholic drinks you've ever had at one time?

- Has anyone ever asked you to try a drug such as marijuana, cocaine, or crack?

- What is the main reason you think kids might try marijuana, cocaine or crack?

- Have you ever smoked marijuana?

- Have you ever used a drug other than alcohol or marijuana to get "higher"?

- In the past six months have you ever felt that life was not worth living?

- Do you know how a girl gets pregnant?

- If a friend or someone in your school had AIDS, would you be worried about catching it?

- In the past year, how often have you been in a fight or tried to beat someone up?

SAMPLE CHARACTERISTICS:

- Schools self-selected to be in study

- Approximately 5,000 students per year

- Grades 4 through 12 (ten- to 18-year-olds)

METHOD OF DATA COLLECTION:

- Connecticut Health Check is a questionnaire administered during health education classes.

VARIABLES:

- See questions above 


\section{Connecticut}

\section{UNIQUE CHARACTERISTICS:}

- The questionnaire is administered during health education classes.

- Questionnaire is computer based; students complete cards and run them through an optical scanner themselves.

- Data are used to compare a particular school to other schools.

- Results are used to raise awareness of issues in a particular school, and to identify areas that need attention.

- Results are used to apply for grants for school-based health centers (schools are able to add additional questions that are specific to their school).

- The printout for each student includes referrals to a professional in the school system for those who are judged as high risk for problems (e.g., suicide).

- Contains questions similar to those on the YRBS

RISK-RELATED ASPECTS:

- Substance use

- Tobacco

- Sexual activity

- HIV/AIDS and other STDs

- Pregnancy

- Driving

- Driving under the influence

- Safety belts

- Mental health (including suicide and body image)

- Physical health (including dietary and physical health) 


\section{Hawaii}

AVAILABILTY:

Sponsoring Agency:

Hawaii State Department of Health

1350 King Street, Suite 206A

Honolulu, HI 96814

Telephone: (808) 594-1012

Contact Person:

Deborah Goebert

DATABASE/REPORT: Hawaii has a number of databases relating to youthful risk taking. They are as follows: (1) an integrated traffic surveillance system utilizing police, ambulance, and death records; (2) an ocean surveillance system, which includes contributing factors for rescues; (3) sources for firearm injuries; and (4) separate surveys on sexual activity, gangs, and drug use among public school students.

\section{ACCESSIBILITY:}

- Reports on gangs and delinquency include: Surveying Hawaii's Youth: Neighborhoods. Delinquency, and Gangs; Gangs and Delinquency in Hawaii: Profiles of Gang Members, Trends in Juvenile Arrests, and Troubled Neighborhoods in Hawaii; Crime, Delinquency, and Gangs in Hawaii: Evaluation of Hawaii's Youth Gang Response System (Part 1); The Youth Gang Response System: A Process Evaluation: Evaluation of Hawaii's Youth Gang Response System (Part 2); Putting Juvenile Crime Trends in Perspective; Just Every Mother's Angel: Interviews with Hawaii's Gang Members; An Evaluation of Act 189: Hawaii's Response to Youth Gangs.

Each project employed different methods. The report, Surveying Hawaii's Youth: Neighborhoods, Delinquency, and Gangs is used as an example of available information.

\section{YEAR(S) OF DATA COLLECTION:}

- 1992

\section{MAJOR AREAS:}

- Demographics (e.g., grade, gender, ethnicity, SES, number of people in household, parents' marital status, subject's employment, and youth center activities)

- Delinquency: (e.g., cut class, damaged school property, created graffiti, stolen, run away, carried weapons, bought/sold drugs, alcohol use, drug use, and gang fights) 
MAJOR OR SAMPLE QUESTIONS:

- Do you feel better with people now as a result of your participation in the program (e.g., agencies participating in the survey: boys and girls clubs, YMCA, Department of Parks and Recreation, etc.)

- $\quad$ Are you doing better in school?

- Is there an activity you would like to do that isn't here?

- Do you know people in your neighborhood who are in gangs?

- How many people in your neighborhood are gang members?

- How many people do you know are gang members?

- Do you have family members who are in gangs?

- Are you now in a gang?

- Have you ever been in a gang?

- Do you want to be in a gang?

- How many times in the last twelve months have you: cut classes at school?, painted/drawn graffiti?, stolen?, run away from home?, carried a hidden weapon other than a plain pocket knife?, bought/sold drugs?, used alcohol?, used drugs?, been involved in gang fights?, purposely damaged or destroyed property belonging to a school?

- Is it hard to know what is right or wrong?

\section{SAMPLE CHARACTERISTICS:}

- 800,5 th to 12 th graders (not a random sample)

\section{METHOD OF DATA COLLECTION:}

- Survey was conducted with youth attending programs in a variety of neighborhoods.

\section{VARIABLES:}

- See major sample questions above

UNIQUE CHARACTERISTICS:

- In-depth information about gang membership

\section{RISK-RELATED ASPECTS:}

- Substance use

- Aggression/violence

- Delinquency/crime (including gang activity)

- Social support and protective factors 


\section{Illinois}

AVAILABLITY:

Sponsoring Agency:

Illinois Department of Public Health 535 W. Jefferson Street

Springfield, II 62761

Contact Person:

Joanne Durkee (Adolescent Health Survey) Telephone: (217) 524-5987

DATABASE/REPORT: The Illinois 9th Grade Adolescent Health Survey

\section{ACCESSIBILITY:}

- Reports

YEAR(S) OF DATA COLLECTION:

- 1991

MAJOR AREAS:

- Safety, accidents, and injuries

- Mental health and suicide

- Fighting and violence

- Alcohol, tobacco, and other drug use

- Sexual behavior related to pregnancy, STDs, and AIDS

- Nutrition and eating habits

- Exercise

MAJOR OR SAMPLE QUESTIONS:

- How old are you?

- What is your sex?

- How do you describe yourself?

- What grade are you in?

- About how many days have you been absent from school during this year?

- Do you intend to graduate from high school?

- Whom do you live with now? 
Illinois

- How far did your father go in school?

- How far did your mother go in school?

- Since the beginning of the 6th grade, have you received instruction on: health education, selecting health products and services, nutrition and choosing healthy foods, effects of drugs and alcohol, abstinence, contraception, HIV/AIDS prevention, STD, suicide prevention?

- Is there a working smoke detector in your home?

- Do you ever ride a bicycle?

- When you ride a bicycle after dark, how often do you use a light?

- When you ride a bicycle, how often do you wear a bicycle helmet?

- Did you wear a safety belt the LAST TIME you rode in a car, truck, or van?

- During the past 12 MONTHS, about how many times did you: take medicine that was prescribed for someone else; ice-skate in an unsupervised area; surf, wind-surf, or boogie board in an unsupervised area; swim alone with no one else around; swim in a restricted or unsupervised area; dive into water without knowing how deep it was; use alcohol or drugs while swimming or boating; drive or ride on a go-cart, snowmobile, or all terrain vehicle; use a handgun, rifle, or shotgun for any reason (including hunting or target shooting)?

- During the past MONTH, did you ride with a driver who had used drugs or had been drinking before driving?

- When you ride on a motorcycle or minibike, about how often do you wear a helmet?

- How hard is it for you to deal with stressful situations at home and at school?

- During the past MONTH, how often have you felt sad and hopeless?

- During the past MONTH, how often have you felt that you have nothing to look forward to?

- When you have problems, how often do you feel you can solve them or find someone to help you solve them?

- Have you ever seriously thought about trying to hurt yourself in a way that might result in your death.

SAMPLE CHARACTERISTICS:

- Random sample of schools

- 5,930, 14- and 15-year-olds

METHOD OF DATA COLLECTION:

School-based survey

VARIABLES:

- See sample questions above 
UNIQUE CHARACTERISTICS:

- Data utilized to identify key problems that should be addressed among 9th graders.

- $\quad$ Results used to assess effectiveness of intervention programs.

- Results are also used to examine trends across time and as a comparison with national statistics.

\section{RISK-RELATED ASPECTS:}

- Substance use

- Sexual activity

- Aggression/violence

- Driving

- Safety belts

- Riding with an intoxicated driver

- Injuries

- Physical health (including nutrition and exercise)

- Mental health (including suicide)

- Health instruction 


\section{Illinois}

\section{AVAILABILTTY:}

Sponsoring Agency:

Illinois Department of Public Health

535 W. Jefferson Street

Springfield, IL 62761

Telephone: (217) 782-0686

Contact Person:

Joanne Durkee

DATABASE/REPORT: Youth Study on Substance Use: 1993

\section{ACCESSIBILITY:}

- Report

YEAR(S) OF DATA COLLECTION:

Beginning in 1990 , every three years

\section{MAJOR AREAS:}

- Prevalence of substance use

- School problems as a result of substance use

- Drinking and driving

- If quit using substance, reasons why

SAMPLE CHARACTERISTICS:

- $13,397,7$ th to 12 th graders

METHOD OF DATA COLLECTION:

- School-based survey

\section{VARIABLES:}

- Substance use: yearly, monthly, weekly use

\section{UNIQUE CHARACTERISTICS:}

- Data used to evaluate trends in use and to plan interventions and media campaigns.

RISK-RELATED ASPECTS:
- Substance use
- Driving
- Driving under the influence
- Aggression/violence 
Indiana

AVAILABILTTY:

Sponsoring Agency:

Indiana Prevention Resource Center Institute for Drug Abuse Prevention Indiana University-Bloomington Creative Arts Building Room 110 840 State Road

46 Bypass

Bloomington, IN 47405

DATABASE/REPORT: Alcohol, Tobacco, and Other Drug Use by Indiana Children and Adolescents

ACCESSIBIIITY:

- Report

YEAR(S) OF DATA COLLECTION:

- 1995

MAJOR AREAS:

- Cigarette smoking

- Alcohol, smokeless tobacco, and other drug use

- Adverse consequences caused by alcohol or other drugs

- Perceived risks of using substances

- Perceived peer approval/disapproval of alcohol and other drug use

- Participation in structured and unstructured activities

MAJOR OR SAMPLE QUESTIONS:

- Items in the survey are derived from the National Household Survey on Drug Abuse and Monitoring the Future

SAMPLE CHARACTERISTICS:

- $63,631,6$ th through 12th graders

- Schools and communities were purposively selected to assure proportional representations from different parts of the state (250 schools in 85 communities).

METHOD OF DATA COLLECTION:

- Self-administered written questionnaires

UNIQUE CHARACTERISTICS:

- Large database

- Comparisons of Indiana data with national data 
Indiana

RISK-RELATED ASPECTS:

- Substance use

- $\quad$ Risk perception

- Social support and protective factors 


\section{Iowa}

AVAILABILITY:

Sponsoring Agency: Iowa Department of Education Grimes State Office Building

Des Moines, Iowa 50319

Telephone: (515) 281-3021

Contact Person: $\quad$ David Wright

DATABASE/REPORT: 1993 Iowa Youth Survey

ACCESSIBILITY:

- Report

YEAR(S) OF DATA COLLECTION:

- 1975-1993 (every three years)

MAJOR AREAS:

- Alcohol use

- Tobacco use

- Marijuana use

- Other Drug use

- Polysubstance use

- Unsafe motor vehicle behaviors

- Impaired driving

- Violence

- Gambling

- Depression and suicide

- Stress

- Drinking parties

- Physical abuse by an adult

- Sexual abuse by an adult

- Parent and family substance abuse problems

- Peer influence

- School environment

- Unsafe neighborhood 
- Poverty

- Single parent family

MAJOR OR SAMPLE QUESTIONS:

- See variables below

SAMPLE CHARACTERISTICS:

- 14,400 subjects, grades 6-12 (72 school districts)

METHOD OF DATA COLLECTION:

- Written, school-based survey (121 question instrument)

VARIABLES:

- External Factors:

family support

parent(s) as social resources

parent-child communication

parent asks about school

parental standards

parental discipline

parental monitoring

time at home

positive school climate

positive peer influence--school performance, altruism, extracurricular, emotional support

involved in music

involved in extra-curricular activities

involved in community activities

involved in church or synagogue

- Internal Factors:

achievement motivation

educational aspiration

school performance

homework

cares about people's feelings

values sexual restraint

self-estéem

prosocial behavior

- Risk Factors:

drinking parties

stress

physical abuse by adult 
sexual abuse by adult

parental addiction

family member addiction

negative peer influence - marijuana use, trouble at school, alcohol use

disruptive school environment

unsafe neighborhood

poverty

single-parent family

- At-Risk Behaviors: Substance Use

frequent alcohol use

binge drinking

daily cigarette use

frequent smokeless tobacco use

frequent use of illicit drugs: marijuana, cocaine, amphetamines, other drugs,

inhalants, steroids

drunk driving

ride with drunk driver

age of onset for alcohol/tobacco/marijuana/other drug use

amount of alcohol consumed per occasion

- Other Risk-Taking Behaviors

depression

attempted suicide

extortion by weapon use, force or violence

beat up someone in anger

gambling suicide ideation

disciplined for fighting or theft on school grounds

- Problems and Resources Related to Substance Use

prevalence of substance use at school perception of health risks from substance use

presence of substance abuse symptoms

student sources of help for substance problems

student sources of substance information

- Miscellaneous

peer tobacco use

peers get drunk

friend has substance abuse problem

peer helping program 


\section{UNIQUE CHARACTERISTICS:}

- Study contains normative and trend data.

- Survey specifically addresses youth substance use behaviors, attitudes and knowledge.

- The Iowa Youth Survey is based upon the survey, Search Institute Profiles of Student Life: Attitudes and Behavior. See appendix.

\section{RISK-RELATED ASPECTS:}

- $\quad$ Substance use (including binge drinking)

- Tobacco

- Aggression/violence

- Driving

- Driving under the influence

- $\quad$ Riding with an intoxicated driver

- Mental Health (including suicide)

- Gambling 


\section{Kentucky}

\section{AVAILABILTY:}

Sponsoring Agency: $\quad$ Kentucky Department for Health Services

Division of Maternal and Child Health

275 E. Main

Frankfort, KY 40621

Telephone: (502) 564-3246

Contact Person: Jay Hopkins

DATABASE/REPORT: Kentucky Alcohol and Drug Use Survey: Grades 6-12

\section{ACCESSIBILITY:}

- Report

YEAR(S) OF DATA COLLECTION:

- 1991

- Survey also conducted in 1986, 1988, 1989

\section{MAJOR AREAS:}

- Alcohol use

- Marijuana use

- Cocaine use

- Inhalant use

- Amphetamine use

- Barbiturate use

- Hallucinogen use

- Narcotic use

- Tranquilizer use

- Other nonprescription drug use

- Dropping out of school

- Negative attitudes toward school

- Tardy or absent from school

- Friends' use of alcohol or drugs

- Availability of alcohol and drugs in or around school

\section{MAJOR OR SAMPLE QUESTIONS:}

- Is it dangerous to use alcohol?

- Is it dangerous to use drugs not prescribed by a doctor?

- Indicate your experience in the use of the following ten controlled substances: alcohol, marijuana, cocaine, inhalants, amphetamines, barbiturates, hallucinogens, 
narcotics, tranquilizers, other nonprescription drugs. [never, 1-5 times in my life, in the past week, 2-10 times in the past month, and/or 11-30 times in the past month] Has your use of alcohol or drugs possibly caused you to....

...be responsible for a traffic accident?

...have trouble with family or friends?

...have trouble with the police?

...have problems in school?

- In or around school, how many people do you know who would give or sell you the following: alcohol, marijuana, cocaine, inhalants, amphetamines, barbiturates, hallucinogens, narcotics, tranquilizers, other nonprescription drugs?

- Have you seriously considered dropping out of school?

- If you should drop out of school, could it be for reasons related to alcohol or drugs?

- Do you have a negative attitude toward school?

- Has your use of alcohol or drugs caused you to be....

...tardy for school at least 5 times in the past month?

...absent from school 1 or more times in the past month?

- How many of your friends use alcohol or drugs?

- When are you most likely to....

...drink alcohol [never, during school day, after school, M-Th nights, weekends]

...use drugs [never, during school day, after school, M-Th nights, weekends]

- At what age did you first try alcohol?

- At what age did you first try drugs?

SAMPLE CHARACTERISTICS:

- 13,619 students in grades 6-12

METHOD OF DATA COLLECTION:

- School-based survey

VARIABLES:

- Age, gender, grade level.

UNIQUE CHARACTERISTICS:

- Longitudinal survey

RISK-RELATED ASPECTS:

- Substance use.

- Driving

- Driving under the influence

- Perception of the negative consequences of using alcohol/drugs.

- Dropping out of school 


\section{Maine}

\section{AVAILABILTTY:}

Sponsoring Agency: $\quad$ Maine Department of Human Sérvices Division of Maternal and Child Health State House Station \#11 Augusta, Maine 04333 Telephone: (800) 698-3624 (207) 287-3311

Contact Person:

DeEtte Hall

DATABASE/REPORT: Violence Among Children, Adolescents, and Young Adults in Maine

ACCESSIBIITY:

- Report

YEAR(S) OF DATA COLLECTION:

- 1993-1994

MAJOR AREAS:

- Violence

- Injury

- Suicide

- Sexual Assault

MAJOR OR SAMPLE QUESTIONS:

Information was collected to address the following questions or issues:

- What are the causes of death among Maine's children?

- What about injuries that do not result in death?

- What is known about assault injuries among young people?

- What is known about hate violence in Maine?

- There are little data available on the incidence of sexual violence in Maine.

- Arrest data provide only a small piece of the puzzle of youth violence in Maine.

- What is known about youth risk taking behavior?

- What do high school youth say about violence among their peers?

- What about youth residing at the Maine youth center?

- How do professionals view violence among children and teens? 


\section{SAMPLE CHARACTERISTICS:}

- Children, teenagers, young adult residents of Maine, and helping professionals

\section{METHOD OF DATA COLLECTION):}

- This report includes the results of surveys conducted with 542 "helping" professionals, in-depth interviews of 26 professionals, and three surveys of 2800 youths. Data from other sources are also reported, including trauma registry reports; uniform crime arrest data and reports; vital statistics mortality data; hospital discharge data; census data; Attorney General's Office hate crime data; mental health program data; Maine Pregnancy Risk Assessment Monitoring System (PRAMS); sexual assault crisis center data; and data from state-specific studies on juvenile offenders, mental health clients, high risk students and homeless youth.

\section{VARIABLES:}

- Knowledge of gangs

- Carries a weapon

- Drinks alcohol

- $\quad$ Attempted suicide

- Offered/sold/given drugs at school in the last year

\section{UNIQUE CHARACTERISTICS:}

- This report synthesizes data from all available surveys regarding youth violence in the state of Maine, including CDC data

RISK-RELATED ASPECTS:

- Substance use

- Aggression/violence

- Mental health (including suicide) 


\section{Maryland}

AVAПLABПITY:

Sponsoring Agency: Maryland Department of Health and Mental Hygiene 201 W. Preston Street

Baltimore, Maryland 21201

Telephone: (410) 225-6783

Contact Person: Norma Kanarek

Elise Weinstein

DATABASE: $\quad$ Maryland Teen Attitudes and Practices Survey 1993

ACCESSIBILITY:

- Data are not published in a report to date.

YEAR(S) OF DATA COLLECTION:

- 1993

MAJOR AREAS:

- Safety belt use

- Impaired driving

- Fighting

- Substance use

- $\quad$ Adolescent sexuality

- Health (mental and physical)

- Exercise

- School activities/attendance

- Perception of peer attitudes

\section{MAJOR OR SAMPLE QUESTIONS:}

- Do you think kids your age care about wearing a safety belt?

- Would you say they care a lot, somewhat, or just a little?

- Do you think kids your age care about the dangers of driving if they've been drinking?

- Would you say they care a lot, somewhat, or just a little?

- How old were you when you smoked your first cigarette?

- Have you smoked at least $\mathbf{1 0 0}$ cigarettes in your life?

- Have you ever smoked a cigarette every day for at least a month? 
- In the PAST YEAR have you ridden on a motorcycle or minibike, either by yourself or with someone else driving?

- How often in the PAST YEAR have you done this? Would you say often, sometimes, or rarely?

SAMPLE CHARACTERISTICS:

- $\quad 1,100$ students, ages 12-17

- Stratified random sample

METHOD OF DATA COLLECTION:

- Telephone interview

VARIABLES:

- Not available

UNIQUE CHARACTERISTICS:

- For questions related to sex and drugs, respondents were asked to estimate the number of persons their age engaged in such activities on a Likert scale (see National section: TAPS-II)

RISK-RELATED ASPECTS:

- Substance use

- Tobacco

- Aggression/Violence

- $\quad$ Driving

- Driving under the influence

- Safety belts

- Mental health

- Physical health 


\section{Massachusetts}

AVAILABILITY:

Sponsoring Agency:

Massachusetts Department of Public Health 150 Tremont St.

Boston, MA 02111

Telephone: (617) 727-9236

Where to request database:

Address:

Massachusetts Tobacco Education Clearinghouse

JSI Research and Training Institute

210 Lincoln Street

Boston, MA 02111

Beth Talha

(617) $482-9485$

DATABASE/REPORT: 1993 Massachusetts Tobacco Survey:

Tobacco Use and Attitudes

\section{ACCESSIBIITYY:}

- Report

YEAR(S) OF DATA COLLECTION:

- October 1993 and March 1994.

MAJOR AREAS:

- Tobacco Use

\section{SAMPLE CHARACTERISTICS:}

- A probability sample of MA housing units with telephones was drawn using randomdigit- dial techniques.

- 11,463 adults responded to the initial telephone interview discussing approximately 21,909 adults (persons interviewed provided information about themselves and all other adults in the household)

- From the original 11,463 households, over 4700 adults (who may or may not have been the household informant) and 1600 youth, ages 12-17, participated in more detailed surveys. If the adult was not the original informant, $\mathrm{s} / \mathrm{he}$ provided demographic information and smoking status.

- The survey oversampled residents in the Boston, Worchester, Fall River-New Bedford, Lowell-Lawrence, and Springfield areas. This oversampling was designed to provide information regarding the effectiveness of urban tobacco control programs. 


\section{METHOD OF DATA COLLECTION:}

- Initial telephone interviews were conducted with adults.

- In-depth telephone interviews were conducted using adults and youth who resided in the households in which an individual participated in the initial telephone interview.

\section{VARIABLES:}

- Age

- Gender

- Race/ethnicity

- Smoking

- Educational level

- Urbanicity

- Susceptibility to smoking (e.g., has used in the past month/or may use in the future)

- Experience with smokeless tobacco

- Exposure to anti-smoking messages

\section{UNIQUE CHARACTERISTICS:}

- Large sample size

- Findings utilized to provide baseline for assessing the impact of Massachusetts' Tobacco Control Program

- Data utilized for designing prevention strategies for teens who have not begun smoking.

\section{RISK-REILATED ASPECTS:}

- Tobacco 


\section{Massachusetts}

AVAILABILITY:

Sponsoring Agency: $\quad$ Massachusetts Department of Public Health Division of Alcohol and Drug Rehabilitation 150 Tremont Street Boston, MA 02111 Telephone: (617) 727-1960

Fax: (617) 727-2700

Contact Person: Jane Poitras

(617) $727-1960$

DATABASE/REPORT: Tobacco, Alcohol and Other Drug Use Trends Among Massachusetts Public School Adolescents 1984-1993

\section{ACCESSIBILITY:}

Report

YEAR(S) OF DATA COLLECTION:

- November 1993 to January 1994

- Every three years

\section{MAJOR AREAS:}

- Tobacco use

- Alcohol use

- Other illicit drug use

- Drugs and driving

- Prevention education

- Knowledge of school rules and penalties for drug use

MAJOR OR SAMPLE QUESTIONS:

- The instrument contained questions related to background variables; tobacco, alcohol, and other drugs; drugs and driving; prevention education; knowledge of school rules; and knowledge of penalties for drug use.

\section{SAMPLE CHARACTERISTICS:}

- 5,321 students, grades 7-12 (134 schools in 74 communities)

\section{METHOD OF DATA COLLECTION:}

- School and class selection were random. Questionnaires were administered by independent, trained survey administrators. 
VARIABLES:

- Grade level

- Gender

- Ethnicity

- Community size

- Age at first use of alcohol, tobacco, or other drugs

- Lifetime and current use

- Amount and frequency of use

- Intentions to continue use

- Perceived availability

- Patterns of consumption

- Attitudes about drugs

UNIQUE CHARACTERISTICS:

- State trend data was compared to national trend data.

RISK-RELATED ASPECTS:

- Substance use

- Tobacco

- Driving

- Driving under the influence 


\title{
Minnesota
}

\section{AVAILABIITY:}

Sponsoring Agency:

Minnesota Department of Education

Department of Prevention and Risk Reduction

Capitol Square Building

550 Cedar Street

St. Paul, MN 55101

Telephone: (612) 296-5086

Fax: (612) 297-5695

Where to request database:

Minnesota Department of Education

Prevention and Risk Reduction Unit

550 Cedar Street

St. Paul, MN 55101

Contact Person:

Barbara Yates, Project Director

(612) 296-4081

DATABASE/REPORT: Reflections of Social Change, 1992

\section{ACCESSIBIITY:}

- Report

YEAR(S) OF DATA COLLECTION:

- 1989 and 1992 (to be continued every three years)

\author{
MAJOR AREAS: \\ - Impaired driving \\ - Violence \\ - Alcohol Use \\ - Marijuana Use \\ - Cocaine Use \\ - Other Drug Use \\ - Tobacco Use \\ - Adolescent sexuality \\ - Nutrition \\ - Students' favorite activities \\ - Antisocial behavior: vandalism, fighting, shoplifting \\ - Emotional health and self-esteem
}


- Suicide attempts

- Weight control

- Family violence

- Sexual abuse

- Family structure

SAMPLE CHARACTERISTICS:

- 85,322 subjects $(1989), 6$ th, 9th and 12th grades

- 131,000 subjects (1992), 6th, 9th and 12th grades

- 334 school districts participated both years ( $81 \%$ of total)

METHOD OF DATA COLLECTION:

- School-based written questionnaire

- Participation of school districts is voluntary (in 1992, all but one participated).

VARIABLES:

- Gender

- Grade level

- Age

- Race/ethnicity

- Family structure

- Primary source of prevention education

- Alcohol and drug use

- Age of first use of alcohol

- Monthly alcohol/other drug use

- Daily tobacco use

- Alcohol intoxication at least once a month

- Has five or more drinks on typical occasion

- Believes it's okay for teens to drink at parties if they don't get drunk

- Believes it's okay for teens to drink if they don't drive

- Driving after drinking/drug use

- Riding with friends after they have been drinking or using drugs

- Reasons given for not using by nonusers

- Believes adults exaggerate dangers of teen drinking

- Believes adults exaggerate dangers of drugs

- Vandalism

- Reasons given for not using by nonusers

- Physical fights

- Shoplifting

- Self-perception of being overweight

- Suicide attempt (ever)

- Fasts, takes diet pills or purges to control weight 
- Family alcohol and/or drug problems

- Victim or witness of family violence

- Family alcohol problem

- $\quad$ Family drug problem

- Worries about racial discrimination

- Victim of sexual abuse

- Sexually active

- Would sit next to HIV student in school lunchroom

- Always uses birth control

- $\quad$ Age at first sexual intercourse

- Always uses a condom

- Sexual activity related to primary source of sex education

- Monthly alcohol or drug use related to primary source of alcohol/drug education

UNIQUE CHARACTERISTICS:

- Very large sample size $(1989-90,000 ; 1992$ - 131,000)

- 432 of the 433 school districts participated

- Utilized to detect trends in usage over time

- $\quad$ Adolescent perceptions of adults' precautions regarding risk taking

RISK-RELATED ASPECTS:

- $\quad$ Substance use

- Sexual activity (including condom use)

- Family violence

- Abuse

- Driving

- Driving under the influence

- Mental health 


\section{Missouri}

AVAILABILTTY:

Sponsoring Agency:

Missouri Department of Health

1738 E. Elm Street

Jefferson City, Missouri

Telephone: (314) 751-6274

Contact Person:

Mark Van Tuinen, Ph.D.

DATABASE/REPORT: $\quad$ Substance Use Among 5th, 8th and 12th Graders: 1987-1988.

\section{ACCESSIBILITY:}

- In-house report

YEAR(S) OF DATA COLLECTION:

- 1987-1988

\section{MAJOR AREAS:}

- Substance Use (alcohol, tobacco, and other drugs)

- Demographic variables

\section{MAJOR OR SAMPLE QUESTIONS:}

- Followed the format of Monitoring the Future

\section{SAMPLE CHARACTERISTICS:}

- Students in grades 5, 8, and 12

- 5th graders $n=1400 ; 8$ th graders $n=2100 ; 12$ graders $n=1800$

\section{METHOD OF DATA COLLECTION:}

- Survey conducted in public and private schools monitored by a field staffer from the Department of Health.

\section{VARIABLES:}

$\begin{array}{ll}- & \text { Age } \\ - & \text { Race } \\ - & \text { Génder } \\ - & \text { Grade } \\ \text { - Urban or rural school } \\ \text { - Type of household }\end{array}$


- Mother's and father's education

- Alcohol

- Cigarettes

- Smokeless tobacco

- Marijuana

- Amphetamines

- Inhalants

- Narcotics

- Cocaine

- Hallucinogens

- Tranquilizers

- Barbiturates

- Heroin

\section{UNIQUE CHARACTERISTICS:}

- The purpose of the survey was to examine effectiveness of a school-based intervention, "MO Says No to Drugs." Because of funding problems, only a pre-test was conducted.

\section{RISK-REIATED ASPECTS:}

- Substance use

- Tobacco 


\title{
New Jersey
}

AVAILABILITY:

Sponsoring Agency:

\author{
State of New Jersey \\ Department of Health \\ Division of Family Health Services \\ CN 364 \\ 50 E. State Street \\ Trenton, NJ 08625-0364
}

Telephone: (609) 984-6137

Fax: (609) 292-3580

Contact Persons:

Elizabeth Solon

Chris Boyle

DATABASE/REPORT: Drug and Alcohol Use

Among New Jersey High School Students: 1993

\section{ACCESSIBILITY:}

- Report

YEAR(S) OF DATA COLLECTION:

- $\quad$ Every three years

- Most recent survey was completed in 1992

- Data will be collected in 1995

\section{MAJOR AREAS:}

- Substance use

- Drinking and driving

- Likelihood of being stopped by the police

- Riding with an impaired driver

- Substance use (e.g., lifetime, annual, monthly)

- Use of specific substances (e.g., alcohol, inhalants, steroids, marijuana, hallucinogens, amphetamines, barbiturates)

\section{MAJOR OR SAMPLE QUESTIONS:}

- How frequently do you smoke cigarettes at the present time?

- How did you get your most recent cigarettes?

- Have you ever received free samples or prizes (boardwalk, fairs, etc.) of a tobacco product (cigarettes, moist snuff, etc.)?

- When did you first smoke cigarettes?

- Would you like to stop smoking? 
- If people smoke one or more packs of cigarettes a day, how much physical harm are they likely to risk?

- How hard do you think it would be for you to get marijuana if you wanted some?

- Where would you most likely get marijuana if you want some?

- Do you think you will be using marijuana ten years from now?

- If people smoke marijuana occasionally, how much physical harm are they likely to risk?

- Do you think it is wrong if a person uses marijuana occasionally?

- Do you think it is wrong if a person uses marijuana regularly?

- There has been much talk about whether or not marijuana use should be made legal.

What do you think should be done?

- If it were legal to use marijuana, should it also be legal to sell marijuana?

- How many times have you used marijuana in your lifetime?

- Which of the following reasons might prevent you from using drugs or marijuana, substances you might otherwise want to use?

- $\quad$ religious values

- disapproval of parents

- $\quad$ fear of getting bad grades in school

- fear of getting into trouble with the law

- fear of physical harm

- $\quad$ nothing would prevent me

- Have you ever used drugs or marijuana before school?

- Have you ever used drugs or marijuana during school?

- Have you ever used drugs or marijuana after school?

- Have you ever used drugs or marijuana at school functions such as football games or dances?

SAMPLE CHARACTERISTICS:

- 3,000 subjects, ages 15 to 18

- Stratified random sample of schools; students randomly selected within schools

METHOD OF DATA COLLECTION:

- Survey given in classrooms

VARIABLES:

- Prevalence of substance use (similar to questions in Monitoring the Future)

UNIQUE CHARACTERISTICS:

- Data used to determine trends in use and to influence policy changes 
RISK-RELATED ASPECTS:

- Substance use

- Tobacco

- Driving

- Driving under the influence

- Social support and protective factors

- Risk perception 


\section{North Dakota}

AVAILABחLTY:

Sponsoring Agency: $\quad$ North Dakota Department of Health

600 East Boulevard

Bismark, ND 58505-0200

Telephone: (701) 328-2367

Fax: (701) 328-1412

Contact:

Danniele Kenneweg

DATABASE/REPORT: Alcohol/Drug Survey

ACCESSIBLITY:

- 1993 Youth Alcohol and Drug Survey Report

YEAR(S) OF DATA COLLECTION:

- Every 3 years since 1980

MAJOR AREAS:

- Alcohol and drug use

SAMPLE CHARACTERISTICS:

- Approximately 30,000, 7th to 12 th graders

METHOD OF DATA COLLECTION:

- Census approach, administered in classroom

VARIABLES:

- Not available

UNIQUE CHARACTERISTICS:

- Alcohol and drug data is used in designing curriculum in the schools. It is also used to form the basis of PSAs, and news releases. The information is also utilized for proposed legislation.

RISK-REILATED ASPECTS:

- Substance use 


\section{North Dakota}

AVAILABILTY:

Sponsoring Agency :

North Dakota Department of Health 600 East Boulevard

Bismark, ND 58505-0200

Telephone: (701) 328-2367

Fax: (701) 328-1412

Contact:

Danniele Kenneweg

DATABASE/REPORT: Nutrition Activity Survey

ACCESSIBULTT:

- Unnamed document will be available in December 1995.

YEAR(S) OF DATA COLLECTION:

- Unknown

MAJOR AREAS:

- Nutrition and physical activity

SAMPLE CHARACTERISTICS:

- Over 600 6th graders

METHOD OF DATA COLIECTION:

- Random sample of 20 schools across the state, one classroom per school

\section{VARIABLES:}

- Food intake (particularly fruits and vegetables)

- Physical activity (e.g., running, jumping, physical education)

- Amount of time watching TV

- Amount of time playing video games

UNIQUE CHARACTERISTICS:

- Insufficient information to date

RISR-REILATED ASPECTS:

- Dietary and physical behavior 


\section{Oklahoma}

AVAILABILTY:

Sponsoring Agency:

Health Promotion and Policy Analysis

Oklahoma State Department of Health 1000 NE Tenth

Oklahoma City, OK 73117-1299

Telephone: (405) 271-5601

Fax: (405) 271-2865

Contact Person:

Neil Hann

DATABASE/REPORT: Teen Wellness Check Health Risk Appraisal

ACCESSIBUITY:

- Printout of compilation of results (for four years) showing percentages of students by gender and grade endorsing each risk factor item

YEAR(S) OF DATA COLLECTION:

- 1985-1991

- Administered at the request of the school; schools self-selected

\section{MAJOR AREAS:}

- Risky driving

- Impaired driving

- Violence

- Substance use

- Tobacco use

- Adolescent sexuality

- Risk for suicide

- Hygiene

- Nutrition

\section{SAMPLE CHARACTERISTICS:}

- 5,440 subjects, 7th through 12 th graders

- Provides as a service to high schools at their request. Not a random sample.

\section{METHOD OF DATA COLLECTION:}

- Administered in the schools by representatives of health department

\section{VARIABLES:}

- $\quad$ Eats a variety of food groups

- Eat breakfast at least 5 times a week 
- Brushes teeth daily

- Immunizations

- Gets 20 minutes of aerobic exercise at least 3 times weekly

- Smokes more than one pack of cigarettes per day

- Any smoking

- Drinks five or more alcoholic drinks in one day

- $\quad$ Any drinking

- Uses alcohol with other drugs

- Drives or ride under the influence

- Does not always use safety belt

- Hitchhiking or picking up hitchhikers

- $\quad$ Ability to swim

- Highly stressed

- Often feels like not worth living

- Overweight $20 \%$ or more

- Females - underweight $20 \%$ or more

- Females -- not doing breast self-examination monthly

UNIQUE CHARACTERISTICS:

- Students receive printout on site

- $\quad$ Referrals are made on site (counselors are present)

- Appraisal developed by the Rhode Island Department of Health

RISK-RELATED ASPECTS:

- Substance use

- Tobacco

- Driving

- Riding with an intoxicated driver

- Hitchhiking or picking up hitchhikers

- Tobacco use

- Safety belt use

- Physical health, nutrition (over or underweight by more than $20 \%$ )

- Mental health 


\section{Oregon}

AVAILABILTY:

Sponsoring Agency : $\quad$ Program Analysis Unit

Oregon Department of Human Services

Office of Alcohol and Drug Abuse Programs

Human Resources Building

500 Summer Street, N.E.

Salem, Oregon 97310-1016

Telephone: (503) 945-6186

Fax: (503) 378-8467

Contact Person: $\quad$ Clinton Goff, Ph.D.

DATABASE/REPORT: The 1994 Oregon Public School Drug Use Survey

\section{ACCESSIBILITY:}

- Report

YEAR(S) OF DATA COLLECTION:

- 1994 (every two years since 1986)

\section{MAJOR AREAS:}

- Alcohol use

- Marijuana/hashish use

- Inhalants use

- Tobacco use

- Cocaine use

- Amphetamine use

- Violence

- Risk and protective items from school, community, family, and peer/individual

\section{SAMPLE CHARACTERISTICS:}

- 11,564 students in grades 6, 8, and 11

- Multistage sampling design was implemented.

- Stage 1: five geographic regions were designated

- Stage 2: Schools were selected in each region so that regional representation in the sample approximated each region's share of the total student population of the state. Schools were chosen randomly within regions after identification of sub-groups of schools to maintain proportional representation of small and large schools. 
METHOD OF DATA COLLECTION:

- School-based self-administered surveys given in school classrooms

VARIABLES:

- Factors associated with the use of cigarettes (for 11th graders)

Number of best friends who smoke

Perceived risks of smoking

Parental attitude toward respondent smoking

Personal attitude - OK for someone your age to smoke

Gender

Someone else in family smokes

Family has clear rules about substance use

Will be perceived as "cool" if I smoke

- Factors associated with the use of alcohol (for 11th graders)

Personal attitude - OK for someone your age to drink

Number of best friends who drink

Region

Parental attitude toward respondent drinking

Someone in family with alcohol or drug problem

Adult attitudes toward alcohol in the school

Race/Ethnicity (greater percentages of alcohol users among Native Americans)

Will be perceived as "cool" if you use alcohol

\section{UNIQUE CHARACTERISTICS:}

- Survey was part of a six-state federally funded effort to measure substance use and risk and protective factors.

- State trends were compared with national trends.

- Prevalence trends within the state

RISK-RELATED ASPECTS:

- Substance use

- Tobacco

- Aggression/violence

- Community violence

- Carrying handguns to school

- Risk perception 


\section{Pennsylvania}

AVAILABILTY:

Sponsoring Agency: Commonwealth of Pennsylvania

Office of the Governor

Governor's Drug Policy Council

P.O. Box 1326-310 Finance Building

Harrisburg, PA 17120

Telephone: (717) 783-8626

DATABASE/REPORT: Alcohol, Drugs, and Pennsylvania Youth: The 1993 Survey

\section{ACCESSIBILTTY:}

Report

YEARS OF DATA COLLECTION:

- 1989, 1991, 1993

MAJOR AREAS:

\begin{tabular}{ll}
- & Substance use \\
- & Driver risks \\
- & Weapons \\
- & Physical fights \\
\hline
\end{tabular}

MAJOR OR SAMPLE QUESTIONS:

- If you or a close friend had a problem with alcohol, tobacco or other drugs, who would you be willing to talk to about it? Here is a list of people whom you might consider. For each one, fill in your answer. Would you talk to: a person my age, a teacher, a coach, an adult friend, a person from church, a doctor, a school nurse, a parent, an adult relative other than a parent, a counselor in a drug center, a policeman, a student support group, a school counselor, the principal or assistant principal.

- How often do you: skip school without an excuse, steal something from a store, cheat on a class test, get drunk, get high on drugs, sneak money from an adult's wallet?

- How often do you:

- $\quad$ Ride in a car when the driver had been drinking while driving or drinking shortly before driving?

- $\quad$ Ride in a car when the driver had been drinking AND smoking pot?

- Drive a car while or shortly after drinking?

- Drive a car while or shortly after smoking pot?

- Drive a car while or shortly after drinking AND smoking pot? 
- When you smoke, how many cigarettes per day do you smoke (on an average)?

- During your life, have you ever injected (shot up) any illegal drug (including steroids)?

- During your life, how many times have you used marijuana?

- During your life, how many times have you used any form of cocaine, including powder, crack, or freebase?

- During your life, how many times have you used the crack or freebase forms of cocaine?

- During your life, how many times have you taken steroid pills or shots?

- During the last 12 months, how many times were you injured and had to be treated by a doctor or nurse?

SAMPLE CHARACTERISTICS:

- $40,000+$ students in 6th, 7th, 9th, and 12th grades

METHOD OF DATA COLLECTION:

- Random sample of public and nonpublic schools

VARIABLES:

- Region

- Grade

- Ethnic background

- Population density

- Community economics

- Intent to use and self-reported use of drugs

- School climate

- Driver/passenger risks

- Fighting and weapons

- Locations and sources of drugs -- self-perceived users only

- Alternative activities

- Negative/disruptive behaviors

- Resource persons

- Decision-making factors 


\section{UNIQUE CHARACTERISTICS:}

- Large sample size

\section{RISK-RELATED ASPECTS}

- Substance use

- Aggression/violence

- Driving

- Driving under the influence

- Social supports and protective factors 


\section{Rhode Island}

AVAILABIITY:

Sponsoring Agency: $\quad$ Rhode Island Department of Health

3 Capitol Hill

Providence, Rhode Island 02908

Telephone: (401) 277-2550

Contact Person: $\quad$ Dr. Jana E. Hesser, (401) 277-2550

DATABASE/REPORT: The 1993 Rhode Island Adolescent Substance Abuse Survey: Report of Statewide Results

ACCESSIBILITY:

\section{- Report}

YEAR(S) OF DATA COLLECTION:

- 1993 (third biennial survey)

\section{MAJOR AREAS:}

- Tobacco use

- Alcohol use

- Marijuana use

- Other substance use

- Parental substance use

- Impaired driving

- Depression

- Extracurricular activities

- Sources of support

MAJOR OR SAMPLE QUESTIONS:

- During the past month, how many days of school have you missed?

- In the past year, were you ever in trouble with school officials?

- In the past year, have you been in a fight involving physical violence?

- In the past six months, have you had the feeling that life was not worth living?

- Have you ever smoked cigarettes?

- In the past six months, have you seriously tried to quit smoking for at least a day?

- Have you heard the radio commercials on 92-PRO FM in which students talk about smoking?

- Does your school have a program to help students quit smoking? 
- If you drink, in what grade did you first drink when your parents were not with you?

- Did you get drunk during the past month?

- Do you think that your drinking causes any problems?

- If your parents ever drank, do you think their drinking has ever caused any problems?

- Have you ever driven under the influence of alcohol or drugs?

- How would your close friends feel if you tried cocaine or crack once or twice?

- If you had a problem related to alcohol or drug use, who would you go to for help?

- How much do you think people risk harming themselves (physically or otherwise) if they smoke one or more packs of cigarettes each day?

SAMPLE CHARACTERISTICS:

- 40,351 subjects, ages 12-18

- Surveyed almost all junior and senior high students in the state (all schools were represented)

METHOD OF DATA COLLECTION:

- School-based survey administered during homeroom or during designated class periods

VARIABLES:

- Gender

- Race/ethnicity

UNIQUE CHARACTERISTICS:

- Large sample size

RISK-RELATED ASPECTS:

- Parental use of tobacco and alcohol

- Riding with an intoxicated driver

- Driving under the influence

- Risk perception

- Mental health (including depression)

- Social support and protective factors 


\section{South Carolina}

\section{AVAILABILITY:}

Sponsoring Agency:

South Carolina Department of Alcohol and Drug Abuse Services

3700 Forest Drive, Suite 300

Columbia, SC 29204

Telephone: (803) 734-9577

Contact Person: $\quad$ Denise Nalty, Ph.D.

DATABASE/REPORT: Several surveys of public school students, dropouts, and GED students

\section{ACCESSIBILITY:}

- Data presently being analyzed

- Additional analyses could be performed at DOT's request

YEAR(S) OF DATA COLLECTION:

\section{- Ongoing}

\section{MAJOR AREAS:}

- Community factors

- Risky driving

- Impaired driving

- Violence

- Substance use

- Protective factors

\section{MAJOR OR SAMPLE QUESTIONS:}

- How much do each of the following statements describe your neighborhood: crime, drug selling, fights, lots of empty or abandoned buildings, lots of graffiti?

- If you wanted to get some marijuana, how easy would it be for you to get some?

- If you wanted to get some LSD, amphetamines, or some other illegal drugs, how easy would it be for you to get some?

- If you wanted to get a handgun, how easy would it be for you to get one?

- How many times in the last 12 months have you: driven a car after drinking alcohol; driven a car after using drugs; ridden in a car that was driven by someone who had been drinking or using drugs? 
- How old were you when you first: used smokeless tobacco, (e.g., chew, snuff, plug, dipping tobacco, chewing tobacco); smoked cigarettes; had more than a sip or two of beer, malt liquor, wine coolers, wine, or hard liquor?

\section{SAMPLE CHARACTERISTICS:}

- Public school sample: stratified random sample across state of grades 8,9,10, and 12

METHOD OF DATA COLLECTION:

- Self-administered questionnaire

VARIABLES:

- Not available

UNIQUE CHARACTERISTICS:

- A similar survey is administered to all samples.

- Survey examines protective and risk factors

- Efforts to survey dropouts and those seeking GEDs

RISK-RELATED ASPECTS:

- Substance use

- Tobacco

- Driving

- Driving under the influence

- Riding with an intoxicated driver

- Aggression/violence

- Community factors

- Social supports and protective factors (including community, family, school, and peers) 


\section{Washington}

\section{AVAIIABILITY:}

Sponsoring Agency: Child and Adolescent Health

Washington State Department of Health

P.O. Box 47880

Olympia, Washington $98504-7880$

Telephone: (360) 586-1255

Fax (206) 586-7868, Building 7

Contact Person

Judy Schoder, MN, RN

Adolescent Health Consultant

DATABASE/REPORT: Preliminary Report for Community Networks: Youth Risk Assessment Database

\section{ACCESSIBILITY:}

- Report

YEAR(S) OF DATA COLLECTION:

- 1990-1993

MAJOR AREAS:

- Juvenile arrests

- Births to teenage mothers

- School dropout rate

- Child protective services (CPS) accepted referrals

- Suicide deaths

- Homicide deaths

- Child abuse and neglect

MAIOR OR SAMPLE QUESTIONS:

- Information obtained from a variety of sources (see below)

SAMPLE CHARACTERISTICS:

- Record-based sample of Washington State youths

METHOD OF DATA COLLECTION:

- Demographic data for 1990 on poverty, children in single parent households, and mobility were obtained from the U.S. Bureau of the Census. 
- Crime and arrest statistics were assembled by most law enforcement agencies in the state in a manner consistent with the FBI's Uniform Crime Reporting (UCR) program guidelines.

- Birth certificate data from 1990 through 1993, and death certificate data from 1988 through 1992, were obtained from the Center for Health Statistics, Washington State Department of Health.

- School dropout data were provided by the Washington State Office of Superintendent of Public Instruction (OSPI).

- Child abuse or neglect data were provided by reports from Washington State Child Protective Services.

VARIABLES:

- Age

- Socioeconomic status

- Number of parents in household

- County

- School-district

- Poverty

- Single parent families

- Mobility

- Youth suicide and homicide deaths

- Accepted child abuse referrals

- Youth violent crime arrests

- School dropouts and births to young mothers

UNIQUE CHARACTERISTICS:

- Compilation of statistics from several sources

RISK-RELATED ASPECTS:

- Pregnancy

- Aggression/violence

- Delinquency/crime

- Suicide

- Homicide

- Child abuse 


\section{Washington}

\section{AVAILABILTY:}

Sponsoring Agency:

Child and Adolescent Health

Washington State Department of Health

P.O. Box 47880

Olympia, Washington 98504-7880

Telephone: (360) 586-1255

Fax: (206) 586-7868

Contact Person:

Judy Schoder, RN

Adolescent Health Consultant

DATABASE/REPORT: A) Washington State Survey of Adolescent Health Behaviors (WSSAHB) 1988-1992

B) Relating Risk Factors - Subsequent Analysis of the 1992 WSSAHB

\section{ACCESSIBILITY:}

Report

YEAR(S) OF DATA COLLECTION:

- 1988-1992

\section{MAJOR AREAS:}

- Driving under the influence

- Safety and violence

- Alcohol use

- Tobacco use

- Other drug use

- Experience with alcohol and drug education

- AIDS/HIV education

- Perceived effects of media advertising

- Medical and dental care

- Adolescent sexuality

- Nutrition

- Physical activity

- Suicide and depression

- Physical abuse

- Sexual abuse 
Washington

MAJOR OR SAMPLE QUESTIONS:

- In the past $\mathbf{3 0}$ days, how often have you driven while drinking alcohol?

- In the past $\mathbf{3 0}$ days, how often have you driven while taking drugs?

- Have you ever carried a weapon to school?

- How important is it to you to get good grades?

- In the last year have you ever thought about dropping out of school?

- How many times have you changed schools in the last 12 months?

- When you are away from home, do your parents know where you are and who you are with?

- Is there drinking or drug use among kids at most parties you attend?

- Have you ever gotten into trouble at home or at school because of your drinking or drug use?

- Have you ever been arrested because of drinking or using drugs?

- How difficult do you think it would be for you to get each of the following types of drugs: marijuana, hashish or cocaine?

- How often do you use each type of the following drugs (never, some, monthly, weekly, daily): smoking tobacco, smokeless tobacco, beer, wine coolers, wine, hard liquor, marijuana or hashish, cocaine, hallucinogens, inhaled substances to get high, drugs purchased from the drugstore to get high, steroids, other drugs (methamphetamine, tranquilizers, heroin, uppers, downers)?

- How do you usually get the beer, wine or liquor you drink?

- How much do you usually drink at one time?

- How old were you when you had your first full drink (a can of beer, a full glass of wine, or a mixed drink)?

- How many drinks does it take for you to get drunk when you drink?

- Think back over the last two weeks. How many times have you had five or more drinks in a row?

- Have you ever used drugs and alcohol together?

- How old were you when you smoked your first cigarette?

- How would you parents feel about your smoking marijuana occasionally?

- Where have you learned the most about the dangers of drugs and drinking?

- Do you think beer, wine and alcohol advertising influences young people to drink?

SAMPLE CHARACTERISTICS:

- 15,463 subjects, 6 th through 12 th grades

METHOD OF DATA COLLECTION:

- Survey given in public schools 
VARIABLES:

- Age

- Gender

- Race

- Rural vs. non-rural

UNIQUE CHARACTERISTICS:

- Questions tapping respondents' perception of prevention programs, including media advertising

RISK-RELATED ASPECTS:

- Substance use

- Tobacco

- Carrying a weapon

- Mental health

- Physical health 


\section{Wisconsin}

AVAILABILTY:

Sponsoring Agency:

Division of Handicapped Children

and Pupil Services

Wisconsin Department of Public Instruction

125 South Webster Street

P.O. Box 7841

Madison, WI 53707-7841

Telephone: (608) 267-3752

Contact Person:

Steve Fernan

DATABASE/REPORT: The Wisconsin Study: Alcohol and Other Drug Use

ACCESSIBIITY:

- Report

YEAR(S) OF DATA COLLECTION:

- 1991

MAJOR AREAS:

- Alcohol use

- Tobacco use

- Other Drug use

- Social context: family, friends, school

MAJOR OR SAMPLE QUESTIONS:

Social context: family, friends, and school

- Have your parents ever tried to talk to you about alcohol and other drugs?

- If you drink, do your parents know?

- How comfortable are you in talking with your parents about alcohol and other drugs?

- How much do you like school?

- How much homework do you typically do?

- Have you had a course that spent "a lot of time on alcohol and drugs"?

Alcohol use

- Have you used alcohol once or more?

- Have you used alcohol once or more in the last $\mathbf{3 0}$ days?

- Have you had 5 or more drinks in a row (binge drinking) once or more in the last 2 weeks?

- In the last 12 months, have you driven a vehicle after drinking alcohol? 
Tobacco use

- If any, how many cigarettes do you smoke per day?

- Have you ever used smokeless tobacco in the last 30 days?

Other drug use

- Have you ever used marijuana?

- Have you ever used cocaine?

- Have you ever used illicit drugs? (One or more of the following without a doctor's prescription: marijuana, cocaine, amphetamines, LSD, PCP, heroin, other narcotics, methaqualone, barbiturates, or tranquilizers.)

- Have you ever used an inhalant?

\section{SAMPLE CHARACTERISTICS:}

- Sample size: 5,834 subjects, ages 11-18

grade $6=1,553$

grade $8=1,437$

grade $10=1,365$

grade $12=1,479$

- Random sample of public school students stratified by geographical region and district enrollment size

METHOD OF DATA COLLECTION:

- Student surveys

VARIABLES:

- Age

- Gender

- Race

- Ethnicity

- Community size

UNIQUE CHARACTERISTICS:

- Prevalence of substance use

- Community factors

- Search Institute survey used in a random stratified sample

RISK-REILATED ASPECTS:

- Substance use (including binge drinking)

- Tobacco

- Driving under the influence 


\section{Wisconsin}

\section{AVAILABIITY:}

Sponsoring Agency:

Bureau for Pupil Services

Wisconsin Department of Public Instruction 125 South Webster Street

P.O. Box 7841

Madison, WI 53707-7841

(608) $266-8960$

Contact Person:

Steve Fernan

DATABASE/REPORT: A Tradition of Tolerance: What Wisconsin Parents Think About Teen Alcohol Use

\section{ACCESSIBIITY:}

- Report

YEAR(S) OF DATA COLLECTION:

- Focus Groups (October/November 1992)

- Telephone survey (December 1992)

MAJOR AREAS:

- Alcohol use

- Mlegal drug use

- Tobacco use

- Impaired driving

- Crime

- Gangs

- Unemployment

MAJOR OR SAMPLE QUESTIONS:

- What is the most important problem facing your community today?

- How seriously are the following problems affecting your community: crime, alcohol abuse, gangs, illegal drug use, unemployment, layoffs, underage drinking (very serious, somewhat serious, not a very serious problem, not a problem, don't know).

- Do you smoke?

- Do your children put pressure on you to quit (for smokers)? 
- Describe the use of alcohol in your household.

- How do you feel about the following comments (strongly agree, somewhat agree, somewhat disagree, strongly disagree, don't know):

I think people are smoking less than they used to.

I think people in Wisconsin drink more than in other states.

Instead of drinking less, people are drinking at home more.

Drinking is part of Wisconsin's culture.

- Which do you think is a bigger problem in Wisconsin: alcohol or illegal drugs (such as marijuana or cocaine)?

- For each activity, tell me if you find it acceptable all of the time, some of the time, or never acceptable:

happy hour

parents throwing beer parties for kids

beer tents at church picnics

beer tents at community functions, such as fairs and festivals

drinking tailgate parties before athletic events

serving alcohol at school sponsored events

serving alcohol at professional sporting events

community block party

- What would you do if you caught your child: smoking, drinking at age 15 or 16 , drinking at age 17 or 18 , drinking and driving, smoking marijuana, smoking crack, doing acid?

(nothing at all, have a discussion but give no punishment, discussion and minor punishment, discussion and moderate punishment, or discussion and severe punishment)

- What do you think the legal drinking age should be?

- Do any of your children smoke?

SAMPLE CHARACTERISTICS:

- Four focus groups of parents of past, present, or future public school students

- Survey of 600 parents of past, present, or future public school students

\section{METHOD OF DATA COLLECTION:}

Focus groups and survey

Survey participants were obtained from randomly selected phone numbers.

Respondents were screened to eliminate nonparents and private school parents. Surveys were conducted in proportion to public school enrollments by county.

\section{UNIQUE CHARACTERISTICS:}

- Results of focus groups used to construct survey

- Parents' perceptions of underage drinking, community concerns, personal use, perceptions of prevalence of use, and role modeling 


\section{RISK-RELATED ASPECTS:}

- Substance use

- Tobacco

- Driving under the influence

- Aggression/violence

- Gangs 
III. APPENDIX 


\section{INTRODUCTION TO APPENDIX}

This appendix highlights important databases that were not included in the national and state collections. Our rationale for not including these databases is provided with each entry, along with journal and/or organizational references for further information. While national databases have to their credit expansive breadth and scope in their efforts to learn as much as possible about a group that is meant to represent the nation as a whole, these appendix items often provide more specialized information on problems and populations of interest.

Items in this appendix come in many varieties. Many of the following databases contribute to research knowledge within carefully defined populations that are not nationally representative, yet contribute to understanding youthful risk takers. Other databases provide data on young people in the past, and these collections frequently allow researchers to make direct comparison between current and older cohorts. Still other databases, such as the Common Core of Data and the October Files of the Current Population Survey, can be combined to yield prevalence rates, in this case for dropouts -- something neither database can provide alone. 
Adolescent Women's Contraceptive Decision-Making Project, Baltimore City, 1988

- Sociometrics reference: AIDS/STD Data Set No. 06-08

- Computer tape or diskettes, $\$ 150 ; \mathrm{CD}-\mathrm{ROM}, \$ 225$

- Demographics, contraceptive behavior, attitudes toward pregnancy and contraception

- Survey sought to gauge any association between consistency of contraceptive use, women's social networks, and attitudes towards pregnancy and contraception

- Measures were taken at baseline, 3 months, 6 months

Reason(s) not included in collection of National Databases:

- Not nationally representative

For more information:

- Sociometrics Corporation

170 State Street, Suite 260

Los Altos, California 94022

Telephone: (415) 949-3482

Fax: (415) 949-3299 


\section{Age-By-Race Specific Crime Rates, 1965-1985: United States}

- Inter-university Consortium for Political and Social Research (ICPSR) 9589

- Changes in demographic composition of the population and their associated changes in total crime rates

- Changes in specific age and race groups' criminality

- All arrests and crimes reported to the police in the United States between 1965 and 1985, using UCR System.

Reason(s) not included in collection of National Databases:

More recent UCR data would allow the same analysis to be done with the inclusion of the years $1986-1995$.

For more information:

\section{Publication:}

Blumstein, A., Cohen, J., and Rosenfeld, R. (1989). Compositional and contextual effects of age on crime rates. San Francisco: Paper presented at the annual meeting of the American Sociological Association. 


\section{American Family Data Library (The)}

- Available through Sociometrics

- Contains data sets for the following surveys:

- $\quad$ National Survey of Families and Households, 1988

- 1976-1987 National Survey of Children: Waves 1, 2, and 3

- $\quad$ National Child Care Survey 1990: Parent Study

- $\quad$ A Profile of Child Care Settings: Home-Based Programs

- $\quad$ A Profile of Child Care Settings: Center-Based Programs

- National Commission on Children: 1990 Survey of Parents and Children

- $\quad$ National Child Care Survey 1990: Low-Income Substudy

- $\quad$ Marital Instability Over the Life Course: 1981-1988

- Stanford Child Custody Study: Family, 1984-1990

- $\quad$ Stanford Child Custody Study: Child, 1984-1990

- 1975 National Family Violence Survey

- 1985 National Family Violence Survey

- $\quad$ National Health Interview Survey on Child Health, 1988

- $\quad$ Treatment Process: A Problem at Three Levels, 1988

- 3 Machine-readable CD-ROMS, \$950, PC or Macintosh

- SUN Workstation Version (1 Optical Cartridge or 18-mm Videotape), $\$ 850$

- Mainframe computer version (4 Machine readable tapes), $\$ 850$

Reason(s) not included in collection of National Databases:

The most relevant of these databases were abstracted and included in the National

Databases; others of possible relevance were included in the appendix.

For more information:

Sociometrics Corporation

Telephone: (415) 949-3482 


\section{Common Core of Data}

- NCES, Office of Educational Research and Improvement

- Public school universe, local education agency universe, state aggregate non-fiscal report, state aggregate fiscal report, school district fiscal data, early estimates

- Community is taken as unit of analysis. Student dropout data may be derived by linking the Common Core of Data with the Current Population Survey.

Reason(s) not included in collection of National Databases:

- Does not contain data at the individual student level

For more information:

- Requests for information may be faxed to L. McDowell, NCES, (202) 219-1728 


\section{Community Intervention Trial for Smoking Cessation (COMMTT), 1990}

- National Cancer Institute

- School-based survey of 13-16 year old smokers $(n=4,129)$

- Random sample of 9th grade classrooms in 10 geographically diverse communities

- Adolescent cigarette brand preferences

- Cigarette marketing strategies that influence adolescents the most

- Variables include: sex, race, ethnicity, age, region, cigarette brand

Reason(s) not included in collection of National Databases:

- Not nationally representative

- Brand variables may show the direction in which advertising needs to be reformed or the kinds of influences that school interventions must exert. However, it would be difficult to fit this data into the broader context of clusters of risk-taking behaviors.

For more information:

Publications:

COMMIT Research Group (1991). Community Intervention Trial for Smoking Cessation (COMMIT): summary of design and intervention. Journal of National Cancer Institute (83), 1620-1628.

Centers for Disease Control and Prevention (1992). Comparison of the cigarette brand preferences of adult and teenaged smokers-United States, 1989, and 10 U. S. communities, 1988 and 1990. MMWR (41), 169-73, 179-81. 


\section{Current Population Survey (CPS), October Files: School Enrollment}

- U.S. Department of Commerce, Bureau of the Census

- ICPSR 6055 (1991 data)

- The monthly, basic CPS contains data on household membership, household characteristics, demographics, and labor force participation

- The annual NCES October supplement to the CPS contains data on basic annual school enrollment and attainment, and additional items relevant to education, e.g., private school tuition, adult education, vocational education, early childhood education, computer usage, and student mobility

- Number of dropouts by race/ethnicity and region

- Prevalence of student dropouts by school may be derived by linking the Common Core of Data with the Current Population Survey.

Reason(s) not included in collection of National Databases:

- Parents or other adults are respondents in this survey, as opposed to students or other young people.

For more information:

- $\quad$ Mary Morris, ICPSR User Support

Telephone: (313) 763-5010

- Elvira Hausken

Elementary and Secondary Education Statistics Division

National Center for Education Statistics

555 New Jersey Avenue NW

Washington, DC 20208-5651

Telephone: (202) 219-1623 
National Adolescent Student Health Survey, 1989

- Sponsors: American School Health Association, Association for the Advancement of Health Education, Society for Public Health Education, Department of Health and Human Services, Public Health Service, Office of Disease Prevention and Health Promotion, Centers for Disease Control, National Institute on Drug Abuse

- 1989 , single point in time

- Stratified random sampling procedure, eighth and tenth graders

- AIDS/STDs, violence, rape, fighting, suicide, nutrition, injury prevention

Reason(s) not included in collection of National Databases:

- The data is no longer publicly available.

For more information:

- Mary Hundley

Association for the Advancement of Health Education

Reston, Virginia

Telephone: 703/476-3437

- Laura Kann

Division of Adolescent and School Health Centers for Disease Control and Prevention Telephone: 404-639-3311 


\section{National Commission on Children: 1990 Survey of Parents and Children}

- ICPSR 9595

- Sociometrics reference: AFDA Data Set No. 19. Computer tape or diskettes, $\$ 100$; CD-ROM $\$ 225$

- Telephone interviews among 1,738 nationally sampled parents and 929 of their 10-17 year old children.

- Black and Hispanic oversamples

- Neighborhood, school, peer pressure, family life, parent-child relationships, frequency and nature of contact with biological parents, parenting

Reason(s) not included in collection of National Databases:

No explicit risk-related aspects. However, data includes self-reported social support and protective factors.

For more information:

\section{Publication:}

Card, J. (1994). The American Family: A Compendium of Data and Sources. New York: Garland Publishing.

Descriptions of 30 data sets concerning family issues, including all datasets available through Sociometrics' American Family Data Archive (AFDA). Available from Garland Press (800) 627-6273, \$72.

- Sociometrics Corporation

Telephone: (415) 949-3482 


\section{National Family Violence Survey}

- Sociometrics reference: AFDA Data Set No. 32

- Mainframe computer tape or diskettes, $\$ 100$; CD-ROM $\$ 225$

- National cross-sectional survey of 6,002 families

- Conflict resolution and violence

- Intra-family violence incidence by race and ethnicity

- Estimates of family violence by state

- Can be compared to similar 1975 survey.

Reason(s) not included in collection of National Databases:

- While information on social and environmental risks may be useful, no explicit variables concerning youths' risk-taking behaviors were included.

For more information:

Publication:

Card, J. (1994). The American Family: A Compendium of Data and Sources. New York: Garland Publishing.

Descriptions of $\mathbf{3 0}$ data sets concerning family issues, including all datasets available through Sociometrics' American Family Data Archive (AFDA). Available from Garland Press (800) 627-6273, \$72.

- Sociometrics Corporation

Telephone: (415) 949-3482 
National Health Examination Survey, Cycle III, 1966-1970

- National Center for Health Statistics

- ICPSR 9377

- National probability sample of 12 - to 17 -year-olds

- Physical health, including health habits and behavior

- Mental health

Reason(s) not included in collection of National Databases:

Survey is too old to include in the absence of more recent follow-ups

For more information:

Publications:

National Center for Health Statistics. The association of health attitudes and perceptions of youths 12-17 years of age with those of their parents, United States, 1966-1970. Vital and Health Statistics Series, 1962-1979, Series 11, No. 161. Hyattsville, MD: U.S. Public Health Service. National Center for Health Statistics.

National Center for Health Statistics. Goodenough-Harris test estimates of intellectual maturity of youths 12-17 years: demographic and socioeconomic factors. Vital and Health Statistics Series, 1962-1979, Series 11, No. 159. Hyattsville, MD: U.S. Public Health Service. National Center for Health Statistics. 
National Health Interview Survey, 1991: Health Promotion and Disease Prevention Supplement

- National Center for Health Statistics

- ICPSR 6053

- Multistage probability sampling design, with black persons oversampled

- Environmental health, tobacco, immunization and infectious disease, occupational safety and health (including safety belt use), chronic and disabling conditions, preventive medicine, activity and fitness, alcohol, mental health, oral health

Reason(s) not included in collection of National Databases:

- Sample does not include those under the age of 18.

- The included risk-taking items are covered in more depth in the YRBS.

For more information:

- Charlotte Schoenborn, NCHS

Telephone: (301) 436-3484, ext. 151 
National Health Interview Survey, 1991: Unintentional Injuries Supplement

- National Center for Health Statistics

- ICPSR 6137

- Multistage probability sampling design, with black persons oversampled

- Head injuries, loss of consciousness, falls, causes of injuries (e.g., work, sports), medical care received

Reason(s) not included in collection of National Databases:

- Supplement is not specific to youths and variables do not emphasize risk taking behaviors that may contribute to injuries.

For more information:

- Charlotte Schoenborn, NCHS

Telephone: (301) 436-3484, ext. 151 
National Household Education Survey, Safety and Discipline Component, 1993

- National Center for Education Statistics

- Computer Assisted Telephone Interviewing (CATT)

- 12,700 parents of children in grades 3 through 12

- 6,500 students in grades 6 through 12

- School characteristics and environment, safety at school, school discipline policy, alcohol/drug education, demographics

Reason(s) not included in collection of National Databases:

While information on environmental risks and preventive education efforts may be useful, no explicit variables concerning youths' risk-taking behaviors were included.

For more information:

Kathryn A. Chandler

Elementary and Secondary Education Statistics Division

National Center for Education Statistics

Telephone: (202) 219-1767 
National Longitudinal Study of the Class of 1972 (NLS-72)

- National Center for Education Statistics

- ICPSR 8085

- Two-stage probability sample by school and by student, with oversampling of schools in low-income areas and those with large minority populations.

- School ability, home life, social life, educational attainment, work experiences, attitudes and opinions

- $\quad$ Five followups, through 1986

- Analyses of NELS:88 could include comparisons with the NLS-72 cohort

Reason(s) not included in collection of National Databases:

- Survey is too old to include in the absence of more recent follow-ups

- NELS:88 provides similar information for more recent cohorts.

For more information:

- Peggy Quinn, NCES

Telephone: (202) 219-1743

Internet: Peggy_Quinn@ed.gov 


\section{National Survey of Men}

- Sociometrics reference: AIDS/STD Data Set No. 14-16

- $\quad$ Computer tape or diskettes, \$150; CD-ROM, \$225

- Sexual behavior and condom use among 20- to 39-year-20-old men

- Baseline data for longitudinal study

\section{Reason(s) not included in collection of National Databases:}

- Does not include data on men under the age of 20

For more information:

- Sociometrics Corporation

Telephone: (415) 949-3482 


\section{National Survey of Women}

- Sociometrics reference: AIDS/STD Data Set No. 17-19

- Computer tape or diskettes, $\$ 150$; CD-ROM, $\$ 225$

- In-person interviews regarding sexual, contraceptive, and fertility behaviors among women who were 20- to 29-years-old at their time of participation in the 1983 Survey of Unmarried Women (available separately as DAAPPP Data Set No. D5-D7)

- Second subsample of women who were 20- to 27-years-old in 1991

Reason(s) not included in collection of National Databases:

- Does not include data on women under the age of 20

For more information:

- Sociometrics Corporation

Telephone: (415) 949-3482 


\section{Search Institute Profiles of Student Life: Attitudes and Behaviors}

- The Search Institute, Minneapolis, Minnesota

- A CD-ROM may be available in 1996

- 152-item survey contains items geared towards perspectives, values, and behaviors of students in grades 6 through 12. Risk taking items include tobacco, substance use, sexual activity, mental health, aggression/violence, and school problems.

\section{Reason(s) not included in collection of National Databases:}

$83 \%$ of communities included were in the Midwest.

- Schools that self-select to participate receive reports reflecting the responses of their student body. Since a national random probability sample was not used, the comparisons between a particular school's youth and "youth nationally" are questionable.

- To protect the confidentiality of the self-selecting schools, separate data components cannot readily be linked by participant within the limited amount of public-use data that is available (e.g., Field Test of Values and Choices, Search Institute's Adolescent Pregnancy Prevention Demonstration Project, Sociometrics DAAPPP D1-D3).

- SEARCH's definitions of community health and behavioral assets and deficits stem from the personal constructs of the authors rather than empirical research. While the survey has a high degree of internal consistency, external validity of data is questionable when it is collected in self-selecting schools. Construct validity also suffers due to the made-up divisions between assets and deficits that SEARCH uses to distinguish "least healthy communities" from "moderately healthy communities."

\section{For more information:}

\section{Publications:}

Blyth, D. A., and Roehlkepartain, E. C. (1993). Healthy communities, healthy youth: How communities contribute to positive youth development. Minneapolis: Search Institute

Search Institute. (draft report). Technical Appendix to the Search Institute Profiles of Student Life: Attitudes and Behaviors. Minneapolis: Author.

Search Institute (1992). Search Institute Profiles of Student Life: Attitudes and Behaviors, Sample Report. Minneapolis: Author, Figures A-I.

- The Search Institute Thresher Square West

Suite 210

700 S. Third Street 
Minneapolis, MN 55415

Telephone: (612) 376-8955, (800) 888-7828 
Prospero Project Condom Study, San Francisco (The), 1989-1991

- Sociometrics reference: AIDS/STD Data Set No. 05

- Computer tape or diskettes, \$100; CD-ROM, \$225

- Face-to-face interviews of 552 male sex workers regarding condom use

- Demographics, self-reported sexual identification, HIV status, type of sex worker ("street hustlers" or "call men"), number of partners, frequency of condom use, frequency of condom failure, conditions under which condom failure occurred

- Interviewers were former sex workers themselves--good ecological validity

Reason(s) not included in collection of National Databases:

- Not nationally representative

- Does not include data on sex workers under the age of 18

For more information:

Sociometrics Corporation

Telephone: (415) 949-3482 


\section{Stanford Child Custody Study: Family, 1984-1990; Child, 1984-1990}

- Sociometrics reference: AFDA Data Set Nos. 25-27, 28-30

- $\quad$ Mainframe computer tape or diskettes, \$100; CD-ROM \$225

- Sample of 1, 124 California families who filed for divorce between September, 1984 and April, 1985

- Includes parental conflict, children's reactions to the divorce, logistical problems, parents' coordination regarding child's upbringing

- Three-wave longitudinal study of post-divorce child custody arrangements

Reason(s) not included in collection of National Databases:

- Not a national sample

- Adolescent follow-up (study II) is still being processed

For more information:

\section{- Publication:}

Card, J. (1994). The American Family: A Compendium of Data and Sources. New York: Garland Publishing.

Descriptions of $\mathbf{3 0}$ data sets concerning family issues, including all datasets available through Sociometrics' American Family Data Archive (AFDA). Available from Garland Press (800) 627-6273, \$72.

- Sociometrics Corporation

Telephone: (415) 949-3482 
1984-1986 Study of Adolescents at Risk and Their Children, in Chicago, St. Louis, and Indianapolis

- Sociometrics reference: DAAPPP Data Set No. F1-F4

- Mainframe computer tape, or 14 IBM hi-density disks, \$100; CD-ROM, \$225; 3.5" Mac hi-density disks (please call)

- Raw data, SPSS program statements, SAS program statements

- Naturalistic, longitudinal study of $\mathbf{4 7 7}$ female adolescents described as "high risk" for pregnancy, yet who have access to health care services.

- Face-to-face interviews covered mental health, physical health, sexual activity, and pregnancy variables

- Health and development of teenage mothers' children

- Teenage mothers and non-mothers who use the services of inner city, public health clinics

Reason(s) not included in collection of National Databases:

Not nationally representative

For more information:

Sociometrics Corporation

Telephone: (415) 949-3482 